University of Tennessee Health Science Center

UTHSC Digital Commons

\title{
Modulation of the Magnetic Properties of Aqueous Metal Ions and the Bioelectrodynamic Effects on Cancerous and Noncancerous Cells
}

Marcy C. Purnell

University of Tennessee Health Science Center

Follow this and additional works at: https://dc.uthsc.edu/dissertations

Part of the Nursing Commons

\section{Recommended Citation}

Purnell, Marcy C. (http://orcid.org/0000-0003-2112-5841), "Modulation of the Magnetic Properties of Aqueous Metal lons and the Bioelectrodynamic Effects on Cancerous and Noncancerous Cells" (2016). Theses and Dissertations (ETD). Paper 377. http://dx.doi.org/10.21007/etd.cghs.2016.0392. 


\title{
Modulation of the Magnetic Properties of Aqueous Metal lons and the Bioelectrodynamic Effects on Cancerous and Noncancerous Cells
}

\author{
Abstract \\ Bioelectrodynamics is the study of how electromagnetism affects the biophysical functions of living \\ organisms by examining the effects on biochemical processing at the cellular level. The Cellular Energy \\ Transfer Science (CETS) system modulates the magnetic behavior of aqueous metal ions by applying \\ to make growth media for cancerous and noncancerous cell lines in vitro. Exposure of cancerous and \\ cycle arrest or apoptosis of the noncancerous cell lines. Microarray and RT-qPCR show the cancerous \\ cells headed to apoptosis by the unfolded protein response (UPR), TNF/TRAIL, and p53 oncogene \\ activation. Alternatively, the noncancerous cells show a significant increase in cell migration/wound \\ healing after exposure to the treated media with no activation of apoptosis pathways.

\section{Document Type} \\ Dissertation \\ Degree Name \\ Doctor of Philosophy (PhD)

\section{Program} \\ Nursing Science \\ Research Advisor \\ Michael A. Whitt, Ph.D. \\ Keywords \\ Bioelectrodynamics, bioenergy, epigenetics, quantum physics, cancer, woundcare

\section{Subject Categories} \\ Medicine and Health Sciences | Nursing
} direct current (DC) with a Lorenz force to a hypotonic saline solution. This treated solution was then used noncancerous cells to this media showed significant growth inhibition, cell cycle arrest, hyperpolarization of transmembrane potential and apoptosis of cancerous cells while not causing a growth inhibition, cell 
Modulation of the Magnetic Properties of Aqueous Metal Ions and the Bioelectrodynamic Effects on Cancerous and Noncancerous Cells

\author{
A Dissertation \\ Presented for \\ The Graduate Studies Council \\ The University of Tennessee \\ Health Science Center
}

\author{
In Partial Fulfillment \\ Of the Requirements for the Degree \\ Doctor of Philosophy \\ From The University of Tennessee
}

By

Marcy C. Purnell

May 2016 
Copyright (C) 2016 by Marcy C. Purnell. All rights reserved. 


\section{DEDICATION}

I would like to dedicate this work to Olivia Grace Lee (November 17, 1988- May 30,2012 ) who believed in this work before anyone ever knew it existed. Her memory has often been the source of my perseverance. 


\section{ACKNOWLEDGEMENTS}

I would like to thank everyone who helped me along this journey with this research project. I would first like to thank my family and many loved friends who have helped me with so many aspects of this research path. Without their love and support I would never have had the courage to complete this project. I would also like to thank my mentor Dr. Michael A. Whitt for his guidance and help in mapping a path to validity with this research. His expertise and experience have proved invaluable. I would like to thank Dr. Rita Kansal for her guidance in the laboratory as I would have been lost without her help.

I would like to thank Dr. Carolyn Graff for her encouragement at my difficult moments in this journey. Her support has been extremely appreciated. I would like to thank my committee members for their support and for pushing me to be the best scientist possible. The contributions they each bring to this journey have been very helpful.

Finally, I would like to thank the inventors of this technology for without this device, none of the work would have been possible. 


\begin{abstract}
Bioelectrodynamics is the study of how electromagnetism affects the biophysical functions of living organisms by examining the effects on biochemical processing at the cellular level. The Cellular Energy Transfer Science (CETS) system modulates the magnetic behavior of aqueous metal ions by applying direct current (DC) with a Lorenz force to a hypotonic saline solution. This treated solution was then used to make growth media for cancerous and noncancerous cell lines in vitro. Exposure of cancerous and noncancerous cells to this media showed significant growth inhibition, cell cycle arrest, hyperpolarization of transmembrane potential and apoptosis of cancerous cells while not causing a growth inhibition, cell cycle arrest or apoptosis of the noncancerous cell lines. Microarray and RT-qPCR show the cancerous cells headed to apoptosis by the unfolded protein response (UPR), TNF/TRAIL, and p53 oncogene activation. Alternatively, the noncancerous cells show a significant increase in cell migration/wound healing after exposure to the treated media with no activation of apoptosis pathways.
\end{abstract}




\section{PREFACE}

All the original work presented henceforth was conducted at the University of Tennessee Health Science Center in Memphis, Tennessee.

I was the lead scientist for the projects in Chapters 2-4 and I was responsible for conducting the areas of concept formation, methods development, data collection and analysis as well as the majority of the manuscript composition with edits being given by Dr. Michael A. Whitt, Dr. Patricia A. Cowan, Dr. Donna Hathaway and Dr. Betsy Tolley. Dr. Michael A. Whitt also helped with concept formation, methods development and graphics development. 


\section{TABLE OF CONTENTS}

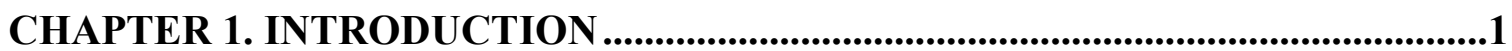

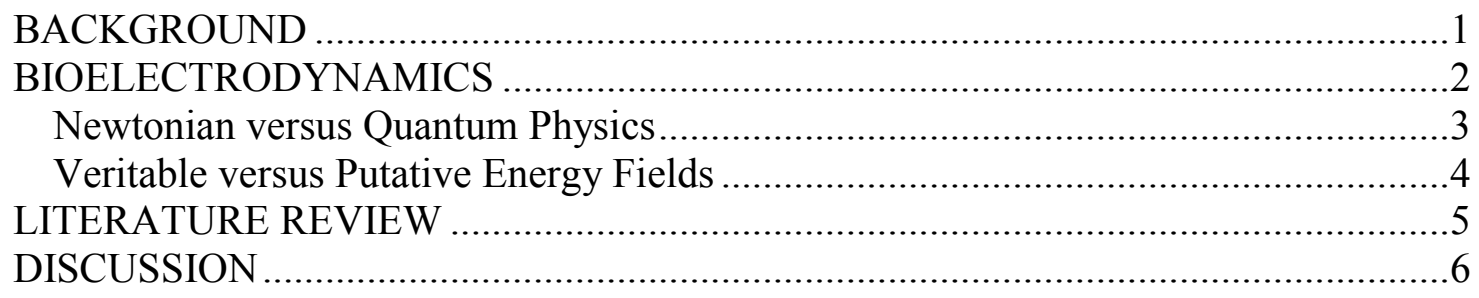

\section{CHAPTER 2. HYPERPOLARIZATION OF PLASMA MEMBRANES THROUGH MAGNETIC MODULATION OF AQUEOUS METAL IONS ...............7}

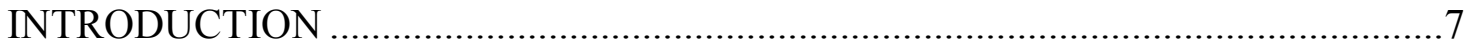

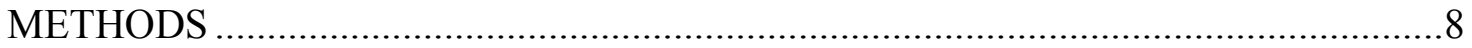

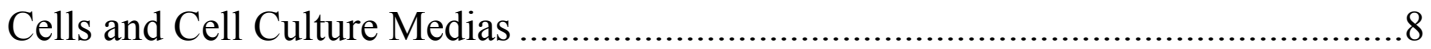

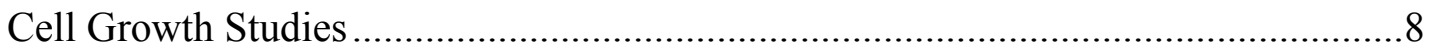

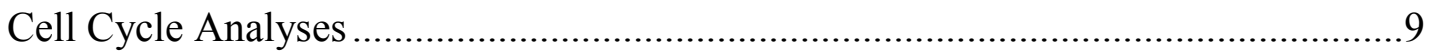

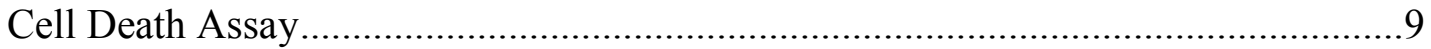

Membrane Potential Analyses ........................................................................ 10

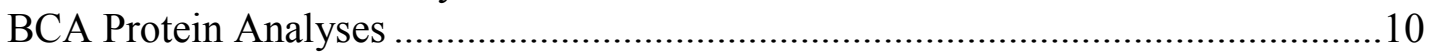

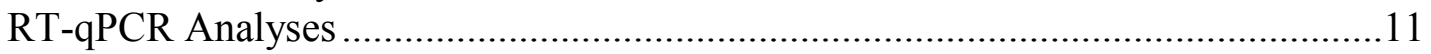

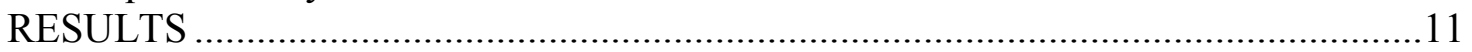

Differential Effects on Cancerous and Noncancerous Cell Growth ...........................11

Differential Effects on the Cell Size of Cancerous and Noncancerous Cells .............14

Differential Effects on the Cell Growth of Media Made on Day 1 Only....................14

Differential Effects on Cell Cycle Progression of Cancerous and Noncancerous

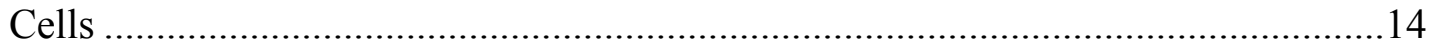

Differential Effects of the Modulation of the Magnetic Behavior of Metal

Aqueous Ions on the Mitotic Index of Cancerous Cells ............................................19

Effects on the Membrane Potential of Cancerous and Noncancerous Cells ..............19

Differential Effects on Cell Death by Phase and Fluorescent Microscopy.................19

Differential Effects on the Recovered RNA and Protein Levels of Cancerous

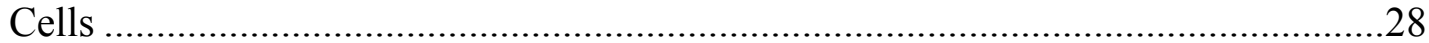

Differential Effects on mRNA Expression per Affymetrix 2.0 Microarray ...............28

Validation of Differential Gene Expression by RT-qPCR of Cancerous and

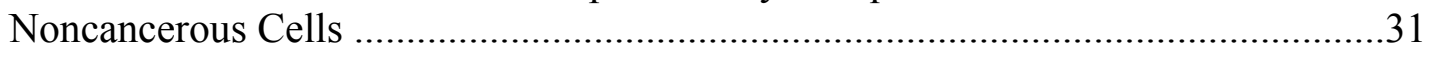

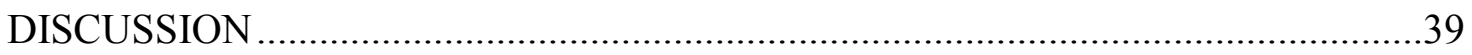

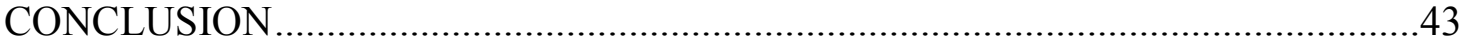

\section{CHAPTER 3. HYPERPOLARIZATION OF PLASMA MEMBRANE}

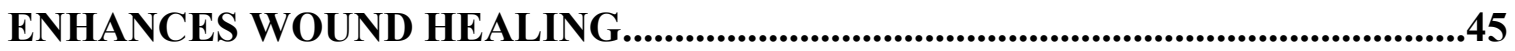

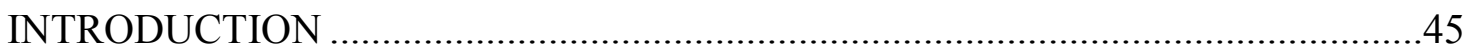

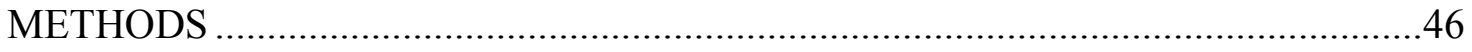

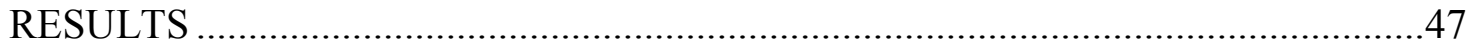

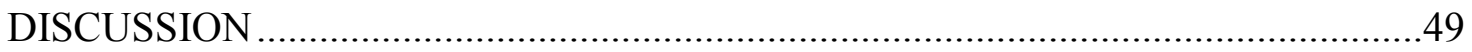




\section{CHAPTER 4. CELLULAR ENERGY TRANSFER SCIENCE SYSTEM MODULATES MAGNETIC IONS IN WATER ................................................52}

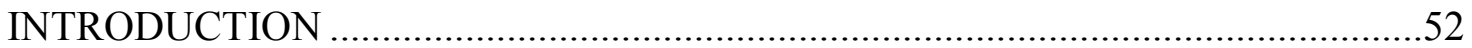

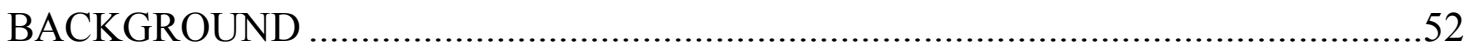

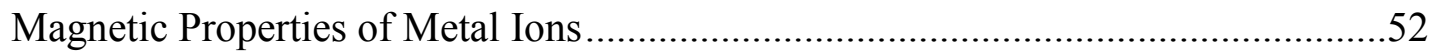

Magnetic Spin, Magnetoresistance and Lorenz Force ........................................54

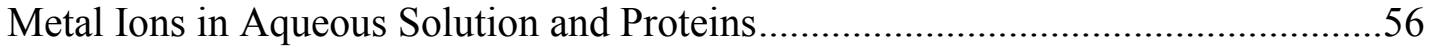

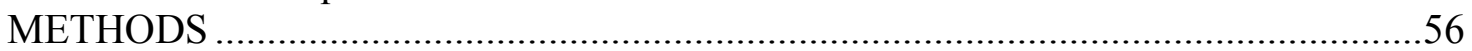

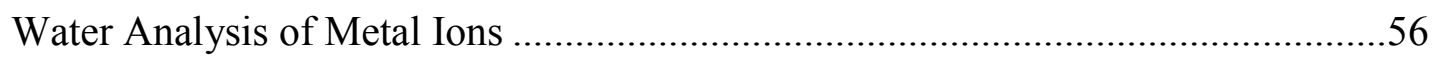

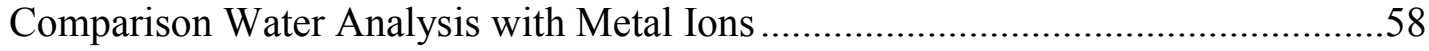

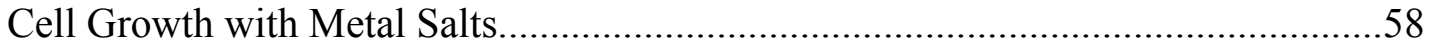

Cell Growth with Autoclaved CETS Treated Water .............................................60

Cell Growth with CETS Treated Water and Magnet............................................60

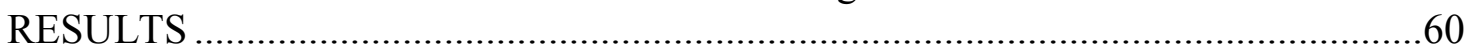

Metal Ions in the CETS treated Water Analysis ................................................60

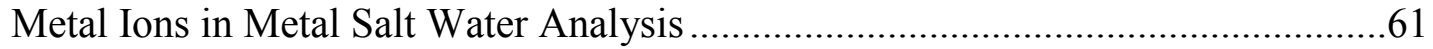

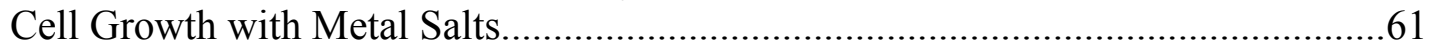

Cell Growth with Autoclaved CETS Treated Water ..............................................61

Cell Growth with CETS Treated Water and Magnet.............................................64

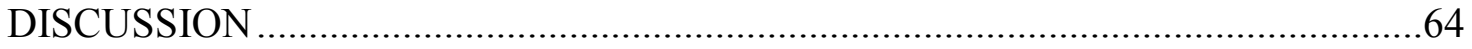

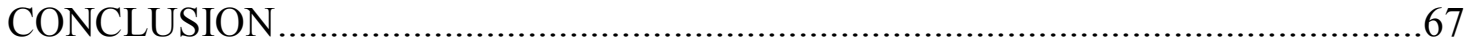

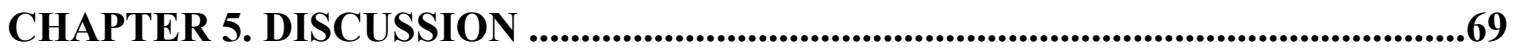

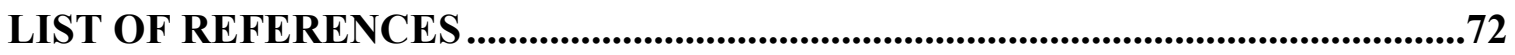

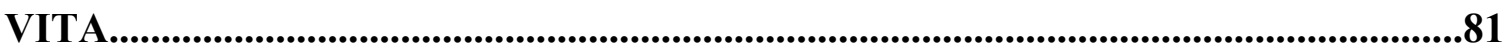




\section{LIST OF TABLES}

Table 1. Doubling Times of the Four Cell Lines Using the Exponential Growth Equation of the Non-Linear Regression Analysis Function of Prizm GraphPad v 5.04....................................................................... 13

Table 2. Percent Change in Membrane Potential.....................................................23

Table 3. Normalized Affymetrix 2.0 Gene Expression Levels of MDA-MB231 and MCF-10A Cells for ER Stress/UPR, Immune/TNF, Cell Cycle, Tumor Targets, Cell Death and Membrane Potential.

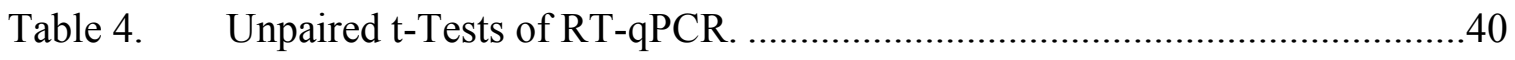

Table 5. Analysis of CETS-Treated and Untreated Dilute Saline. ............................57

Table 6. Comparison of Metal Ions in CETS Treated Filtered and Metal Salt Filtered Water. 


\section{LIST OF FIGURES}

Figure 1. Cell Growth/Time in Control and Treated Media.......................................12

Figure 2. Growth Rate of MDA-MB231 Cells in Media Reconstituted from 2, 3, 7

and 14 Day Old Water..............................................................................

Figure 3. B16, L929, MDA-MB231, MCF-10A Cells Size with Sceptor 2.0 Cell

Counter (Merck Millipore).........................................................................16

Figure 4. MDA-MB231 versus MCF-10A Daily Cell Size Analysis. ...........................17

Figure 5. Effect of Storing Media on Cell Growth Inhibition.......................................18

Figure 6. Cell Cycle Analysis Using Propidium Iodide and Cell Flow Cytometry.....20

Figure 7. Tubulin Staining of MDA-MB231 Cells after Growth in Both Control and Treated Media for One Day................................................................21

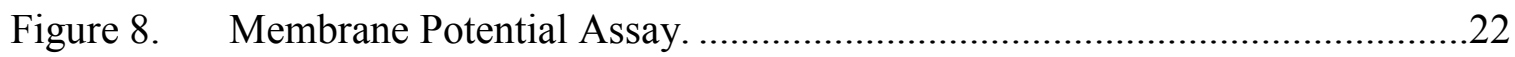

Figure 9. MDA-MB231 Cells Control versus Treated for 14 days..............................23

Figure 10. MDA-MB231 Fluorescent Microscopy with Annexin Staining....................25

Figure 11. MDA-MB231 Cells Phase Contrast Microscopy. ............................................25

Figure 12. MDA-MB231 Cells Treated 14 Days versus Treated 14 Days and Placed

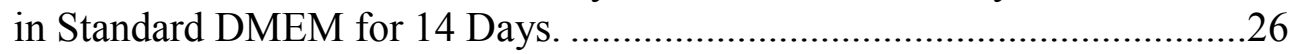

Figure 13. MDA-MB231 Control and Treated Cells Grown in Control and Treated Media for 7 Days and then Both Groups Placed in Control Media on Day 8 .

Figure 14. RNA Recovered from Treated versus Control MDA-MB231 Cells. ...........29

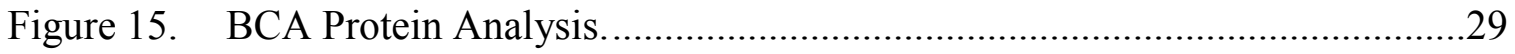

Figure 16. ER Stress/Unfolded Protein Response.........................................................30

Figure 17. Heat Map from Affymetrix 2.0 Gene Expression Values..............................32

Figure 18. Heat Map of Genes Validated with RT-qPCR ..............................................32

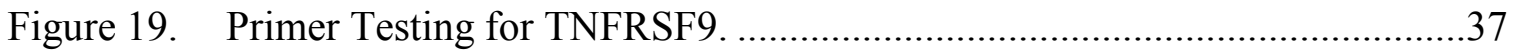


Figure 20. Amplification Curves of Fluorescence over Cycles for Real Time qPCR with Triplicate Testing of Gene Expression on a 96 Well Plate when Comparing Control and Treated Gene Expression Levels of MDA-

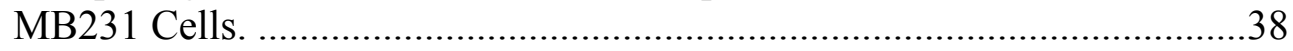

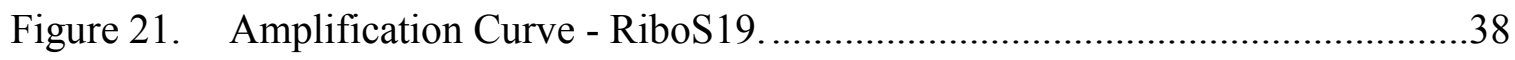

Figure 22. RT-qPCR Fold Change.............................................................................

Figure 23. L292 Cells Scratch Assay- Percent Area Healed/Time. ................................48

Figure 24. L292 Treated Cells Scratch Assay................................................................48

Figure 25. L292 Control Cells Scratch Assay.............................................................50

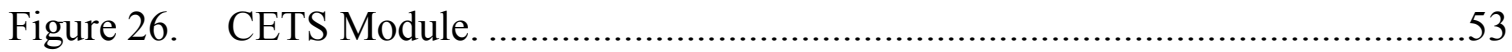

Figure 27. Metal Salt Experiments........................................................................62

Figure 28. MDA-MB231 Cell Autoclave Experiment...................................................63

Figure 29. MDA-MB231 Magnet Experiment.............................................................65 


\section{LIST OF ABBREVIATIONS}

$\mathrm{AC}$

AREG

ATP

CASP4

CCNE2

CETS

CHAC1

CLIC4

COPD

DC

DDIT3

DMEM

DNA

EDEM2

EGF

ERN1

FBS

GI

GMR

HERPUD1

HMMR

JMY

$\mathrm{MHz}$

MR

$\mathrm{NaCl}$

RIBOS19

RIN

RT-qPCR

TENS

TGF

TNFRSF9

VEGF

Vmem

XBP1
Alternating Current

Amphiregulin

Adenosine Triphosphate

Caspase 4

Cyclin E 2

Cellular Energy Transfer Science

ChaC Glutathione-Specific Gamma-

Glutamylcyclotransferase 1

Chloride Intracellular Channel 4

Chronic Obstructive Pulmonary Disease

Direct Current

DNA-Damage-Inducible Transcript 3

Dulbecco's Modified Eagles Medium

Deoxyribonucleic Acid

ER Degradation

Epidermal Growth Factor

Endoplasmic Reticulum to Nucleus Signaling 1

Fetal Bovine Serum

Gastrointestinal

Giant Magnetoresistance

Homocysteine-Inducible, Endoplasmic Reticulum

Stress-Inducible, Ubiquitin-Like Domain Member 1

Hyaluronan-Mediated Motility Receptor

Junction Mediating and Regulatory Protein

Megahertz

Magnetoresistance

Sodium Chloride

Ribosomal Protein 19

RNA Integrity Number

Real Time quantitative polymerase chain reaction

Transcutaneous Electrical Nerve Stimulation

Transforming Growth Factor

Tumor Necrosis Family Superfamily 9

Vascular Endothelial Growth Factor

Transmembrane Potential

X-Box Binding Protein 


\section{CHAPTER 1. INTRODUCTION}

\section{BACKGROUND}

Eight years ago I visited a day spa where I had my first experience with a footbath. This footbath was recommended to me by another colleague due to the effects she had experienced from this experience. The footbath lasted 30 minutes and when I left that day, I experienced decreased joint pain, increased stamina and many other noticeable health improvements. This one experience catapulted me into a journey I could have never expected. I began to research this device and found many remarkable anecdotal reports across the globe ranging from increased stamina, decreased joint pain, enhanced wound healing, cancer treatment symptom relief, improvement in insomnia, improvement in renal and liver disease, enhanced plant growth and many more. Due to the alternative nature of this device and the footbaths, I decided it would be best to initially quantify the effects at the cellular/molecular level. I then approached Dr. Michael A. Whitt, Professor and Chair of the Department of Microbiology, Immunology and Biochemistry at the University of Tennessee Health Science Center and began to pursue my Ph.D. which began this experimental testing of this footbath device we named the Cellular Energy Transfer Science (CETS) system.

Initially, my goal was to establish that this device/footbaths would not cause harm to cells or organisms. Due to the anecdotal reports of enhanced plant growth when plants were watered with water that had been treated by the CETS system, we decided to conduct an initial pilot experiment with plants to see if we would notice any difference in plants watered with the CETS treated water versus plants watered with the control (untreated) water. This initial plant experiment showed significant health differences between the control and treated groups so we decided to move on to and design in vitro experiments. Dr. Whitt suggested we begin testing with cancer cells and he provided a mice melanoma cell line (B16 cells) to begin our controlled in vitro experiments. We initially had no idea if there would be any measurable effects on the growth of these cancer cells and we were surprised when a significant growth inhibition was noted with the B16 cells that were grown in the media that was reconstituted with the CETS system treated water. These experiments were repeated several times and then it was decided we should test a noncancerous cell line to see if there was a growth inhibition of these cells. The CETS treated water did not cause a significant growth inhibition in the noncancerous cells (L929 cells-mouse fibroblasts). These unexpected findings peaked our interests and we decided to further pursue this body of work in order to hopefully establish the mechanisms behind these results.

The objectives/aims that we began to pursue with regards to cancerous and noncancerous cells were as follows:

1. To examine whether the electromagnetic field generated by the CETS system differentially affects the growth of cancerous and noncancerous cell lines in vitro. 
2. To determine if cancerous cells showing a significant growth inhibition following treatment with CETS were displaying an arrest in a specific phase of the cell cycle.

3. To determine differential effects of treated media and treated water at different time intervals on the cell growth of cancerous and noncancerous cell lines.

4. To quantify and visualize how quickly the cancerous cells ceased to undergo mitosis following treatment with CETS with tubulin staining.

5. To determine if an increase in mRNA following treatment with CETS in human cancerous cell line corresponds to an increase in protein production in the treated cells.

6. To determine if any real time genomic changes could be measured following treatment with CETS in the human cancerous and noncancerous cell lines.

7. To determine if a form of cell death is occurring after treatment with the CETS in the cancerous cell lines.

Due to the anecdotal reports of enhanced wound healing across the globe with the CETS system, the objective/aim we pursued with regards to cell migration in fibroblasts was:

8. To determine if cell migration is affected after treatment with the CETS in a noncancerous/fibroblast cell line.

Since the CETS system treated water was showing significant experimental effects, the objectives/aims we pursued with analyses of the water were:

9. To determine the mechanisms that may be occurring in the water that could explain significant effects noted.

10. To conduct pre-treatment and post-treatment aqueous metal ion analyses with water treated by the CETS.

\section{BIOELECTRODYNAMICS}

In order to understand how we might begin to study and explain these observed experimental effects, we began to look at the concepts of bioelectrodynamics. The subject of bioelectrodynamics is an interdisciplinary subject that has exhibited a rebirth in medical science and seeks to understand and identify the important roles that electromagnetism plays in biology and the biophysical function of all living organisms. ${ }^{1}$ The existence of electrical signals in plants, animals and humans was discovered centuries ago. ${ }^{2}$ These electrical signals play important roles in the development, physiology, regeneration and pathology of cells. ${ }^{3}$ In recent decades, scientists have come to view these phenomena to be the result of some action rather than the mediator of cell physiology and have begun to see the comprehensive link between cell biology and bioelectricity. ${ }^{4}$ Currently in Western medicine we utilize electromagnetic signals in diagnostics and in the treatment for chronic disease in limited applications. The electrocardiogram and the electroencephalogram are used to record dynamic extracellular electrical signals of the heart and brain. Electrical stimulation devices such as cardiac 
pacemakers, defibrillators, bone growth stimulators and TENS units are currently used for treatments of health issues. Science appears to accept these dynamic electrical signals but reject the little known and understood coexisting steady electrical signals of most other non-excitable cells. Many electrical-based therapies in the past were considered fraudulent and viewed with much skepticism. Western medicine currently uses the investigation and alteration of the biochemical signaling side of the cell through research on and use of pharmaceuticals, but in the last decade the scientific literature has begun to address the role that electromagnetism could play in treating health issues. ${ }^{4}$

\section{Newtonian versus Quantum Physics}

Prior to the beginning of the $20^{\text {th }}$ century, science embraced Newtonian physics as the basis for life processes. ${ }^{6}$ Concepts based in Newtonian physics refer to the organizational structure of matter in which the smallest known particle, the atom, consists of protons, neutrons and electrons. Western practitioners believed that all things could be divided into parts of the whole. This emphasis on particle theory led to the belief that if you could affect one particle or pathway of the cell/atom that has gone awry, health could be restored. This became the basis for the pharmaceutical industry explosion and development of small molecules (medications) that affected specific cell signaling pathways normally controlled by the binding of hormones, cytokines, growth factors, ions, messengers etc., to their cognate receptors.

Alternative views of how energy and health are related with regards to quantum physics was first recognized by Chinese practitioners thousands of years ago. ${ }^{7}$ They realized that when the measurable energy fields of an organism are strong, the organism remains healthy; when it is weak the organism becomes vulnerable to sickness and ultimately death. Quantum physicists suggested that "atoms" or matter are actually energy fields that are constantly spinning, moving or vibrating. ${ }^{6,8,9}$ The concept that energy and matter are one in the same was recognized and described by Max Planck who is considered the father of quantum theory. ${ }^{10}$ He stated that energy $€$ is equal to a constant ( $h$ ) multiplied by its frequency $(v)$ or $€=h v$. Therefore, it is impossible to separate living organisms into energy and matter since they are coexistent and it stands to reason that we should consider and not ignore the role that energy and its associated energy fields can play in affecting living matter (organisms).

Bioelectrodynamics recognizes that living organisms are energetic beings and each have individuality that is based in the make-up of its subatomic particles but there is a commonality which resides on the energy frequency side of their physical composition. In bioelectrodynamics an organism can be viewed as vibrating fields of energy. An organism's DNA sequence defines its constituent physical properties but there is also a unique frequency or pattern of energy that makes it unique. ${ }^{11}$

The environment, organism and individual cells are an integration of interdependent energy fields. Organisms are affected by the energy field of other organisms around them. ${ }^{12}$ Flow of energy is information in the quantum world and is 
holistic meaning the whole being and not one specific chemical pathway is involved in the energy ebb and flow. Since Newtonian physics divides living organisms into individual parts and targets their cell signaling pathways through the use of biochemical means, this creates a series of interconnected events that can lead to unwanted upstream and downstream effects. As one delves into the metabolic processes of the cell, it does not take long to realize the complicated and multidimensional nature of the cell and how quickly changes are occurring in multiple pathways simultaneously. ${ }^{13}$ Energy medicine has the ability to simultaneously enhance many biological processes that are necessary for and are the basis of life. Electromagnetic energy fields are absorbed by all excitable and non-excitable cells in the organism and affect and enhance multiple pathways at the same. ${ }^{14}$

Bioelectrodynamics can utilize an electrical energy source that affects not only the organism but the field immediately surrounding the organism. The tertiary interaction of these three components: 1) energy source, 2) environment, and the 3) organism are all involved in the process of bioelectrodynamics. The energy source can consist of regulated electrical current (alternating current/AC or direct current/DC) delivered through a specifically designed power pack, natural sources that emit electrical fields such as lightning, sunlight, cosmic radiation, or other man-made devices such as cellular phones, microwaves, electrical power lines, televisions, other living organisms and surrounding objects. The environment is the immediate area surrounding the organism (cell or individual) such as the extracellular matrix of the cell as well as the energy field surrounding the organism (person). If electromagnetic fields generated by the energy source, the organism/cell and the environmental field interact either positively or negatively, physiologic processes of the living organism can be affected in a quantum or tertiary fashion. ${ }^{14,15}$ When an energy emanates from an appropriate source that is beneficial to the living organism this energy becomes bioenergy and will be utilized and absorbed by the whole organism to be used for cell physiological processing. Multiple cell signaling pathways of the whole organism will be affected by an external electromagnetic energy source in a harmonic vibration with the environment.

\section{Veritable versus Putative Energy Fields}

The National Center for Complementary and Integrative Health has divided energy medicine into veritable applications or those that can be measured for diagnosis and treatment, and putative applications (biofields), those that have defied measurement by lack of reproducibility. ${ }^{16}$ Eastern medicine applications have historically been considered putative by involving a health practitioner and a client with the practitioner addressing the electromagnetic fields of the whole living organism through such methods as acupuncture, reflexology, massage, healing touch, Reiki etc. Putative energy fields have been the most controversial of the alternative energy medicine practices but they are gaining popularity in the American marketplace as well as academic medical centers where $85 \%$ of medical schools offer elective courses in these alternative health practices. ${ }^{16}$ 
Recent veritable research has demonstrated that remarkable effects on the health of a living organism can be acquired by addressing its electromagnetic field. ${ }^{17}$ Moreover, it is known that organisms must process environmental electromagnetic signaling to survive and these signals are indeed now measurable with recent advances in medical science. ${ }^{12}$ The speed of an electromagnetic energy signal is 186,000 miles per second and the speed of a chemical reaction is less than $1 \mathrm{~cm}$ per second. ${ }^{6}$ This indicates how much more efficient a holistic electromagnetic signal operates that is based in quantum theory compared to a chemical signal which is based in Newtonian theory. These new measurement tools in the field of nanotechnology and the development of veritable energy medicine applications have the potential to produce significant and reproducible research findings and clinical results that will offer credible and valid applications in Western medicine.

\section{LITERATURE REVIEW}

We can measure transmembrane potential (Vmem) of cells, a phenomena resulting from differential ion concentrations across the cell membrane. ${ }^{18,19}$ We know that cell behavior is regulated by not only chemical gradients but also by bioelectric cues. ${ }^{12}$ Vmem differences have been found in cancerous, injured and proliferating cells. ${ }^{19,20}$ Cancerous, injured and proliferating cells have a more depolarized membrane potential of approximately $<-30 \mathrm{mV}$, while noncancerous cells have a resting potential of $>-70 \mathrm{mV} .{ }^{19}$ Cells have been found to respond to different electromagnetic signals when undergoing division, migration and differentiation. ${ }^{2}$ Furthermore, scientists have found that bioelectricity or electromagnetic fields involve the changing gradients of transmembrane potential, ion channel activity and electromagnetic fields that are produced and sensed by non-excitable cells in living organisms. ${ }^{1,20,21}$ Therefore, bioelectricity shows an effect well beyond excitable cells and has been shown to affect wound healing, cell migration, nerve growth, limb regeneration and cancer. ${ }^{3,22}$ Changes in transcription, after depolarization of the cell membrane, occurs across multiple genes and it appears that bioelectric cues or signals override chemical signals since human mesenchymal stem cells will not differentiate without hyperpolarization in spite of potent chemical inducers. ${ }^{23}$

Bioelectric gradients have also been found to mediate signaling beyond cell to cell communication and actually appear to communicate throughout the whole organism and beyond. ${ }^{12}$ This suggests that bioelectric cues are a very efficient medium for carrying information. For example, planarian flatworms can remarkably regenerate themselves from partial body fragments. ${ }^{24}$ The partial body fragments require communication to control whether the regrowth occurs symmetrically or asymmetrically where one edge becomes a head or becomes a tail in order to grow the entire whole organism. The cells must be able to conduct long-range communication since gap junction (cell-cell) communication would not suffice for this high level differentiation from the remaining partial body fragments. ${ }^{25}$ 
It has also been shown that electrical events tell the cells what to do; voltage changes have been found to be a sign of cancer as well as determine whether or not cancer may develop. ${ }^{20}$ In addition, a research group at Tuft's University has found that in addition to cells being regulated by their own internal voltage potential they are also regulated by surrounding organisms, as well as the environment. ${ }^{12}$ This finding opens the door for potential research in the areas of cancer, wound care and any other disease process that can be attributed to a depolarized Vmem that leads to cell damage, inflammation, and death. ${ }^{19}$ The four cardinal signs of inflammation are: redness, swelling, heat and pain; the fifth cardinal sign of inflammation is loss of function. ${ }^{26}$ Since loss of function is thought to originate with inflammation of the cell, Vmem augmentation with bioelectromagnetic energy could offer a new treatment options for chronic disease.

To test this hypothesis, a single-group open label phase I/II trial was performed to assess the safety and efficacy of intrabuccal administration of low levels of electromagnetic fields in patients with advanced hepatocellular carcinoma. The results of this study indicated that treatment with low levels of $27.12 \mathrm{MHz}$ radiofrequency electromagnetic fields was associated with a decrease in tumor size that is mediated by genetic expression as well as increased progression-free survival for $>6$ months in the participants. ${ }^{17}$

\section{DISCUSSION}

These in vitro experiments and in vivo human trials demonstrate the potential of electromagnetic fields as diagnostic tools and as treatments for disease. Now that tools have been developed that can quantify processes on the cellular level, including the effects of electromagnetic fields and bioelectricity on living organisms; research on examining the mechanisms by which cells interact with bioelectrical signals, chemical gradients and physical forces has begun to emerge. ${ }^{32,33}$ Subsequently, molecular analysis of the effects of bioelectricity may point us to a way we can understand the mechanisms that occurs at the cellular level and lead us to biomedical transformations. The concepts of bioelectrodynamics gave us a basis for pursuing these in vitro effects from the application of electromagnetic fields by the CETS system. The methods we adopted were based on the applications to people, plants and animals that have been used across the globe for 20 years. In Chapters 2, 3 and 4, we will begin to pursue our aims in order to quantify in vitro effects that the CETS system treated water has on cancerous and noncancerous cells. These in vitro experiments may open the door for future applications of veritable quantum physics in Western medicine. 


\section{CHAPTER 2. HYPERPOLARIZATION OF PLASMA MEMBRANES THROUGH MAGNETIC MODULATION OF AQUEOUS METAL IONS}

\section{INTRODUCTION}

Water is the most abundant chemical in all living things and makes up $80 \%$ of all living organisms. Almost two decades ago, a device was invented in Australia that utilizes 2.5 amperes of direct current (DC) that is applied perpendicularly to a module/array of copper and stainless steel plates. This device, the Cellular Energy Transfer Science system (CETS) creates a bio-charge, which can be defined as a form of organic or bio-electricity, from an artificial energy source that can be applied to living organisms through a medium of water. The CETS has been widely sold across the globe in holistic markets and administered in the form of footbaths and baths with reports of pain relief, increased stamina, improvements in renal and hepatic function, support in cancer treatment recovery, decreased recovery time from illness and injury and many other health applications. ${ }^{15}$ Users of this device immerse part or all of their body in the water for 20-35 minutes every other day. The device has been approved by the Therapeutic Goods Administration to be marketed as a therapeutic device in Australia. The current manufacturer in the United States reports that approximately 15,000 units are sold yearly with over two million footbaths/baths given worldwide to date since the invention was marketed (S. Walker, personal communication).

It has been shown that cell behavior is regulated by chemical gradients as well as bioelectric cues. ${ }^{12}$ Plasma membrane potential (Vmem) differences which represent these cues have been found to differ for cancerous, injured and proliferating cells. ${ }^{20,21}$ Cancerous, injured and proliferating cells have a measurable depolarized membrane potential of approximately $<-30 \mathrm{mV}$, while noncancerous cells have a resting potential of $>-70 \mathrm{mV} .{ }^{19}$ Cells have also been shown to respond to different electromagnetic signals when undergoing division, migration and differentiation. ${ }^{2}$ In addition, electromagnetic fields have been found to induce gradient changes of Vmem that are produced and sensed by non-excitable cells and in living organisms. ${ }^{20,21}$ Therefore, bioelectricity has been shown to induce effects beyond excitable cells and to affect wound healing, cell migration, nerve growth, limb regeneration and cancer. ${ }^{1,3,22}$ Due to the interesting anecdotal testimonials, the therapeutic uses of the CETS system from across the globe, and the scientific basis for membrane potential differences in cancerous, injured and proliferating cells; we undertook testing at the molecular level to quantify what, if any, effects were occurring to drive these widespread claims. 


\section{METHODS}

\section{Cells and Cell Culture Medias}

Four cell lines were used for this investigation: B16 cells (murine melanoma), L929 cells (mouse fibroblasts), MDA-MB231 cells (human triple negative breast cancer) and MCF-10A cells (human breast epithelial cells). The L929, MDA-MB231 and MCF$10 \mathrm{~A}$ cells were obtained from ATCC and the B16 cells from the laboratory of Dr. Larry Pfeffer (Department of Pathology, UTHSC). The B16, L929 and MDA-MB231 cells were all cultured in 1X Dulbecco's Modified Eagles Medium (\#D6429) with 10\% Fetal Bovine Serum (DMEM-10) from Atlanta Biologicals. To prepare 1X DMEM, a 10X DMEM (\#D2429) solution was diluted 9:1 with a hypotonic $(3 \mathrm{mM})$ saline solution that had been treated for 30 minutes with the CETS system and filtered through Corning bottle top cellulose acetate membrane vacuum 0.22 micron filter (CLS430521, Sigma). The hypotonic saline solution was made using deionized water from the laboratory and a 5M sodium chloride (Molecular Biology grade- \#V4221, Lot \# 18693201 DNase/RNase/Protease free) solution from Promega Corporation. The medium was supplemented with the appropriate concentrations of folic acid, 0.004gm/L (SigmaAldrich-F8758-5G, Lot \# SLBF 16021), glucose 4000mg/L (Sigma-Aldrich G7021100G, Lot \# 071N01455), glutamine 0.584gm/L (Sigma-Aldrich-G7513, Lot \# RNBC5892) and sodium bicarbonate $3.7 \mathrm{gm} / \mathrm{L}$ (Biowittaker \# 15-6131) in order to obtain the exact concentrations of standard DMEM. Fetal bovine serum was added to the diluted DMEM to achieve a $10 \%$ concentration.

The MCF-10A cells were cultured in DMEM/F12 (Invitrogen \#11330-032) with 5\% Horse Serum (Invitrogen \# 11330-032) that was made by adding EGF, Hydrocortisone, cholera toxin and insulin. In order to make the treated and control media, we used DMEM 10X (Sigma-\# D2429 diluted 9:1 and F-12 Nutrient Mix powder (Life technologies \# 21700-026) mixed to manufacturer protocol specifications using either treated or control saline. The diluted DMEM and F-12 media was then mixed 1:1 was filtered through a 0.22 micron filter and then combined with appropriate concentrations of EGF 20ng/ml (PeproTech 100-47), hydrocortisone 0.5mg/ml (SigmaAldrich \#H-0888), cholera toxin 100ng/ml (Sigma-Aldrich \#C-8052) and insulin 10 $\mathrm{mcg} / \mathrm{ml}$ (Sigma-Aldrich \#I-1882). Horse serum was then added to obtain a 5\% concentration in the cell culture media.

\section{Cell Growth Studies}

We cultured the treated groups of B16, L929 and MDA-MB231 cells in the DMEM-10 with media that was reconstituted with a hypotonic saline solution that had been treated with the CETS system for 30 minutes and the control groups of each of the three cell lines were cultured in media that was reconstituted with the same hypotonic saline solution prior to treatment with the CETS system. The treated group of MCF-10A cells was cultured in the DMEM/F12-5 media that had been reconstituted with a 
hypotonic saline solution that had been treated with the CETS system for 30 minutes and the control group was cultured in media that was reconstituted with a hypotonic saline solution that had not been treated with the CETS system. On day one, aliquots of 10,000 cells were plated in three 6-well plates for each of the two groups for each of the four cell lines. They were plated in their standard (non-CETS treated) DMEM-10 or DMEM/F125 media on day 1 . On day 2 , the treated $(n=18)$ and control $(n=18)$ media for each of the four cell lines were made and the original standard media was replaced in each of the wells with the newly prepared treated and control media. On days 3 through 7, wells from the control group and treated group of each cell lines were trypsinized, removed from 3 wells of each group and counted using a Scepter cell counter (EMD Millipore). Remaining wells had the control and treated media replaced daily with freshly prepared treated or control media unless otherwise specified in the figure legends.

\section{Cell Cycle Analyses}

Cell cycle analyses were performed with each cell line that were grown in treated versus control media for three days with the media replaced daily with freshly made treated or control media. The cells were trypsinized and washed twice with phosphate buffered saline (PBS) containing $0.1 \% \mathrm{FBS}$ and subsequently fixed with $-20^{\circ} \mathrm{C}$ ethanol by adding drop wise to the pellet while vortexing to minimize clumping. After overnight incubation at $4^{\circ} \mathrm{C}$, the cells were washed twice with ice cold PBS by centrifugation at $850 \mathrm{~g}$ for 5 minutes and re-suspended at a final concentration of $1,000,000 / \mathrm{ml}$ in a total volume of 300 microliters. The cell suspensions were placed in PBS after treating with DNase free RNase $(50 \mathrm{mcl}$ of a $100 \mathrm{mcg} / \mathrm{ml}$ stock RNase) to remove all remnants of RNA and then stained with 200 microliters of propidium iodide (50 microgram $/ \mathrm{ml} \mathrm{stock}$ ) prior to cell cycle flow cytometry. The data were analyzed using ModFit LT software.

\section{Cell Death Assay}

Annexin V-FITC Apoptosis Detection Kit (APOAF Sigma-Aldrich) was used to conduct an apoptosis assay on the murine melanoma and the human breast carcinoma. After initiating apoptosis, cells translocate the membrane phosphatidylserine (PS) from the inner face (cytoplasmic side) of the plasma membrane to the cell surface. Once the PS is on the cell surface from the failure of flippase, it can be easily detected by staining with a green fluorescent protein, Annexin V that has a high affinity for PS. Propidium iodide (PI) was also added with this assay to detect the cells that have already undergone necrosis/cell death. Because PI enters the cell membrane of dead cells, it differentiates apoptotic from the dead cells. The MDA-MB231 and B16 cells were plated $\left(1 \times 10^{6}\right)$ and grown in treated and control media in $60 \mathrm{~mm}$ plates for 3 days before performing the experiments. They were then typsinized and removed and washed twice in PBS. The pellet of treated and control cells were then resuspended in $500 \mathrm{mcl}$ of 1x Binding Buffer at a concentration of $1 \times 10^{6}$ cells $/ \mathrm{ml}$. Then $5 \mathrm{mcl}$ of annexin V-FITC and $10 \mathrm{mcl}$ of propidum iodide were added to the cells. The cells were then analyzed with cell flow cytometry and microscopy. 


\section{Membrane Potential Analyses}

Membrane potential analyses were performed on all four cell lines using FivePhoton Membrane Potential Assay (Five-Photon Biochemical). This assay utilizes a membrane permeant dye formulation of oxonol dyes for transmembrane potential measurement. Membrane potential assay dyes enter depolarized cells and bind to their intracellular membranes or proteins that leads to enhance fluorescence. An increase in depolarization leads to an elevated influx of the voltage sensitive dye and an increase fluorescence that can be measured by fluorescent microplate readers or flow cytometers. After washing twice with PBS to remove serum factors, 60,000 cells were plated in the wells of a 96-well plate and placed in $100 \mathrm{mcl}$ of serum-free media. The wells were plated with both the treated and control groups of each cell line. The cells were exposed to the treated and control serum-free media for the time points of: 45 minutes, 12 hours, 24 hours and 72 hours prior to the addition of $100 \mathrm{mcl}$ External Assay Buffer to make a $1 \mathrm{X}$ dye solution and $200 \mathrm{mcl}$ was added to each well. The cells were then incubated in the dark at 37 degree Celsius in a CO2 incubator for 20 minutes to load the dye prior to placing in a fluorescent plate reader. The fluorescence was measured in the 530 excitation Iwavelength $(\mathrm{nm})$ and 565 emission wavelength $(\mathrm{nm})$ with a 550 emission cut-off $(\mathrm{nm})$. The lipophilic, anionic dye partitions across the plasma membrane of live cells and is dependent on the membrane potential across the membrane. When the cells are depolarized, more indicator dye enters the cells causing an increase in fluorescence signal.

\section{BCA Protein Analyses}

The MDA-MB231 cells were plated $\left(3 \times 10^{6}\right)$ in two $10 \mathrm{~cm}$ plates and grown in treated media and control media. Media were change daily until confluence. BCA Protein Assay Reagent Kit (Pierce 23225 23227) is a detergent-compatible formulation based on bicinchoninic acid (BCA) for the colorimetric detection of quantitation of total protein was used for this analysis. This method utilizes a well-known reduction of copper by protein in an alkaline medium with sensitive and selective colorimetric detection of the cuprous cation. The cells were trypsinized and pelleted using $500 \mathrm{rpm}$ for 5 minutes, then lysed in $300 \mathrm{mcl}$ of mammalian cell lysis buffer (Abcam ab179835). Total protein concentration was determined using the microplate procedure and the dilution parameters of $0,200,400,600,800$ and $100 \mathrm{micrograms} / \mathrm{ml}$ were made according to the preparation of diluted albumin (BSA) standards with 50 parts of BCA Reagent A with 1 part BCA Reagent B (50:1, Reagent A:B). Once the dilutions were made, $25 \mathrm{mcl}$ of each standard and unknown sample replicates were pipetted into the microplate wells. Prior to placing wells in a 37 degree Celsius incubator for 30 minutes, $200 \mathrm{mcl}$ of the working reagent was added to each well. The plate was then cooled to room temperature and measured at the absorbance of $562 \mathrm{~nm}$ on a plate reader. 


\section{RT-qPCR Analyses}

In order to validate some of the significant genomic effects seen in the microarray analysis on the MDA-MB231 cells, we conducted Real-Time qPCR using LC 480 and UPL probes. Ten genes were chosen: (1) $\mathrm{CHaC}$ glutathione-specific gammaglutamylcyclotransferase 1 (CHAC1), (2) Endoplasmic Reticulum to Nucleus Signaling 1 (ERN1), (3) Homocysteine-Inducible, Endoplasmic Reticulum Stress-Inducible, Ubiquitin-Like Domain Member 1 (HERPUD1), (4) Tumor Necrosis Factor Receptor Family 9 (TNFRSF9), (5) Junction-mediating and regulatory protein of p53 (JMY), (6) Cyclin E2 (CCNE2), (7) Hyaluronan-mediated motility receptor (HMMR), (8) DNADamage-Inducible Transcipt 3 (DDIT3), (9) Caspase 4 (CASP4), (10) Chloride Intracellular Channel Protein 4 (CLIC4) and RIBOPROTS19 (housekeeping). The primers were designed using universal probe library. Transcriptor First Strand cDNA Synthesis Kit (Roche Cat. No. 04379012 001) was used to make cDNA with the original microarray samples. Then the following reagents were added to the wells in the appropriate measurements according to the protocol in order to make $8 \mathrm{mcl}$ of this master mix for each well used in the 5-dilution factors (in triplicate) of the cDNA: universal library probe (UPL probe, Roche) at 10uM, LC480 master mix (2X concentration, Roche), mixed left and right primers at $10 \mathrm{uM}$ each in DNase, RNase \& Protease-free water (Corning cellgro, \# 46-000 Cl), and nuclease free water. The five dilutions of cDNA were: undiluted, 1:10, 1:100, 1:1,000, 1:10,000. The $8 \mathrm{mcl}$ of the master mix and 2 mcl of the cDNA were added to wells of a 96 well plate. The plates were centrifuged and activated for 5 minutes at 95 degrees. Then there was an amplification of 45 thermal cycles using $500 \mathrm{C}$ for 2 minutes (separation), $950 \mathrm{C}$ for 10 minutes (initialization) and $950 \mathrm{C}$ for 15 seconds (denaturation), and $600^{\circ} \mathrm{C}$ for 1 minute (annealing), and $70-740 \mathrm{C}$ for 5 minutes (elongation). The amplicons were then plotted for validation.

\section{RESULTS}

\section{Differential Effects on Cancerous and Noncancerous Cell Growth}

Cell growth studies were conducted to examine whether the electromagnetic field generated by the CETS system differentially affected the growth of cancerous and noncancerous cells lines in vitro. We observed a significant growth inhibition of doubling times between control and treated groups of both the murine melanoma and human breast carcinoma cell lines when maintained in CETS-treated media while there was little to no growth effect on the noncancerous murine fibroblasts or human breast epithelial cells (Figure 1). Growth rates and doubling times (Table 1) extracted from this analysis could then be compared using the Mann-Whitney U-test. This nonparametric test does not require a normal or Gaussian distribution. The measurements of the growth rate are independent since each replicate represents a different culture dish. The data were also log-transformed to fit a linear mixed effects model. Significance between the cancerous cell control and treated groups was declared with both methods with an alpha of $<0.05$. 

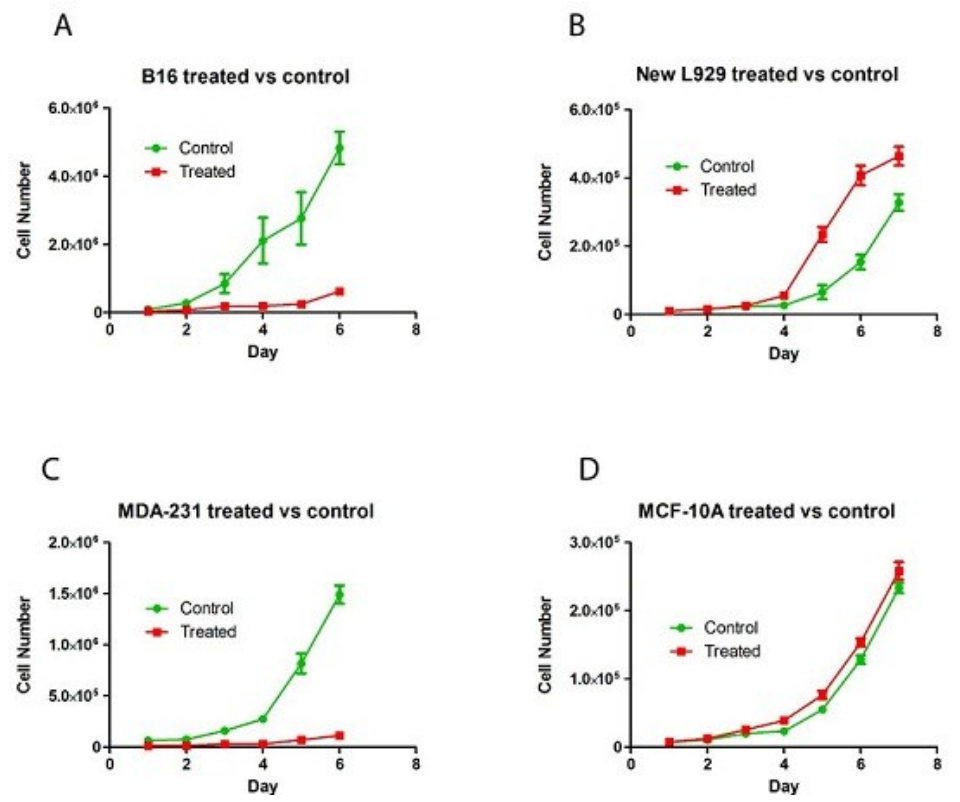

Figure 1. Cell Growth/Time in Control and Treated Media.

$\sim 10,000$ cells were plated in standard media in triplicate for each cell line. Control and treated media were reconstituted daily with CETS control/treated water and replaced daily. Wells were counted in triplicate daily with three repeats. Growth rate with MannWhitney U-test $(\mathrm{p}<0.05)$. (A) Murine melanoma-Z-score is 3.4486; $\mathrm{p}=0.00056$; $\mathrm{U}$ value is 52.5 ; CV-99. (B) Murine fibroblasts-Z-score is 0.4276 ; $\mathrm{p}=0.6672$; $\mathrm{U}$-value is 203; data are normal and z-value can be used. (C) Human breast carcinoma -Z-Score is 4.3978; $\mathrm{p}=0$; $\mathrm{U}$-value is 22.5; CV-99. (D) Human breast epithelial cells-Z-score is$0.8701 ; \mathrm{p}=0.3843$; $\mathrm{U}$-value is 134 ; data are normal and $\mathrm{z}$-value can be used. 
Table 1. Doubling Times of the Four Cell Lines Using the Exponential Growth Equation of the Non-Linear Regression Analysis Function of Prizm GraphPad v 5.04 .

\begin{tabular}{lll}
\hline Cell Line & Control & Treated \\
\hline Mouse melanoma (B16-F10) & 30.5 hours & $>7$ days \\
Mouse fibroblast (L929) & 21.5 hours & 21.5 hours \\
Human breast cancer (MDA-MB-231) & 23.0 hours & $>7$ days \\
Human breast epithelium (MCF-10A) & 24.6 hours & 28.1 hours
\end{tabular}


There was no significant difference in the growth rates of the noncancerous cell control and treated groups with both methods.

We then proceeded to determine how long the effects of the treated water that was used to reconstitute the growth media would retain the effects that led to the significant growth inhibition of cancerous cells. The first set of experiments was conducted with treated water that was made fresh daily to make the growth media that was changed daily in the wells over 7 days. To determine how long the effect lasted, we treated water with the CETS system and allowed the treated water to sit for set time periods of 2, 3, 7and 14 days prior to making the treated media which was prepared and changed daily. For example, in the " 2 day old" sample, media was prepared using treated or control dilute saline beginning 2 days post treatment and the media was prepared daily using the same solution therefore on days 2-7. We observed a significant growth inhibition of growth in all samples demonstrating the effect is maintained for up to two weeks after initial treatment with the CETS system (Figure 2).

\section{Differential Effects on the Cell Size of Cancerous and Noncancerous Cells}

Due to the observed microscopic changes in cell morphology that were noted in the experiments and the fact that cell size is known to decrease when cells undergo various changes such as cell cycle progression and apoptosis, cell size data was collected using the Scepter 2.0 Cell Counter (Merck Millipore) and analyzed with unpaired t-tests. There was a significant difference in cell size between the treated and control groups in the cancerous cells while no significant difference was detected in the noncancerous cells lines (Figure 3). The MDA-MB231 cells show the largest significance and the data suggest that the cell size increases initially in the treated group and begins to decrease or shrink on day 6 (Figure 4).

\section{Differential Effects on the Cell Growth of Media Made on Day 1 Only}

In order to determine if the effects on the growth inhibition of cancer cells required daily making of replacement media that was made only on day 1 and not made fresh daily like the original growth experiments, we conducted the experiments by making growth media on day 1 and used the media made on day one to replace the control and treated media daily with the murine melanoma and the human breast carcinoma. After cell counts were conducted until day 7 , the effect of growth inhibition appeared to wear off at around day 6 but the murine melanoma and human breast carcinoma showed an overall growth inhibition (Figure 5).

\section{Differential Effects on Cell Cycle Progression of Cancerous and Noncancerous Cells}

In order to determine if the cancerous cells that were showing a significant growth inhibition were displaying an arrest in a specific phase of the cell cycle, cell cycle 
A

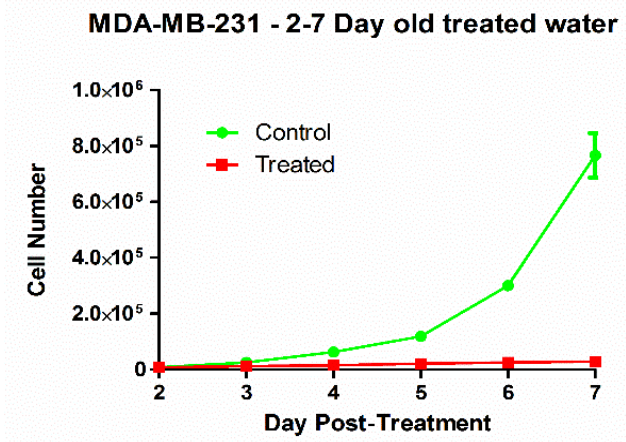

$\mathrm{C}$

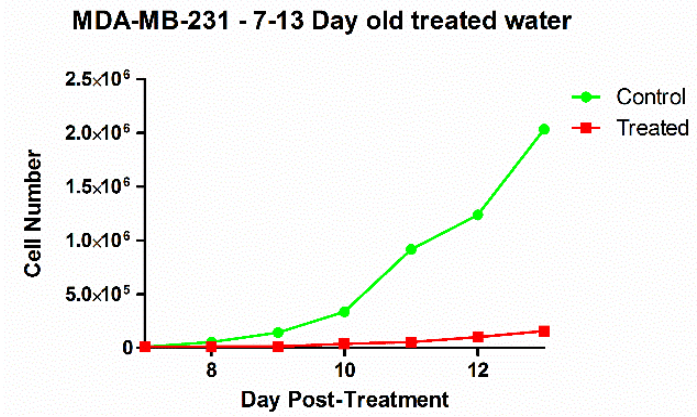

$\mathrm{B}$

MDA-MB-231 - 3-9 Day old treated water

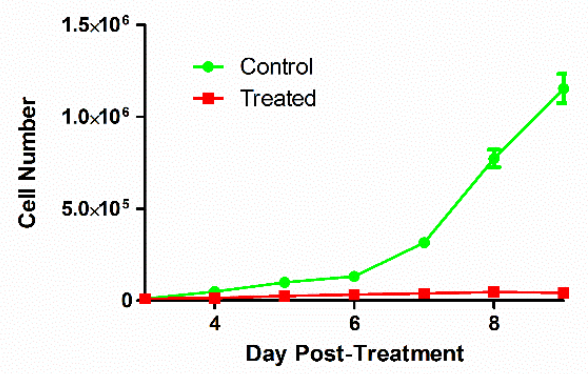

$\mathrm{D}$

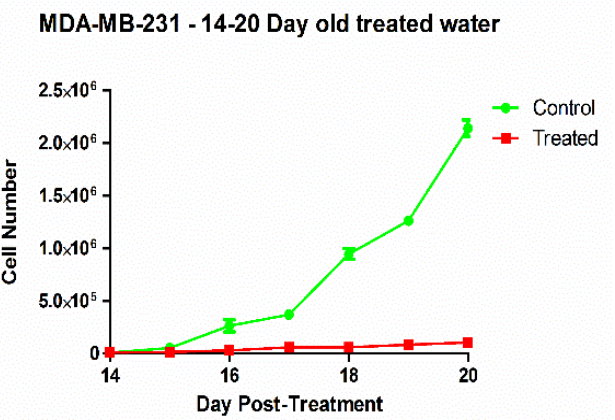

Figure 2. Growth Rate of MDA-MB231 Cells in Media Reconstituted from 2, 3, 7 and 14 Day Old Water.

$\sim 10,000$ MDA-MB231 cells were plated in standard media and after one day of growth the standard media was replaced with control or treated media daily. Control and treated media were made from 2, 3, 7, or 14 day old water and replaced daily. Wells were counted in triplicate daily from both control and treated groups. MDA-MB231 cell growth rates using Mann-Whitney $U$ tests $(\mathrm{p}<0.05)$. (A) 2-7 days-Z-score is 3.1164; $\mathrm{p}=$ 0.0018 ; $\mathrm{U}$-value is 63; $\mathrm{CV}=99$. (B) 3-9 days-Z-score is 3.8866; $\mathrm{p}=.0001$; $\mathrm{U}$-value is 65.5; $\mathrm{CV}=99$. (C) 7-13 days-Z-score 3.3583; $\mathrm{p}=0.0078$; $\mathrm{U}$ value $86.5 ; \mathrm{CV}=99$. (D) 14 20 days-Z-score 3.2828; $\mathrm{p}=0.00104$; $\mathrm{U}$ - value is $89.5 ; \mathrm{CV}=99$. 

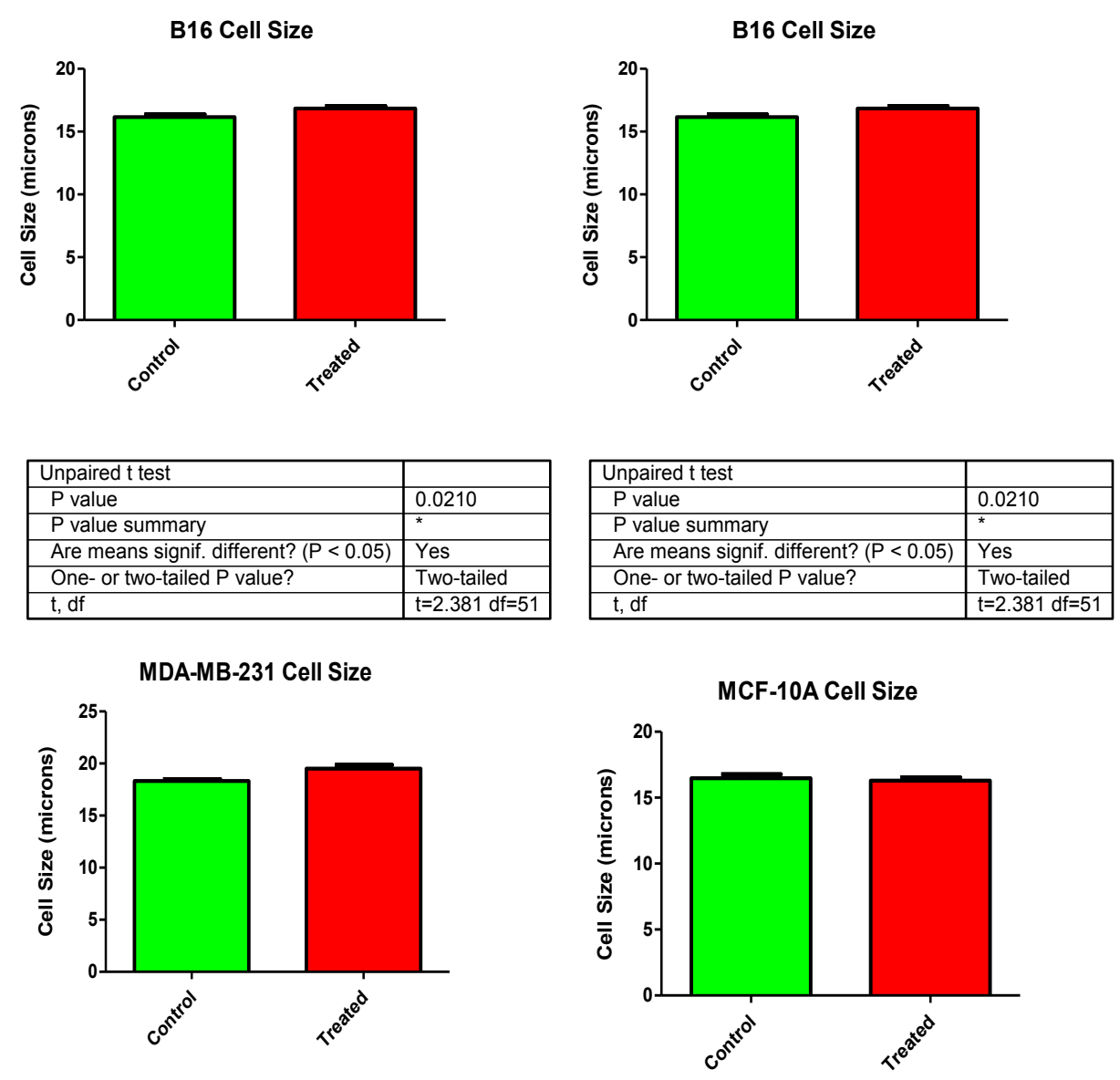

\begin{tabular}{|l|l|}
\hline Unpaired t test & \\
\hline$P$ value & 0.0046 \\
\hline$P$ value summary & ${ }^{* *}$ \\
\hline Are means signif. different? $(P<0.05)$ & Yes \\
\hline One- or two-tailed $P$ value? & Two-tailed \\
\hline $\mathrm{t}, \mathrm{df}$ & $\mathrm{t}=3.032 \mathrm{df}=34$ \\
\hline
\end{tabular}

\begin{tabular}{|l|l|}
\hline Unpaired $t$ test & \\
\hline$P$ value & 0.6134 \\
\hline$P$ value summary & $n s$ \\
\hline Are means signif. different? $(P<0.05)$ & No \\
\hline One- or two-tailed $P$ value? & Two-tailed \\
\hline$t, d f$ & $t=0.5101 \mathrm{df}=33$ \\
\hline
\end{tabular}

Figure 3. B16, L929, MDA-MB231, MCF-10A Cells Size with Sceptor 2.0 Cell Counter (Merck Millipore).

Cell size was analyzed by counting/analyzing cell size daily while counted in triplicate for 7 days while treated and control groups of each cell lines were grown in the control and treated media. The results shown are the means of cell size for days 1-7. Unpaired ttests show a significant difference in cell size between the treated and control groups of the cancerous B16 and MDA-MB231 cells. There is no significant difference noted between the noncancerous L929 and MCF-10A cells. 


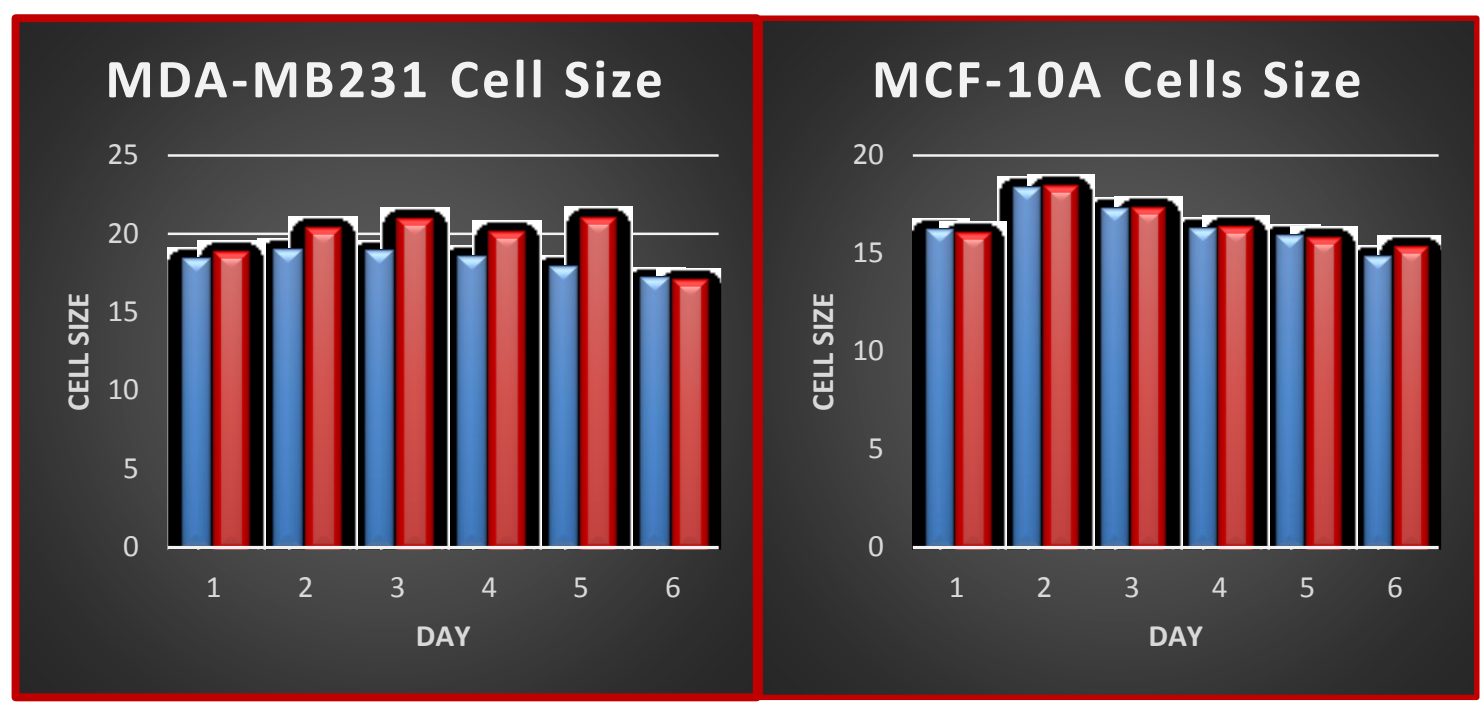

Figure 4. MDA-MB231 versus MCF-10A Daily Cell Size Analysis.

When analyzing the daily cell size changes, the MDA-MB231 treated cells (red) show an increase in cell size on days 1-5 when compared to control (blue) and then appear to have a drop in cell size on day 6 . The MCF-10A cells appear to be larger when initially placed in the treated (red) and control (blue) media, but overall have uniform size between control and treated cells from day 1-6. 
A

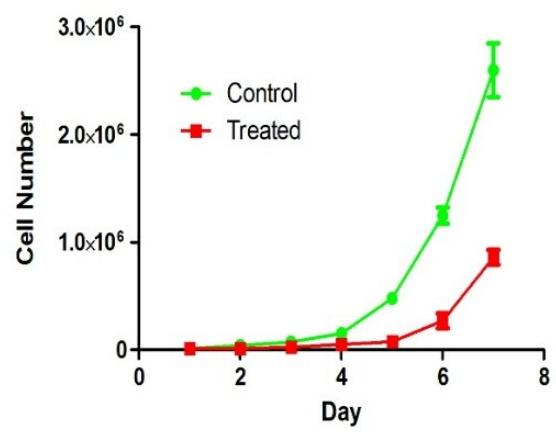

B

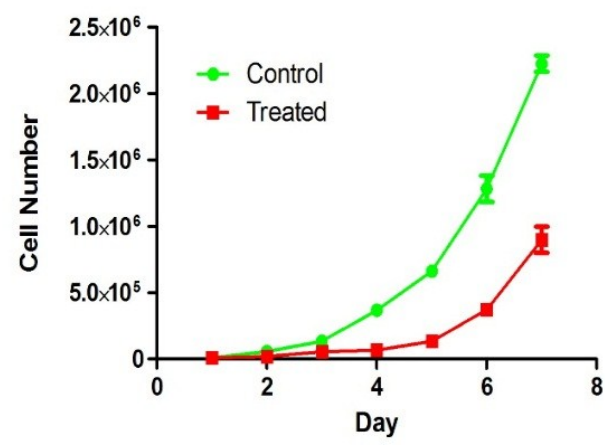

Figure 5. Effect of Storing Media on Cell Growth Inhibition.

Control and treated media for (A) B16 and (B) MDA-MB231 cells were made on day 1 and this media made on day 1 were used to replace the control and treated media daily. Cells were counted daily in triplicate. B16 Cells cultured in media prepared on Day 1 (media changed daily) unpaired t-tests; mean (C) 656795; mean (T) 186,752.4; $\mathrm{p}=$ $0.032002 ;$ ts $=2.222029 ; \mathrm{df}=40$. MDA-MB231 cells cultured in media prepared on Day 1 (media changed daily) unpaired t-tests; mean (C) 676232.1; mean (T) 220645.7; $\mathrm{p}=$ $0.016367 ;$ ts $=2.506314 ; \mathrm{df}=40$. 
analyses were conducted on all four cell lines with cell flow cytometry utilizing ModFit. When compared to controls, CETS-treated murine melanoma did not enter in S phase and showed a two-fold increase G0/G1 phase while treated MDA-MB231 cells were halted in $\mathrm{S}$ and G2/M phases were unable to complete mitosis (Figure 6).

\section{Differential Effects of the Modulation of the Magnetic Behavior of Metal Aqueous Ions on the Mitotic Index of Cancerous Cells}

In order to quantify and visualize how quickly and if the cancerous cells ceased to undergo mitosis, human breast carcinoma cells were grown in control or treated media for one day. The cells were then fixed and stained with DAPI to visualize the nuclei and with an anti-tubulin antibody followed by a rhodamine-conjugated secondary antibody. The untreated control cells had $\sim 17 \%$ of the cells undergoing active cell division, whereas cells grown in the treated media showed some nuclear condensation, but no detectable mitotic spindle formation (Figure 7).

\section{Effects on the Membrane Potential of Cancerous and Noncancerous Cells}

Due to the known Vmem differences in cancerous, injured or proliferating cells, we decided to conduct membrane potential assays on all four cell lines. We hypothesized that the treated media would have a differential effect on membrane potential of the treated versus control cells. Upon analysis of the data, we found that all four cell lines showed rapid hyperpolarization of the cells when placed in media that occurs in the first 45 minutes. When the cells are hyperpolarized the indicator dye exits the cells, resulting in a decrease in fluorescence signal. All four cell lines remained hyperpolarized while maintained in the treated media (Figure 8). Percent differences between the treated and control groups show the noncancerous cells return closer to baseline at 24 hours posttreatment, while the cancerous cells remain in a more hyperpolarized state (Table 2).

The results indicate that all four cell lines undergo a rapid hyperpolarization and remain hyperpolarized during maintenance in the treated media. In the microarray analysis delineated below, gene CLIC4 was upregulated 2.75 times which is a chloride channel made up of a diverse group of proteins that stabilize cell membrane potential, trans-epithelial transport, maintenance of intracellular $\mathrm{pH}$ and regulation of cell volume.

\section{Differential Effects on Cell Death by Phase and Fluorescent Microscopy}

In Figure 9, we left the breast carcinoma growing in treated media for 14 days and the control cells grew for 5 days until confluence. The treated cells in Figure 9 (right) show the cells rounding up off the bottom as well as cell shrinkage, nuclear condensation and blebbing when compared to the control cells in Figure 9 (left). Due to the significant cell growth inhibition, cell cycle arrest and the observed effects of cell

shrinkage (Figure 4), nuclear fragmentation and "blebbing" (Figure 9) we proceeded to 
A

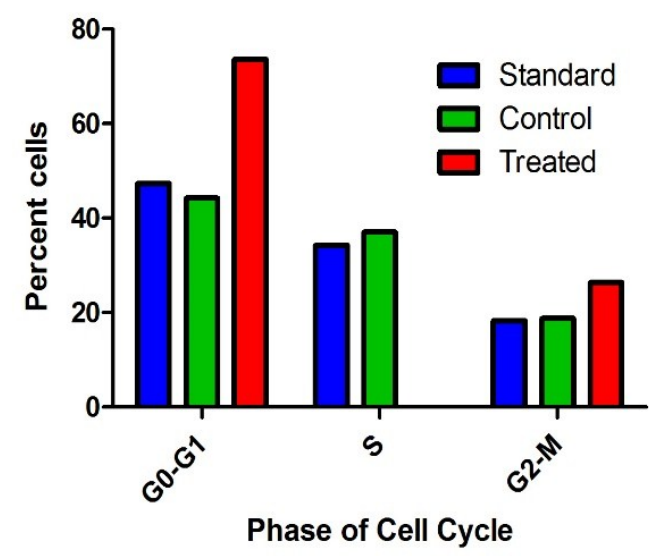

C

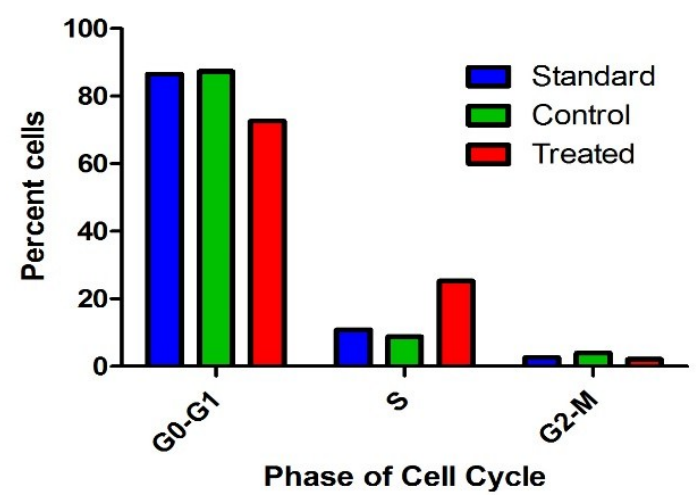

B

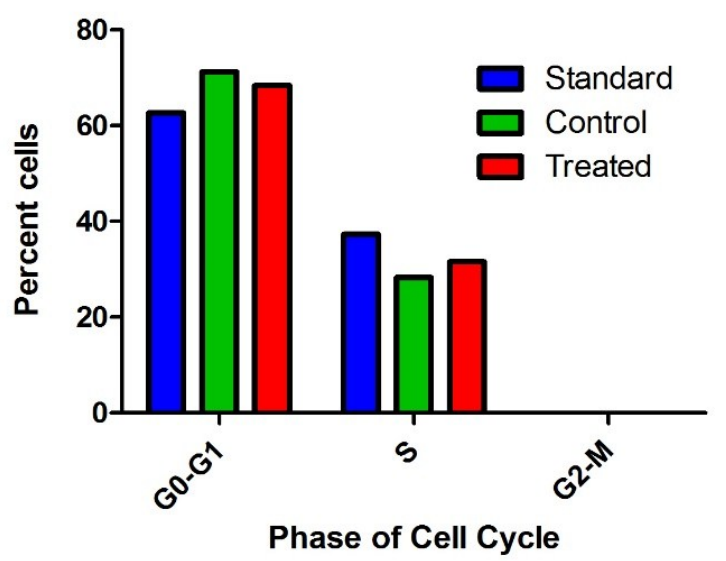

D

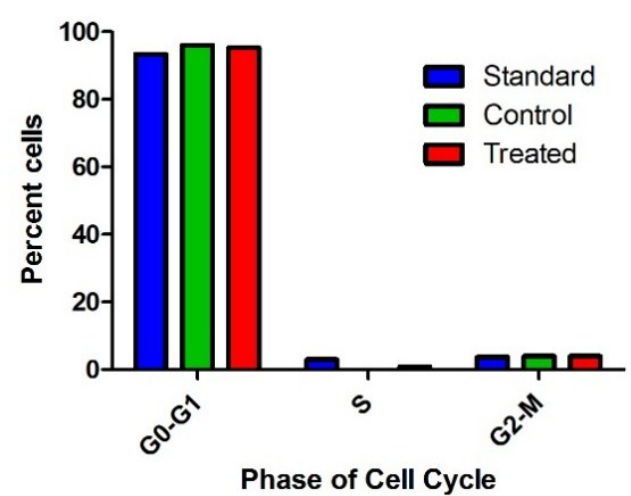

Figure 6. Cell Cycle Analysis Using Propidium Iodide and Cell Flow Cytometry.

A) Treated murine melanoma did not enter in S phase and showed a two-fold increase G0/G1 phase while treated (B) Treated L929 (C) Treated MDA-MB231 cells were halted in $\mathrm{S}$ and $\mathrm{G} 2 / \mathrm{M}$ phases were unable to complete mitosis. (D) Treated MCF-10A cells had no change in the cell cycle. 


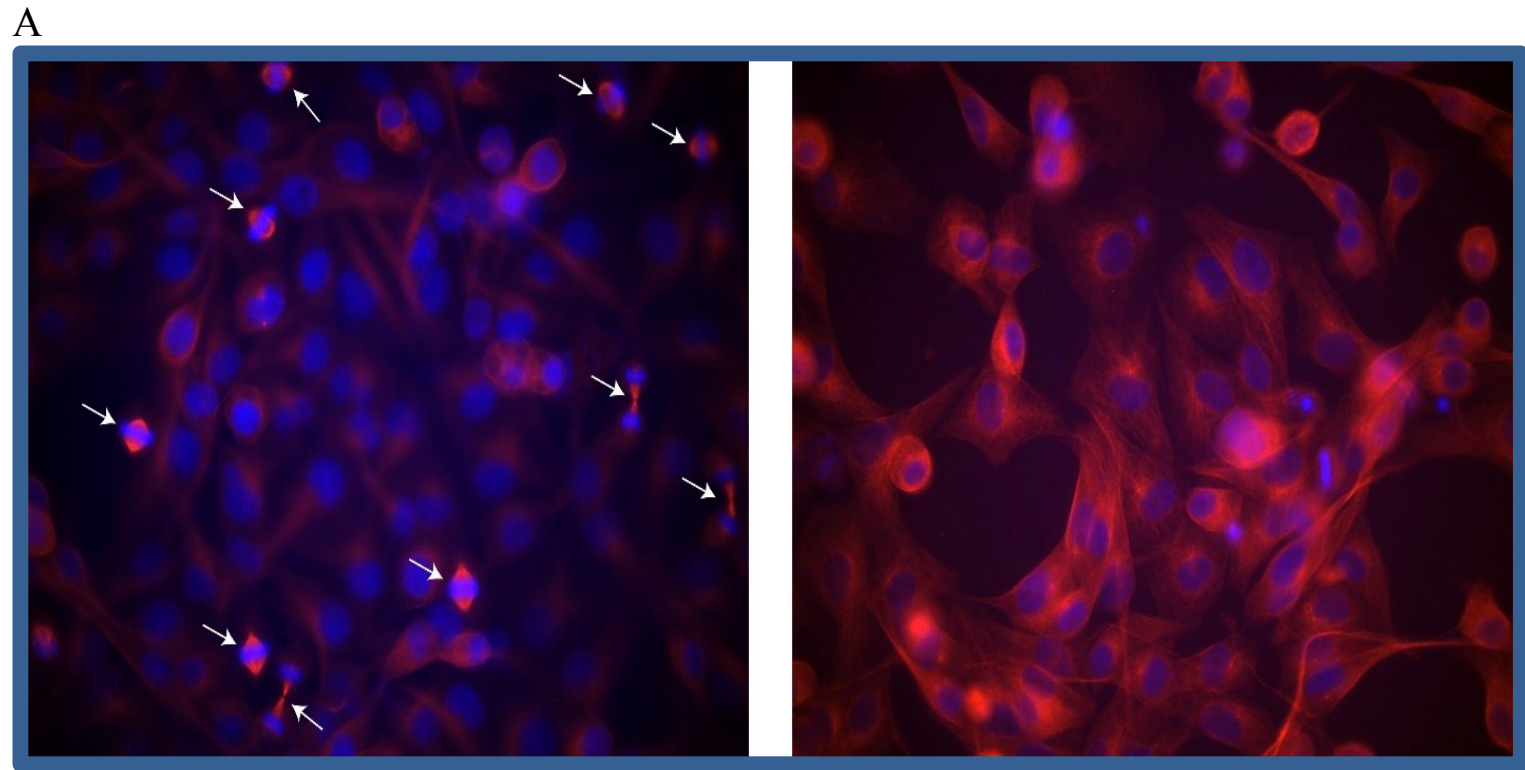

B

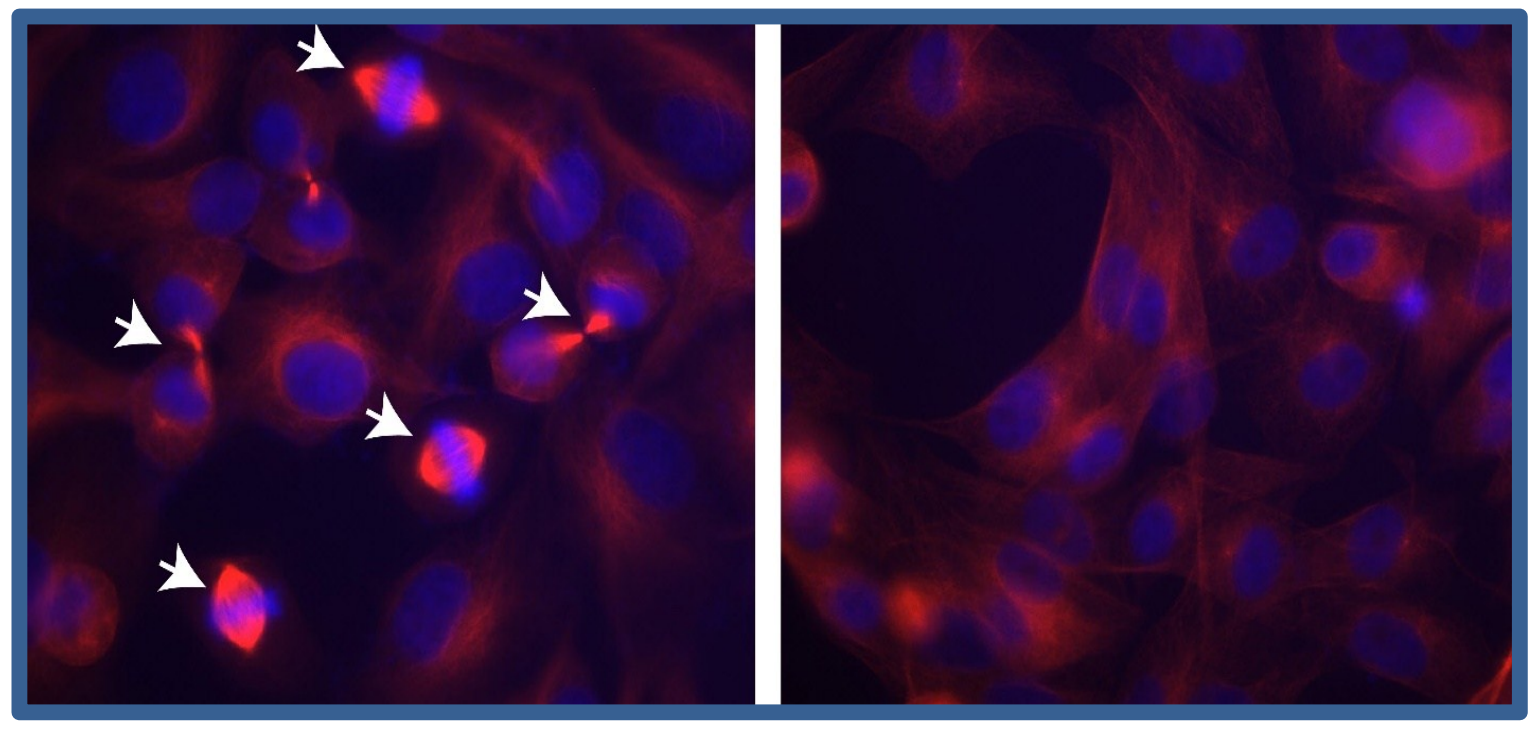

Figure 7. Tubulin Staining of MDA-MB231 Cells after Growth in Both Control and Treated Media for One Day.

Cells were fixed and stained with DAPI to visualize the nuclei and with an anti-tubulin antibody followed by a rhodamine-conjugated secondary antibody. A). The human breast carcinoma were then grown in control or treated media for one day and were fixed and stained DAPI to visualize the nuclei and with an anti-tubulin antibody followed by a rhodamine-conjugated secondary antibody. The untreated control cells (left) had $\sim 17 \%$ of the cells undergoing active cell division (arrows), whereas cells grown in the treated media (right) showed some nuclear condensation, but no detectable mitotic spindle formation. B) Higher magnification of A. 
B16 - 24 hrs

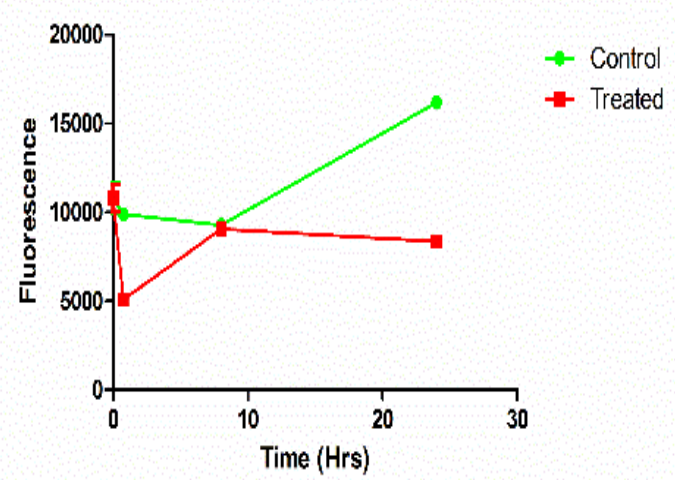

MDA-MB-231 - $24 \mathrm{hrs}$

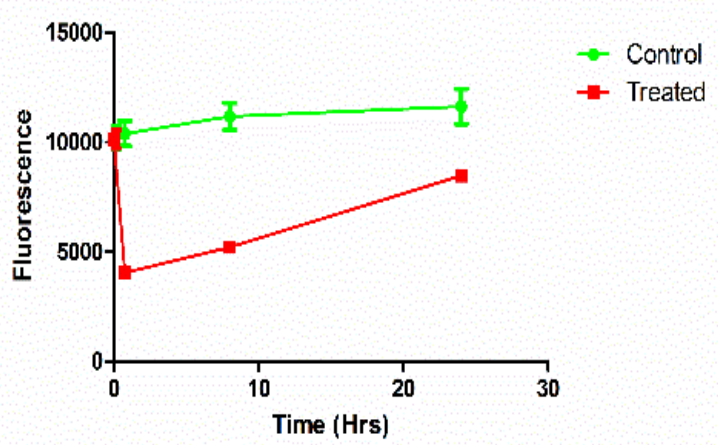

L929 -24 hrs

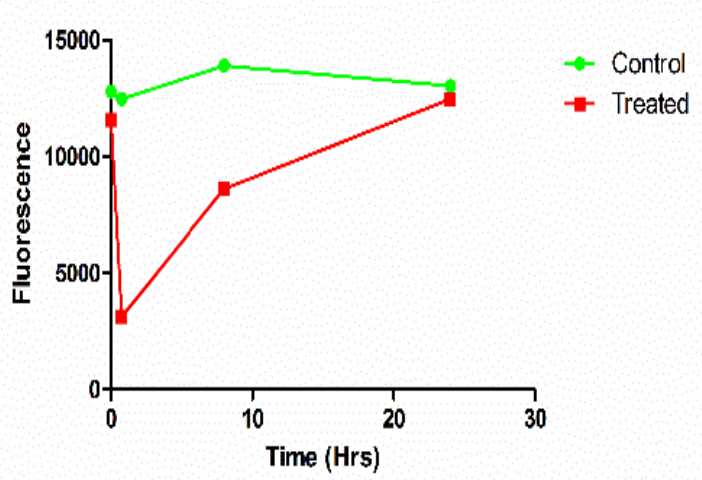

MCF-10A - 24 hrs

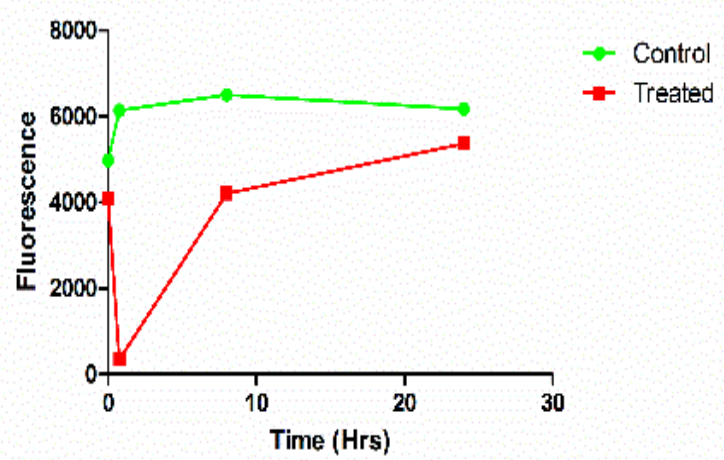

Figure 8. Membrane Potential Assay.

Percent increase was noted between control and treated groups of MDA-MB231, MCF$10 \mathrm{~A}, \mathrm{~B} 16$ and L929 cells after exposure to treated media for the time points of 45 minutes, 8 hours and 24 hours. Cells were analyzed using Five Photon's membrane potential assay. The graphs show change in fluorescence over time. When a cell is depolarized the fluorescence increases and when it is hyperpolarized the fluorescence decreases. Table 2 shows percent change between control and treated cells at the specific time points below. 
Table 2. Percent Change in Membrane Potential.

\begin{tabular}{lccc}
\hline Cell Line & $\begin{array}{c}\text { 45 Minutes in } \\
\text { Treated Media } \\
\text { as Compared to } \\
\text { Controls }\end{array}$ & $\begin{array}{c}\mathbf{8} \text { Hours in } \\
\text { Treated Media } \\
\text { as Compared to } \\
\text { Controls }\end{array}$ & $\begin{array}{c}\text { 24 Hours in } \\
\text { Treated Media } \\
\text { as Compared to } \\
\text { Controls }\end{array}$ \\
\hline MDA-MB231 & $\uparrow 70 \%$ & $\uparrow 61 \%$ & $\uparrow 32 \%$ \\
MCF-10A & $\uparrow 94 \%$ & $\uparrow 31 \%$ & $\uparrow 12 \%$ \\
B16 & $\uparrow 60 \%$ & $\uparrow 29 \%$ & $\uparrow 34 \%$ \\
L929 & $\uparrow 76 \%$ & $\uparrow 35 \%$ & $\uparrow 06 \%$ \\
\hline
\end{tabular}
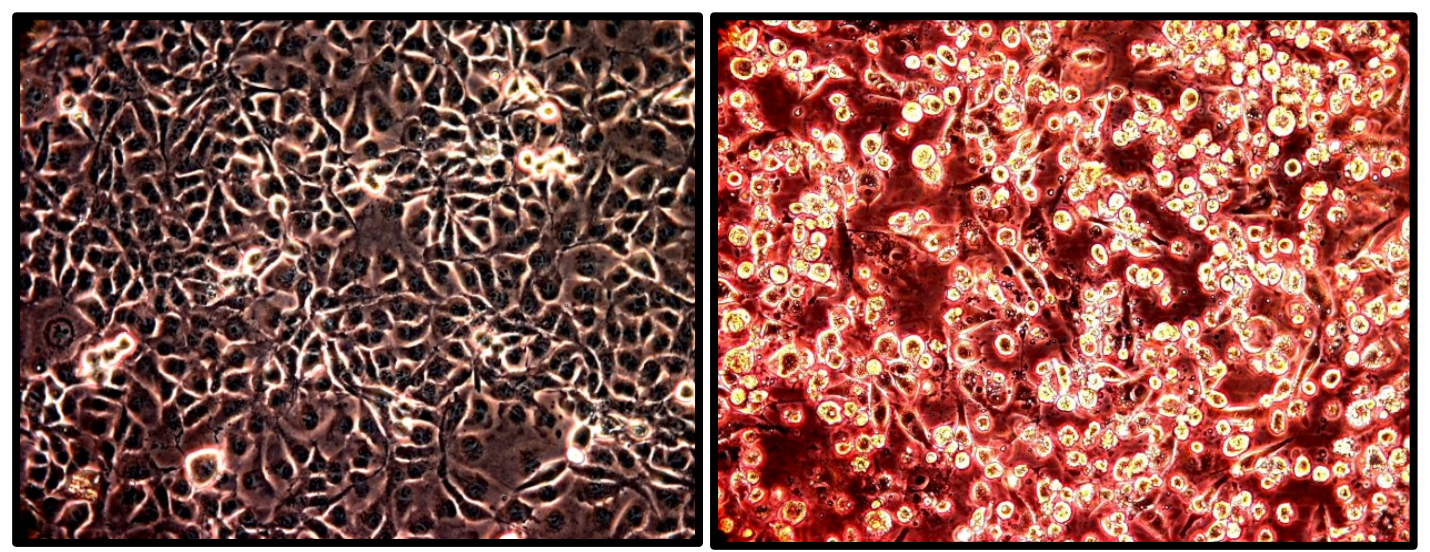

Figure 9. MDA-MB231 Cells Control versus Treated for 14 days. Control (left) Treated (right). 
conduct an Annexin V-FITC Apoptosis Detection assay utilizing cell flow cytometry. Upon completion of the cell flow analysis, we were unable to differentiate treated stained and unstained in order to quantify the effect of interest. We then proceeded to phase and fluorescent microscopy of the stained treated and unstained treated cells and we found the treated cells displayed an auto-fluorescence in all color spectrums. Auto-fluorescence interferes with detection of specific signals and is a natural emission of light by biological structures such as mitochondria and lysosomes when they have absorbed light. The treatment appears to induce auto-fluorescence and therefore the cell flow cannot differentiate between the different groups. We did note there was a visible staining of areas of the membrane in the treated group of the breast carcinoma in the FITC channel representing annexin $\mathrm{V}$ staining when examined with fluorescent microscopy while there was none noted in the control group (Figure 10). Figure 11 shows the different microscopic appearance in the phase contrast pictures of the control and treated stained cells.

Another interesting observed phenomena occurred when these cells in Figure 9 were placed back in standard DMEM, it appears that the cells that were rounding up and appearing to undergo a cell death have continued to become apoptotic and form disorganized cell clusters while the cells that were growing have continued to grow and divide, albeit in with a different morphological appearance and at a slower rate since this cell line characteristically becomes confluent in less than 5 days (Figure 12). We also conducted an experiment where we grew MDA-MB231 cells in control and treated media for 7 days and then placed both groups back in control media. On analysis of four different groups: control days 1-7, control days 8-14, treated days 1-7 and treated days 814 , we found that there was no change in the growth of the control group but there was a decreased growth rate in both the treated groups when compared to control (Figure 13). There was also a decreased growth curve noted in the treated cells when placed back in the control media on day 8 when compared to the treated cells on days 1-7 and the control cells on days 1-7. This suggests there may be a lasting change in the growth rate of the treated cells once they are returned to control media after 7 days of growth in the treated media. Further studies are warranted to quantify the mechanisms to explain this observed phenomena.

We conducted an experiment where the MDA-MB231 cells were grown in treated and control media for 8 days. At the end of the $8^{\text {th }}$ day, the treated cells were placed back in control media to see if the growth rate would correspond to the original growth rate that occurred in days 1-8. The 95\% confidence intervals were used to analyze the groups and there was a significant difference in growth rates between the control and treated cells when the cells had been growing in treated media for 8 days. The treated cells also appear to continue to grow more slowly than the control with no rebound once they are placed back in control media at day 8 (Figure 13). 

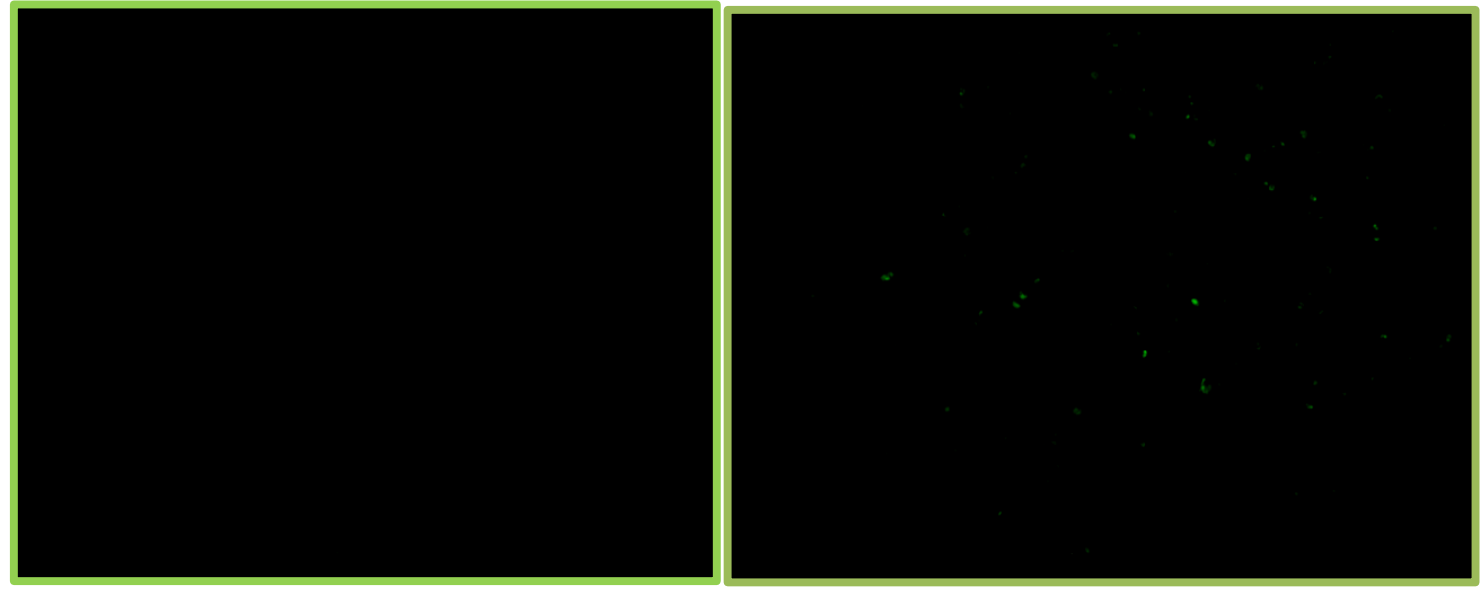

Figure 10. MDA-MB231 Fluorescent Microscopy with Annexin Staining. Control (left) Treated (right).

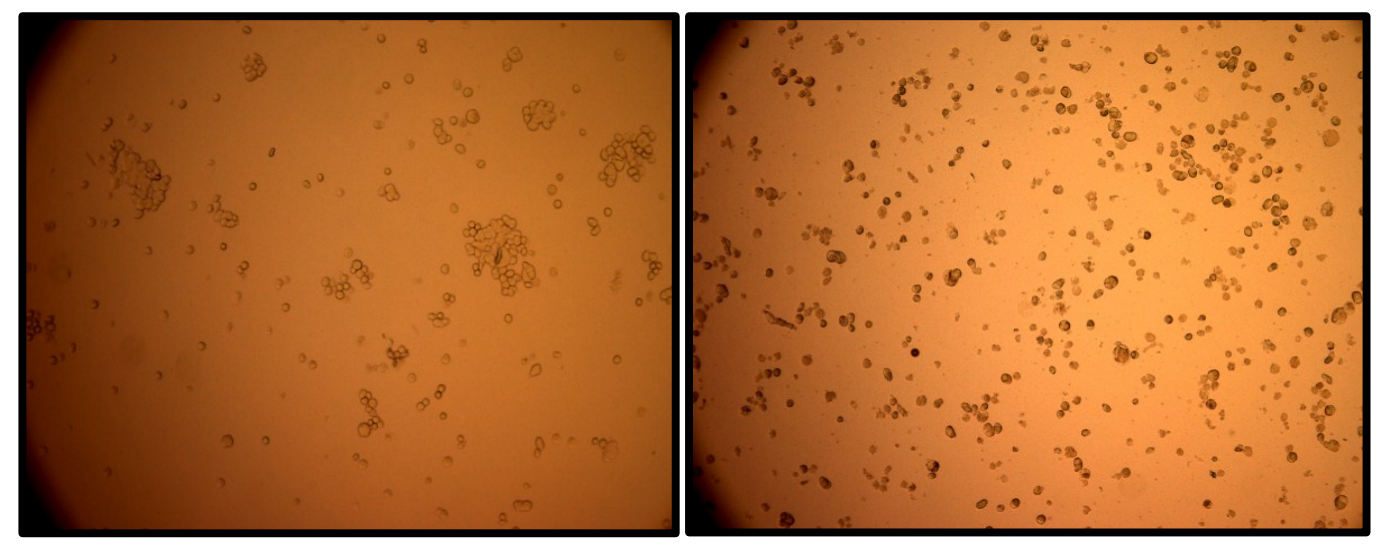

Figure 11. MDA-MB231 Cells Phase Contrast Microscopy. Control (left) Treated (right). 

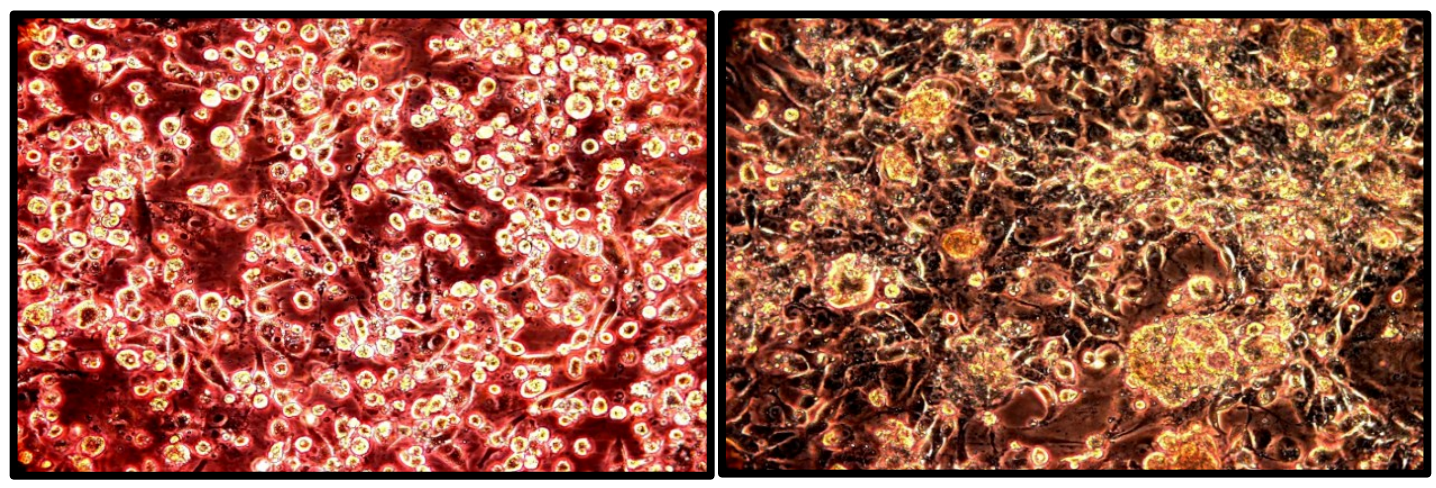

Figure 12. MDA-MB231 Cells Treated 14 Days versus Treated 14 Days and Placed in Standard DMEM for 14 Days.

Treated 14 days (left) Treated 14 days and placed back in standard media (right). 


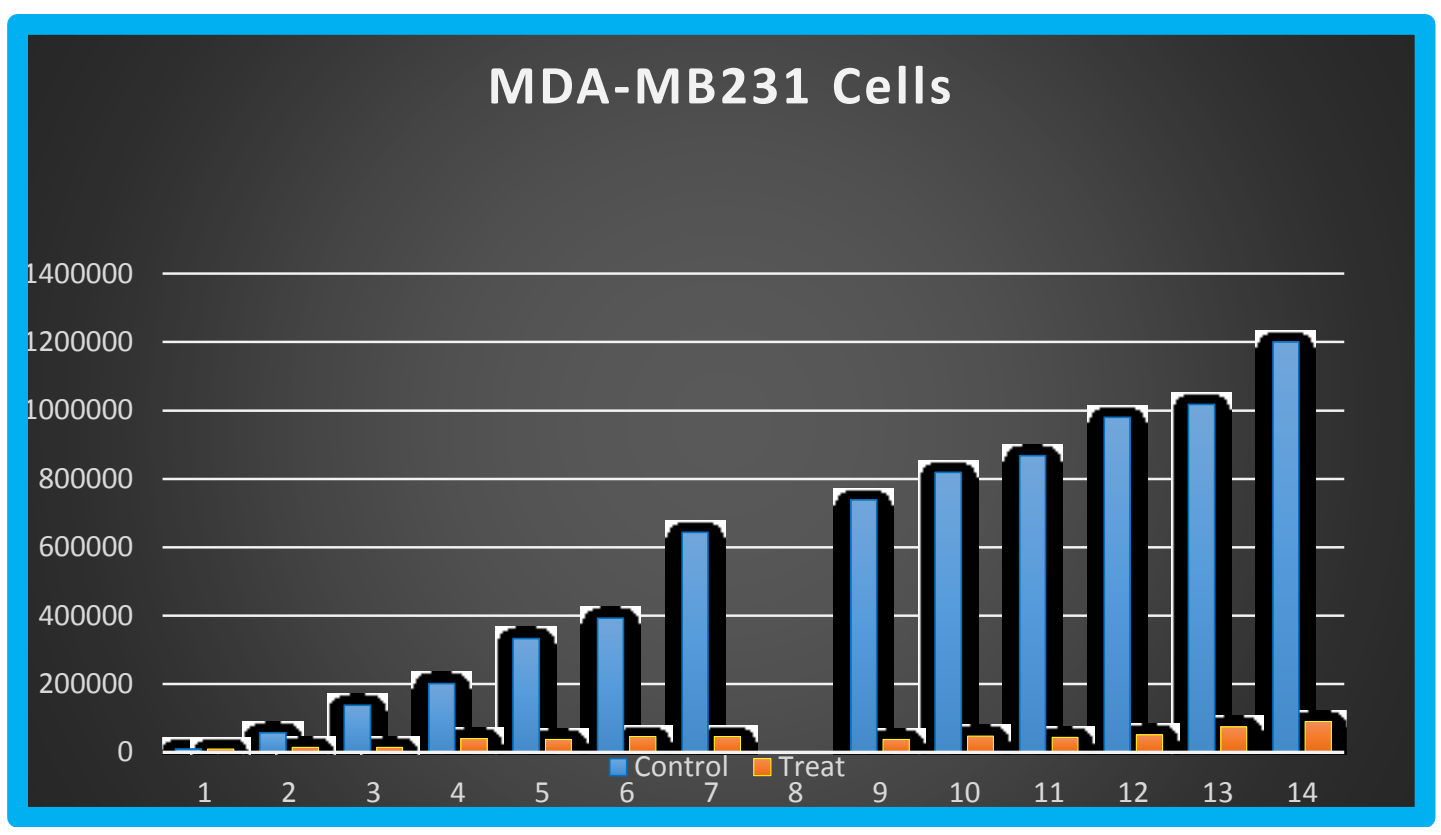

Figure 13. MDA-MB231 Control and Treated Cells Grown in Control and Treated Media for 7 Days and then Both Groups Placed in Control Media on Day 8. Data were analyzed with GLM of SAS 9.4. The data were divided into 4 groups analyzing cell growth/time. The slopes and $95 \mathrm{CI} \%$ within the treatment period were analyzed. These 4 groups were analyzed: B11- control cell growth from day 1-8 (blue); B12-control cell growth from day 8-12 (blue); B21-treated cell growth from day1-8 (yellow); B22-treated cell growth back in control media from day 8-14 (yellow). After analyzing $95 \mathrm{CI} \%$, we found that B11=B12 and these two slopes showed continuous growth. We also found that B22<B21 which suggests that there was no rebound in growth of the treated cells when placed back in control media on day 8 and in fact there was a reduced growth which suggests a reduced growth rate in these cells after grown in treated media. When we compared B22 to B11, there was no overlapping of confidence intervals between the two groups suggesting there was a significantly reduced rate of growth in B22 when compared to B11. 


\section{Differential Effects on the Recovered RNA and Protein Levels of Cancerous Cells}

When conducting our microarray analysis on the MDA-MB231 cells grown in the treated media for 3 days, we noted there was a significant increase in RNA in the treated groups when compared to control (Figure 14). We then conducted an assay to determine if this increase in RNA corresponded to an increase in protein production as well in the treated cells. Upon analysis of the BCA protein data, paired t-tests showed no significant difference in the protein content between the treated and control groups of MDA-MB231 cells after being grown in the treated media for 3 days $(p=0.71126)$. The control group did show a slight increase in protein content over the treated groups although not declared significant (Figure 15).

\section{Differential Effects on mRNA Expression per Affymetrix 2.0 Microarray}

Due to the significant effects that were seen in cell growth/proliferation, cell cycle, membrane potential, and tubulin assay; Affymetrix 2.0 microarray analyses were conducted on both the human breast carcinoma cell line and the human breast epithelial cell in order to see what, if any, effects on gene expression could be measured. Data were normalized using the RMA Sketch Global normalization function in an Affymetrix expression console and analyzed with QIAGEN'S Ingenuity Pathway Analysis (IPA) to identify relationships, mechanisms, functions and pathways of relevance in the data. Results of this analysis indicated that the treated group of the carcinoma cell line displayed a significant upregulation in pathways of the Unfolded Protein Response (UPR), Phenylethylamine Degradation 1, tRNA charging and Serine and Glycine Biosynthesis. Strong changes were also displayed in the upstream regulators of TRIB3, PPRC1, ATF4, SCD and GNE. The expression of over 1,000 genes showed a 2- 18 fold change after growth in the treated media compared to cells grown in the control media. The significant changes in gene expression that were upregulated in the treated group of the cancerous cells were in the areas of cell survival/death, cell cycle progression, immune modulation and membrane potential. Endoplasmic r eticulum (ER) stress leads to a compensatory mechanism in cells referred to as the Unfolded Protein Response (UPR). The UPR is a cellular stress response that is related to ER stress and has been known to be conserved in all mammalian species (Figure 16). ${ }^{46}$ The UPR shows significant upregulation in these three arms that are used when the UPR is initiated in order to restore function in the cell: 1) halting protein translation (see PERK-ERN1) 2) degradation of the misfolded proteins (see EDEM2/ERO1-LB) 3) activation of signaling pathways that lead to soliciting the help of molecular chaperones that are involved in protein folding (IRE1, XBP1). ${ }^{46}$ The UPR also shows an upregulation in the apoptosis or programmed cell death (CHOP/DDIT3/CHAC1) arm. Therefore, the microarray analysis diagram below (Figure 16) shows significant upregulation (purple highlights) in all three arms of the UPR and in the stress response leading to apoptosis of the MDA-MB231 cells. Finally, GADD34 (see below) is a CG3825 gene product from transcript CG3825RA that binds to PP1 and facilitates translational elongation of specific transcriptional factors that lead to phosphorylation of eIF2-a, thereby terminating global protein translation and inducing apoptosis. ${ }^{54}$ There was also a down regulation in many cell cycle 


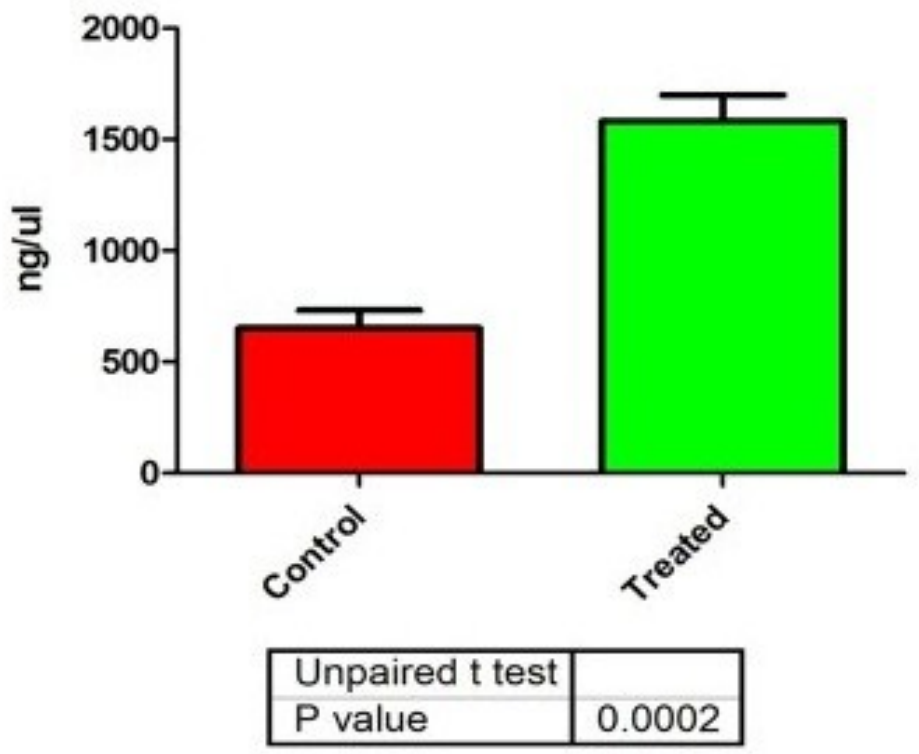

Figure 14. RNA Recovered from Treated versus Control MDA-MB231 Cells.

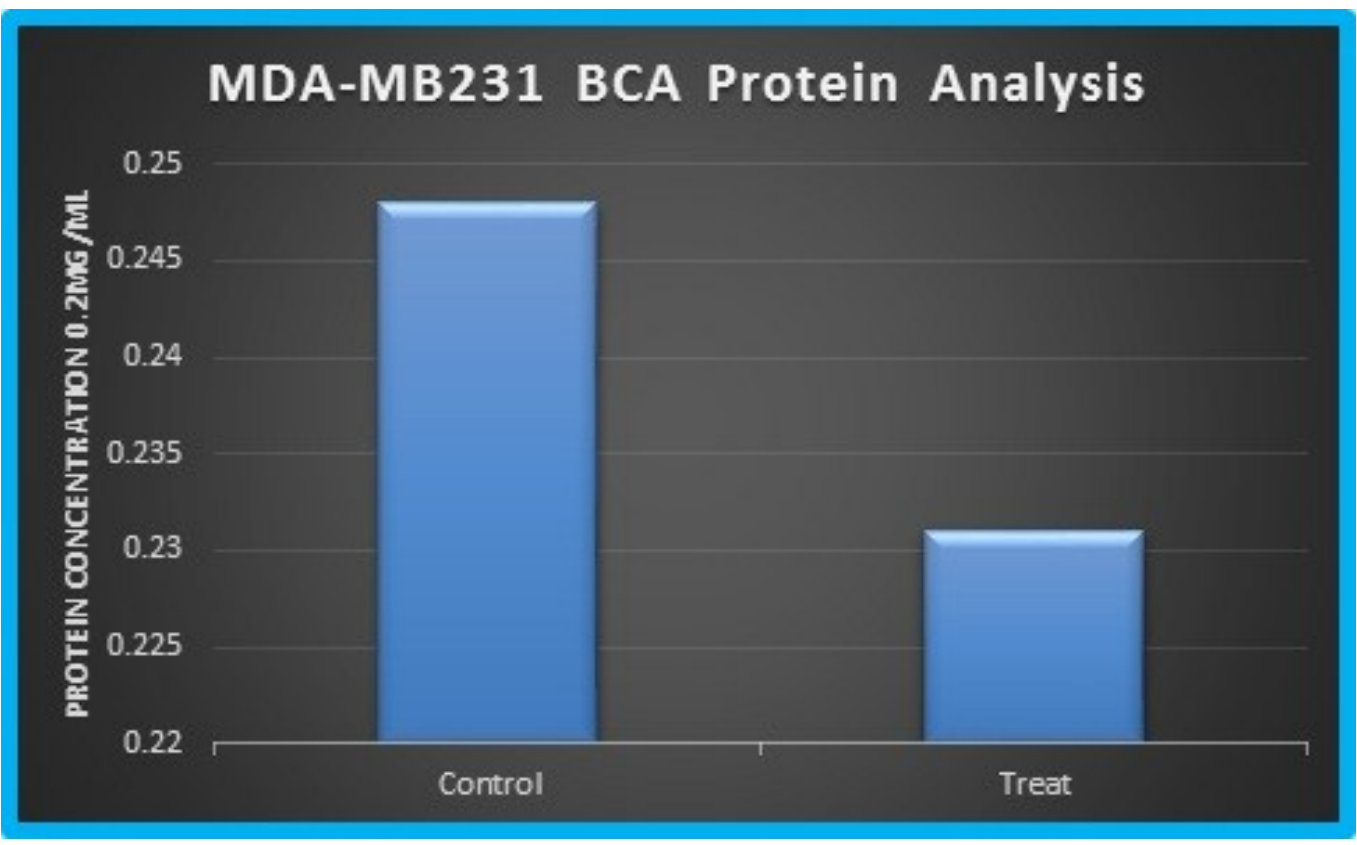

Figure 15. BCA Protein Analysis.

BCA protein analysis showing difference in the protein concentration at $0.2 \mathrm{mg} / \mathrm{ml}$ dilution of MDA-MB231 cells when grown in control and treated media for three days Unpaired t-tests - Control mean 0.248; Treated mean 0.231; ts- 0.380879; df- 10; $\mathrm{p}=$ 0.71126 . This shows no signficant difference in protein conentrations but does suggest a slight decrease in the treated protein concentration when compared to control. 


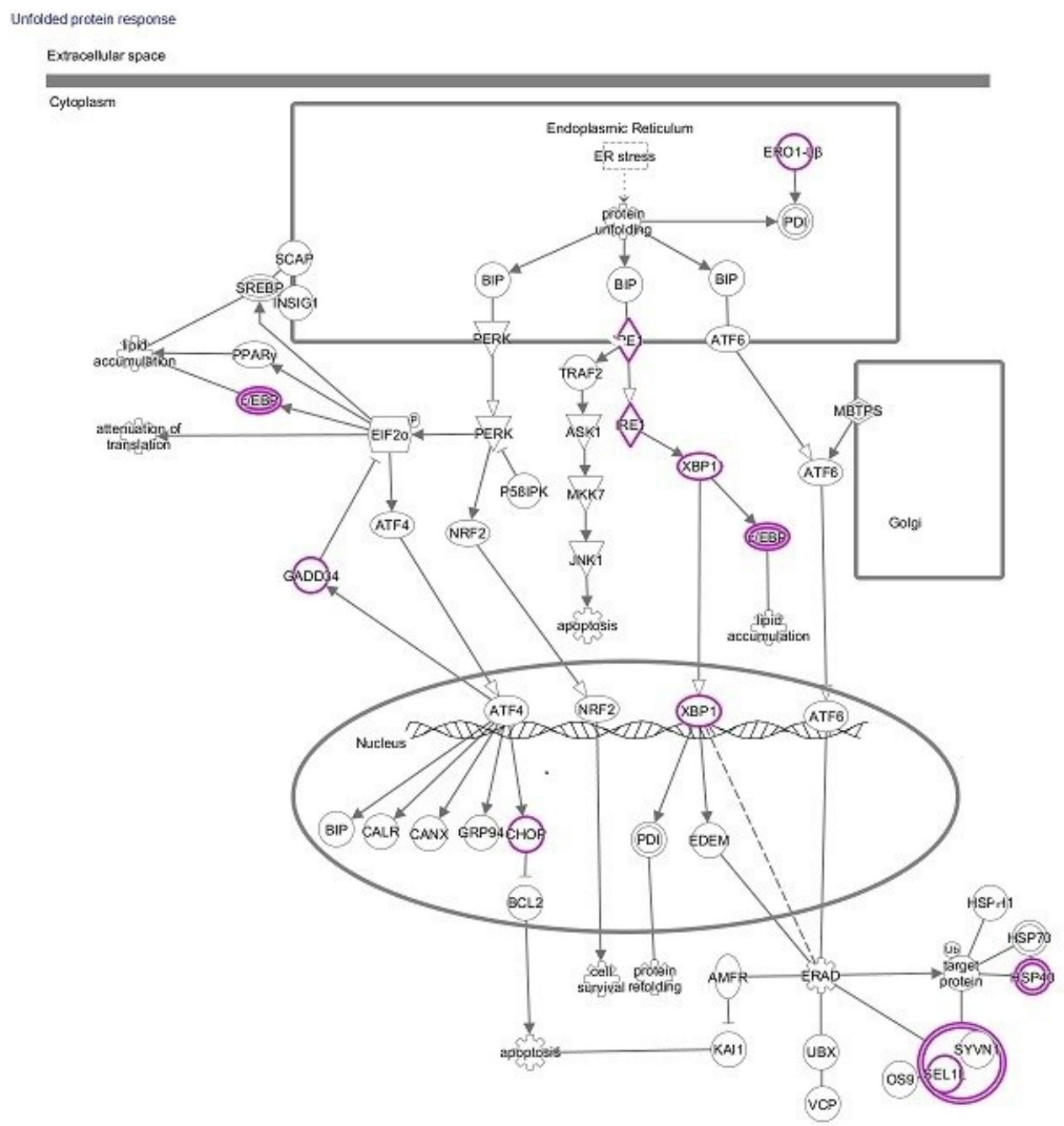

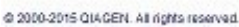

Figure 16. ER Stress/Unfolded Protein Response.

Data were analyzed through the use of QIAGEN's Ingenuity ${ }^{\circledR}$ Pathway Analysis (IPA ${ }^{\circledR}$, QIAGEN Redwood City, www.qiagen.com/ingenuity). 
progression genes with an upregulation in many genes in the p53 pathway. Significant changes also occurred with an upregulation in the tumor necrosis factors (TNF) as well in the immune responses of several cytokines.

The MCF-10A cell line microarray showed an up regulation in the pathways of: Superpathway of Serine and Glycine Biosynthesis I, Serine Biosynthesis, Role of IL-7A and Granulocyte Adhesions and Diapedesis. While the microarray did show a significant fold increased in the ER Stress and Unfolded Protein Response pathways in the MDAMB231 cells, it did not show an increased fold change ER Stress or the Unfolded Protein Response in the MCF-10A cells. There was an 8-fold decrease in the CHAC1 expression and this had been shown to correspond to a reversal in ER stress/UPR. ${ }^{106}$ The MCF10A cells did not show a down regulation of cell cycle progression. There was a greater increase in immune cytokines in the MCF-10A cells when compared to the MDA-MB231 cells. While the MDA-MB231 cells showed a significant fold change in the upregulation of the p53 pathway, there was no up regulation in the tumor necrosis factors or the p53 pathway in the MCF-10A cells. Two heat maps were generated to show both the microarray data and the real time PCR validations (Figures 17 and 18). A list of the gene expressions for both the treated and control groups in both cell lines that were evaluated and validated in order to make biological correlations to our experimental data are listed in Table 3.

\section{Validation of Differential Gene Expression by RT-qPCR of Cancerous and Noncancerous Cells}

Once all primers were tested for appropriate efficiency of 1.8-2.1 (Figure 19) based on conformity of the standard deviations of all of the dilutions, cDNA was made from 5 biological control samples of the MDA-MB231 cells and 5 biological treated samples of the MCF-10A cells using the Transcriptor First Strand cDNA Synthesis Kit.

The RNA and all the above listed reagents were then placed in a thermal block LightCycler 480 instrument with a heated lid and run through the 60 minute cycled experimental program for denaturation, amplification, melting and cooling. The cDNA was placed in a $-80 \mathrm{C}$ freezer until use for real-time qPCR.

Real-time qPCR for each gene was run in triplicate for each of the 5 control and 5 treated biological samples. Relative quantification was used to analyze the changes in the gene expression in the samples relative to the reference sample that was analyzed from each of the biological replicates. Amplification curves were noted on all the gene samples (Figure 20) and each sample was run in triplicate (Figure 21).

The ER Stress/UPR pathway genes of: ERN1, HERPUD1, XBP1, DDIT3 and CHAC1 all showed a significant increase in gene expression in the treated MDA-MB231 cells. The ER Stress/UPR showed no up regulation in the MCF-10A by validation of DDIT3. The CHAC1 gene in treated MDA-MB231 cells showed a 256-fold increase which shows a strong response in the apoptotic arm of the UPR after 3 days in the treated 


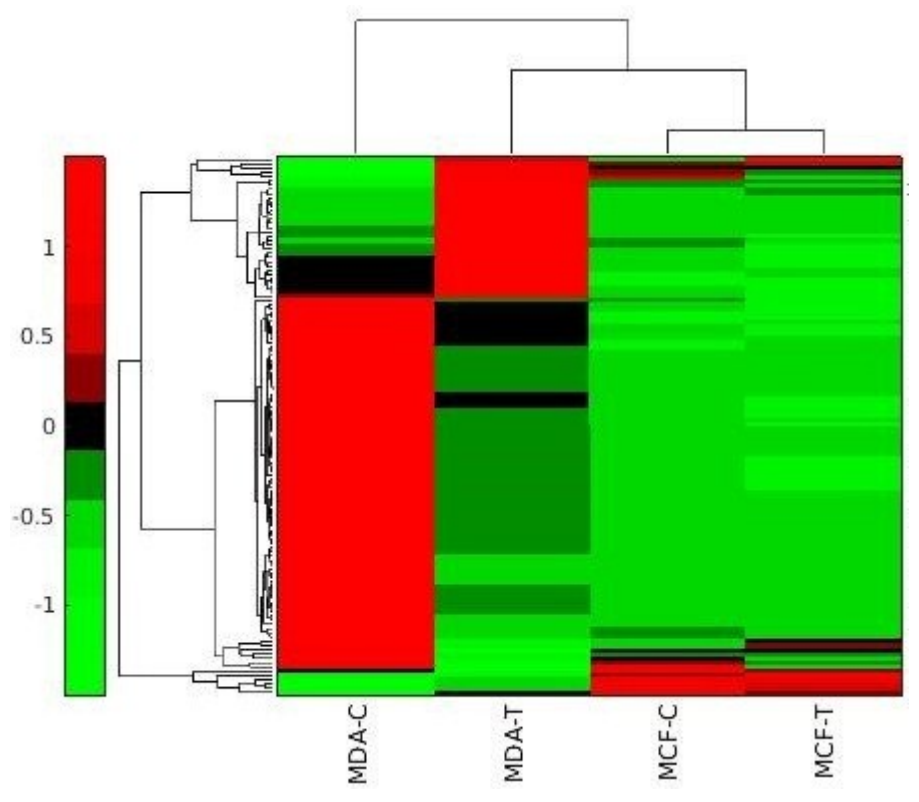

Figure 17. Heat Map from Affymetrix 2.0 Gene Expression Values.

(See Table 3) Values related to ER stress/UPR, immune/TNF, cell cycle, tumor targets, cell death and membrane potential across the four conditions of the control and treated of the MDA-MB231 and MCF-10A cell lines.

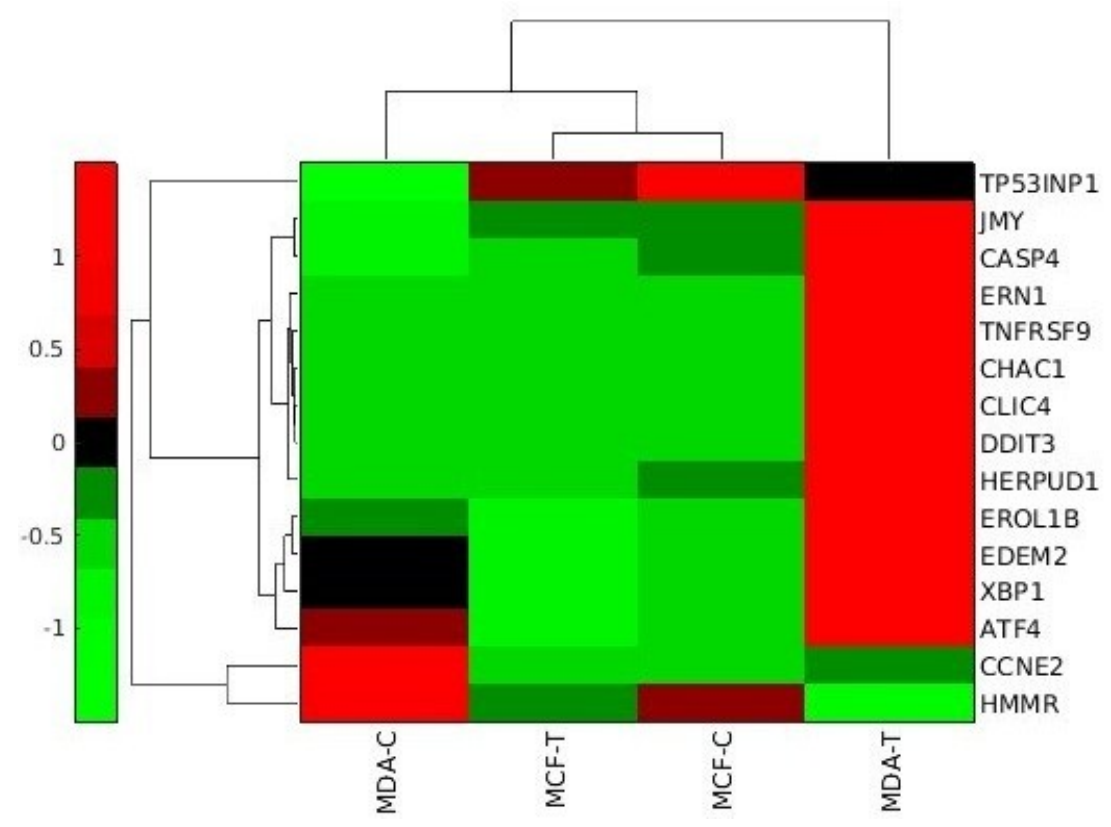

Figure 18. Heat Map of Genes Validated with RT-qPCR.

TP53INP1, JMY, CASP4, ERN1, TNFRSF9, CHAC1, CLIC4, DDIT3, HERPUDI, EROL1B, EDEM2, XBP1, ATF4, CCNE2 and HMMR. 
Table 3. Normalized Affymetrix 2.0 Gene Expression Levels of MDA-MB231 and MCF-10A Cells for ER Stress/UPR, Immune/TNF, Cell Cycle, Tumor Targets, Cell Death and Membrane Potential.

\begin{tabular}{|c|c|c|c|c|}
\hline Gene & $\begin{array}{c}\text { MDA-MB231 } \\
\text { Control } \\
\text { Expression }\end{array}$ & $\begin{array}{c}\text { MDA-MB231 } \\
\text { Treated } \\
\text { Expression }\end{array}$ & $\begin{array}{c}\text { MCF-10A } \\
\text { Control } \\
\text { Expression }\end{array}$ & $\begin{array}{c}\text { MCF-10A } \\
\text { Treated } \\
\text { Expression }\end{array}$ \\
\hline DDIT3 & 92.20325 & 604.7977 & 74.5718 & 38.54762 \\
\hline FBXW10 & 17.46405 & 81.63718 & 12.86469 & 19.93201 \\
\hline ERN1 & 167.6198 & 1715.344 & 180.1033 & 177.2253 \\
\hline CHAC1 & 208.6184 & 3336.654 & 224.6349 & 67.11283 \\
\hline CBLB & 300.1236 & 1641.758 & 293.6763 & 254.1021 \\
\hline HERPUD1 & 1783.141 & 5490.769 & 1948.906 & 1336.873 \\
\hline FAM129A & 885.9388 & 2438.941 & 164.713 & 43.46248 \\
\hline ATF4 & 1885.499 & 3100.368 & 884.2608 & 612.7664 \\
\hline XBP1 & 1657.966 & 3991.217 & 646.7754 & 396.2133 \\
\hline TBC1D3H & 302.5868 & 707.418 & 295.0598 & 210.7293 \\
\hline SEL1L & 1245.15 & 2877.084 & 1030.507 & 742.8039 \\
\hline EDEM2 & 346.4626 & 758.4768 & 246.9249 & 121.0007 \\
\hline EROL1B & 198.7048 & 356.374 & 166.5647 & 130.24 \\
\hline PP1R15A & 621.7018 & 2642.331 & 445.151 & 518.1046 \\
\hline GADD45A & 206.6781 & 855.5336 & 669.77 & 766.9318 \\
\hline TP53INP1 & 92.76067 & 267.6483 & 458.6459 & 322.1881 \\
\hline DRAM1 & 678.105 & 1709.15 & 301.5608 & 301.5608 \\
\hline PRSC1 & 573.9486 & 159.1545 & 89.98862 & 65.02022 \\
\hline GTSE1 & 1697.772 & 476.1245 & 149.0838 & 150.521 \\
\hline JMY & 240.5889 & 1179.91 & 483.9303 & 433.1115 \\
\hline IL1A & 50.914898 & 682.6169 & 3773.235 & 6656.809 \\
\hline SPHK1 & 224.5578 & 542.8292 & 74.35 & 84.3 \\
\hline IL8 & 135.5218 & 542.5673 & 285.7594 & 689.56 \\
\hline IL20Rb & 216.931 & 855.3889 & 2492.348 & 2037.954 \\
\hline TNFS4 & 38.17249 & 104.0848 & 31.551 & 29.38311 \\
\hline TNFRSF 10 & 1322.594 & 2931.227 & 679.15 & 354.5 \\
\hline IL21R & 88.24291 & 186.0786 & 34.35 & 34.02 \\
\hline TRIB3 & 578.2565 & 2925.584 & 534.79 & 197.3 \\
\hline IL13RA2 & 268.6343 & 714.5335 & 10.6687 & 15.999 \\
\hline OSMR & 1435.055 & 3519.421 & 1430.7 & 1591.7 \\
\hline $\mathrm{ABBC} 3$ & 265.6539 & 648.5226 & 1368.9 & 1353.1 \\
\hline TNFRSF9 & 130.5561 & 1854.911 & 45.3355 & 33.309 \\
\hline IFi30 & 3007.301 & 826.8794 & 1181.883 & 1707.668 \\
\hline CCNE2 & 1550.488 & 156.7187 & 45.6 & 31.78 \\
\hline HIST1H2BB & 1454.32 & 176.3751 & 43.2 & 68.3 \\
\hline HIST1H2BM & 9383.078 & 904.6331 & 1089.2 & 673.5 \\
\hline HIST1H2AB & 206.6644 & 31.26837 & 16.4 & 15.1 \\
\hline HIST1H3H & 182.1673 & 33.49529 & 47.7 & 106.8 \\
\hline HIST1H2AJ & 49.123 & 11.901 & 8.85 & 9.54 \\
\hline
\end{tabular}


Table 3. Continued.

\begin{tabular}{|c|c|c|c|c|}
\hline Gene & $\begin{array}{c}\text { MDA-MB231 } \\
\text { Control } \\
\text { Expression }\end{array}$ & $\begin{array}{c}\text { MDA-MB231 } \\
\text { Treated } \\
\text { Expression }\end{array}$ & $\begin{array}{c}\text { MCF-10A } \\
\text { Control } \\
\text { Expression }\end{array}$ & $\begin{array}{c}\text { MCF-10A } \\
\text { Treated } \\
\text { Expression }\end{array}$ \\
\hline HIST1H4B & 450.5416 & 113.0835 & 22.25 & 18.6 \\
\hline HIST1H2AM & 167.8033 & 42.64463 & 22.93 & 16.9 \\
\hline HIST1H3B & 204.3861 & 58.02624 & 11.73 & 6.98 \\
\hline HIST1H4A & 219.4193 & 62.61253 & 21.9 & 15.2 \\
\hline HIST1H2BL & 180.3614 & 54.36535 & 164.2 & 93.9 \\
\hline CASC5 & 2899.345 & 956.1502 & 485.2 & 499.3 \\
\hline HIST2H3D & 139.2912 & 45.06532 & 79.91 & 59.5 \\
\hline HIST2H2AB & 4406.727 & 1618.736 & 1337.66 & 491.5 \\
\hline CDCA7 & 114.252 & 158.884 & 135.68 & 139 \\
\hline CDCA3 & 690.5287 & 128.4345 & 85.279 & 66.4689 \\
\hline MCM10 & 2026.938 & 409.4398 & 146.7 & 95.14 \\
\hline E2F8 & 1701.76 & 344.8467 & 93.04 & 67.344 \\
\hline CENP1 & 1211.37 & 248.7287 & 206.29 & 126.7361 \\
\hline DSCC1 & 1055.73 & 227.4702 & 136.52 & 53.78 \\
\hline CCNA2 & 3625.114 & 813.5735 & 789.6391 & 715.2556 \\
\hline CDKN2C & 529.6627 & 118.9669 & 86.3 & 77.336 \\
\hline LMNB1 & 105.6866 & 23.76363 & 170.453 & 117.7738 \\
\hline CHAF1B & 1302.628 & 306.5765 & 266.99 & 156.226 \\
\hline PCNA & 3565.479 & 859.501 & 708.95 & 627.721 \\
\hline CENPE & 1585.373 & 386.5323 & 384.29 & 280.6339 \\
\hline SPC25 & 973.4363 & 237.5617 & 68.93 & 54.43 \\
\hline CLSPN & 257.1571 & 63.77828 & 45.25 & 46.39 \\
\hline MYBL2 & 663.0643 & 175.7511 & 162.5156 & 195.258 \\
\hline MAD2L1 & 2916.937 & 761.4398 & 261.8003 & 146.9315 \\
\hline CDCA2 & 1287.288 & 343.2617 & 277.99 & 314.51 \\
\hline CDC45 & 2032.203 & 546.5767 & 194.04 & 135.39 \\
\hline DLGAP5 & 3326.605 & 918.2717 & 294.9 & 322.08 \\
\hline SKP2 & 4475.243 & 1275.213 & 1584.21 & 1247.42 \\
\hline GRPR & 462.8514 & 132.1584 & 23.264 & 19.78769 \\
\hline KIF23 & 3014.659 & 1006.878 & 458.2247 & 432.4457 \\
\hline KIF15 & 1047.023 & 351.514 & 210.2767 & 146.1035 \\
\hline CDK1 & 1191.199 & 418.2505 & 302.653 & 219.0567 \\
\hline CDKN3 & 2829.865 & 818.9569 & 558.78 & 441.95 \\
\hline ORC1 & 787.6633 & 228.1306 & 138.7296 & 108.0838 \\
\hline KIF20B & 1491.5 & 485.3235 & 479.7726 & 370.89 \\
\hline CCNB1 & 1460.134 & 437.5147 & 394.2499 & 414.196 \\
\hline PLK1 & 7734.812 & 2320.248 & 2193.42 & 1800.224 \\
\hline $\mathrm{CDC} 20$ & 4119.106 & 1241.424 & 1542.313 & 1298.382 \\
\hline TTK & 2063.557 & 623.2984 & 404.7908 & 388.5892 \\
\hline SGOL1 & 2204.15 & 680.1693 & 357.85 & 353.49 \\
\hline CENPK & 965.4617 & 298.0388 & 117.869 & 86.63 \\
\hline
\end{tabular}


Table 3. Continued.

\begin{tabular}{|c|c|c|c|c|}
\hline Gene & $\begin{array}{c}\text { MDA-MB231 } \\
\text { Control } \\
\text { Expression } \\
\end{array}$ & $\begin{array}{c}\text { MDA-MB231 } \\
\text { Treated } \\
\text { Expression } \\
\end{array}$ & $\begin{array}{c}\text { MCF-10A } \\
\text { Control } \\
\text { Expression } \\
\end{array}$ & $\begin{array}{c}\text { MCF-10A } \\
\text { Treated } \\
\text { Expression }\end{array}$ \\
\hline CDK15 & 597.6559 & 187.5154 & 25.435 & 22.931 \\
\hline OIP5 & 656.4835 & 210.1888 & 108.08 & 65.89 \\
\hline PRC1 & 3544.327 & 1135.643 & 626.4265 & 457.0201 \\
\hline AURKA & 1372.692 & 441.3315 & 241.9177 & 182.5047 \\
\hline DNA2 & 680.8584 & 220.6961 & 158.5015 & 128.2752 \\
\hline PLK4 & 740.555 & 241.9631 & 118.182 & 81.45791 \\
\hline MCMY & 1946.111 & 754.5332 & 316.8071 & 318.7342 \\
\hline FOXM1 & 2150.082 & 834.0797 & 453.6553 & 534.8372 \\
\hline CENPO & 1545.834 & 528.9465 & 173.4009 & 134.9089 \\
\hline $\mathrm{CDC} 25 \mathrm{~A}$ & 906.8274 & 355.5253 & 81.97407 & 73.47563 \\
\hline KIF4A & 1226.718 & 483.1996 & 285.4267 & 325.8651 \\
\hline BORA & 833.334 & 333.975 & 177.7702 & 161.6121 \\
\hline PRIM1 & 1933.796 & 639.5529 & 289.6865 & 144.092 \\
\hline KIF23 & 3014.659 & 1006.878 & 458.2247 & 432.4457 \\
\hline BUB1 & 3482.412 & 1171.759 & 535.3447 & 538.2644 \\
\hline NUF2 & 1068.651 & 362.4769 & 158.0058 & 117.314 \\
\hline CENPA & 1604.808 & 623.0319 & 259.9626 & 173.262 \\
\hline NEK2 & 1471.66 & 508.0363 & 798.9699 & 809.4927 \\
\hline CDC25C & 559.6721 & 194.3788 & 150.2855 & 97.89624 \\
\hline CDK15 & 597.6559 & 187.5154 & 25.436 & 22.93094 \\
\hline CIT & 708.1124 & 251.2761 & 290.004 & 225.4576 \\
\hline CCNF & 509.6929 & 181.4399 & 143.653 & 115.1559 \\
\hline CDCA8 & 2367.439 & 856.6898 & 532.59 & 448.22 \\
\hline ASF1B & 3257.62 & 1238.113 & 417.605 & 193.1282 \\
\hline CENPL & 407.7961 & 156.0273 & 124.78 & 103.6942 \\
\hline CCNA1 & 1235.768 & 475.7696 & 132.0476 & 199.9614 \\
\hline CENPM & 559.2139 & 212.9774 & 116.38 & 91.68 \\
\hline KIF11 & 3238.945 & 939.4666 & 708.69 & 495.69 \\
\hline CDC45 & 2032.203 & 546.5767 & 194.04 & 135.38 \\
\hline CENPF & 1518.461 & 633.5304 & 1067.66 & 1123.12 \\
\hline CASP4 & 78.27916 & 167.4708 & 99.7621 & 93.61928 \\
\hline CASP6 & 315.9396 & 153.2165 & 110.2821 & 103.9024 \\
\hline UNC5B & 165.5258 & 1028.606 & 765.4645 & 432.6196 \\
\hline CARS & 410.5192 & 1051.12 & 212.4383 & 107.2973 \\
\hline BEX2 & 54.2207 & 128.0799 & 39.484 & 39.164 \\
\hline JUNB & 700.5781 & 1589.828 & 1304.435 & 1068.991 \\
\hline HMMR & 681.7925 & 183.141 & 504.2788 & 362.3813 \\
\hline PTTG1 & 267.0026 & 72.87782 & 45.128 & 40.01671 \\
\hline FANCA & 907.874 & 292.4976 & 196.06 & 128.35 \\
\hline TGFB2 & 2404.895 & 897.6522 & 212.696 & 258.4106 \\
\hline FAM83D & 2544.584 & 698.6316 & 700.476 & 661.334 \\
\hline
\end{tabular}


Table 3. Continued.

\begin{tabular}{lcccc}
\hline Gene & $\begin{array}{c}\text { MDA-MB231 } \\
\text { Control } \\
\text { Expression }\end{array}$ & $\begin{array}{c}\text { MDA-MB231 } \\
\text { Treated } \\
\text { Expression }\end{array}$ & $\begin{array}{c}\text { MCF-10A } \\
\text { Control } \\
\text { Expression }\end{array}$ & $\begin{array}{c}\text { MCF-10A } \\
\text { Treated } \\
\text { Expression }\end{array}$ \\
\hline KIFC1 & 1314.23 & 428.6075 & 179.392 & 145.62 \\
E2F1 & 2050.937 & 671.5983 & 108.8849 & 92.29729 \\
CLIC4 & 2043.479 & 5258.273 & 2021.464 & 1791.211 \\
CLIC2 & 57.95258 & 117.7829 & 345.69 & 274.86 \\
\hline
\end{tabular}



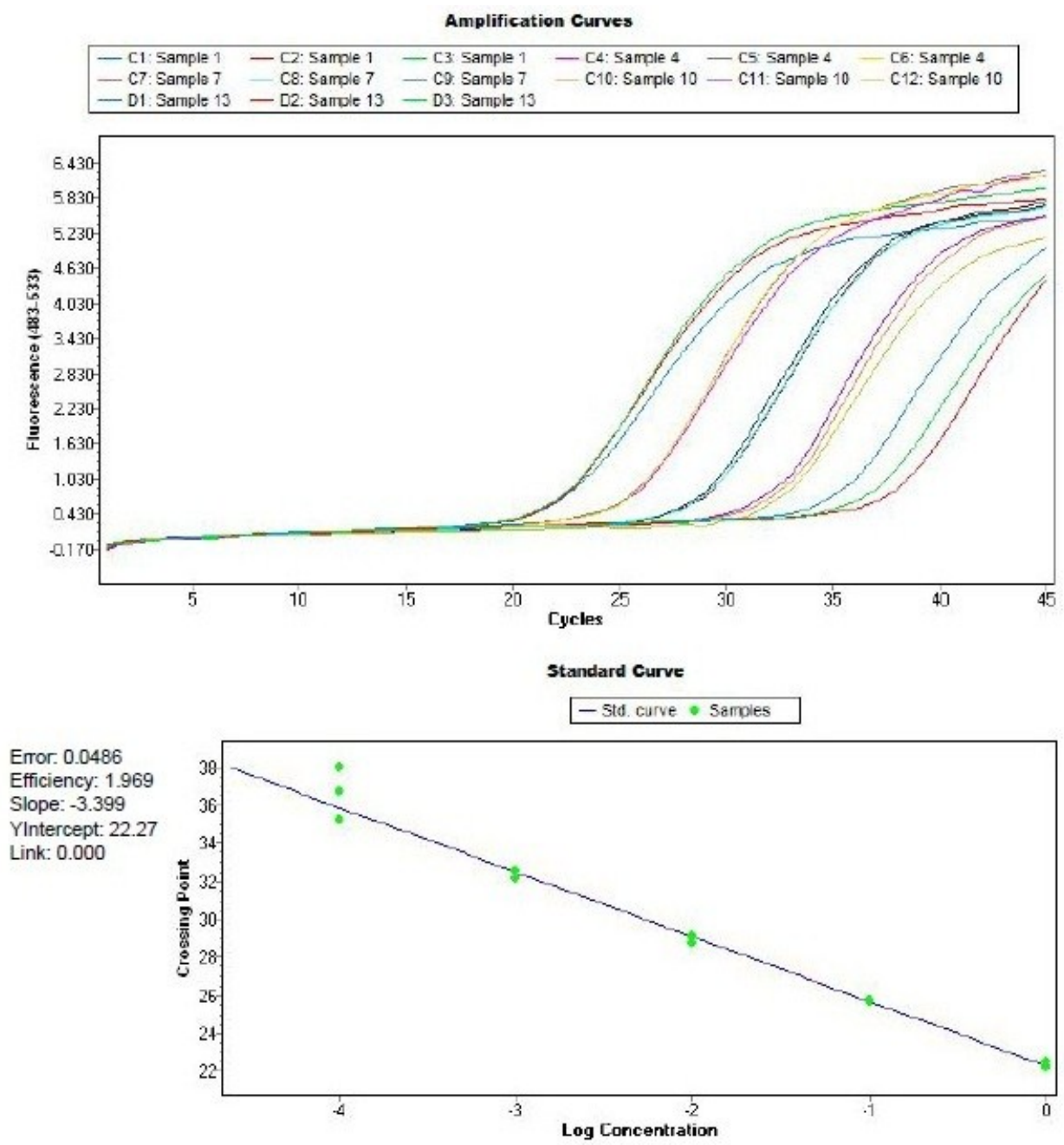

Abs Quant/2nd Derivative Max for TNFRSF9 (Abs Quant/2nd Derivative Max)

Results

\section{Figure 19. $\quad$ Primer Testing for TNFRSF9.}

All primers were designed and then tested on cDNA from MDA-MB231 cells. This shows the amplification curves of the 5 different dilutions used for TNFRSF9. The expression values for each dilution are plotted on a standard curve. An efficiency is determined based on the slope and y intercept. An efficiency of 1.8-2.1 is required for each primer prior to validation experiments. Each of the primers were designed for each gene and taken through efficiency testing prior to real time qPCR validation on the genes of interest. 


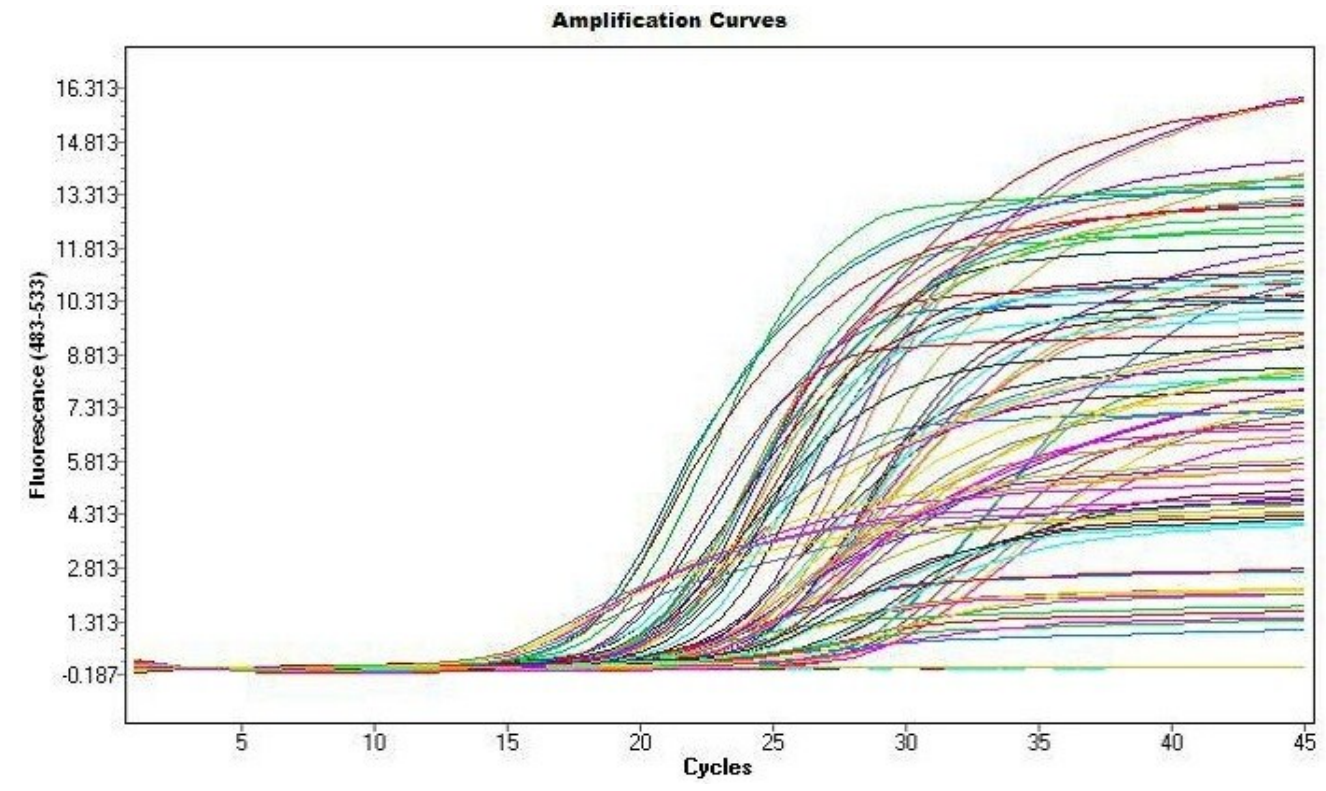

Figure 20. Amplification Curves of Fluorescence over Cycles for Real Time qPCR with Triplicate Testing of Gene Expression on a 96 Well Plate when Comparing Control and Treated Gene Expression Levels of MDA-MB231 Cells.

The fluorescence occurs using TaqMan probes that become degraded by Taq polymerase and releases the fluorophore thereby relieving the quenching effect. The fluorescence detected in the quantitative PCR thermal cycler is directly proportional to the fluorophore released and the amount of DNA template present in the qPCR.

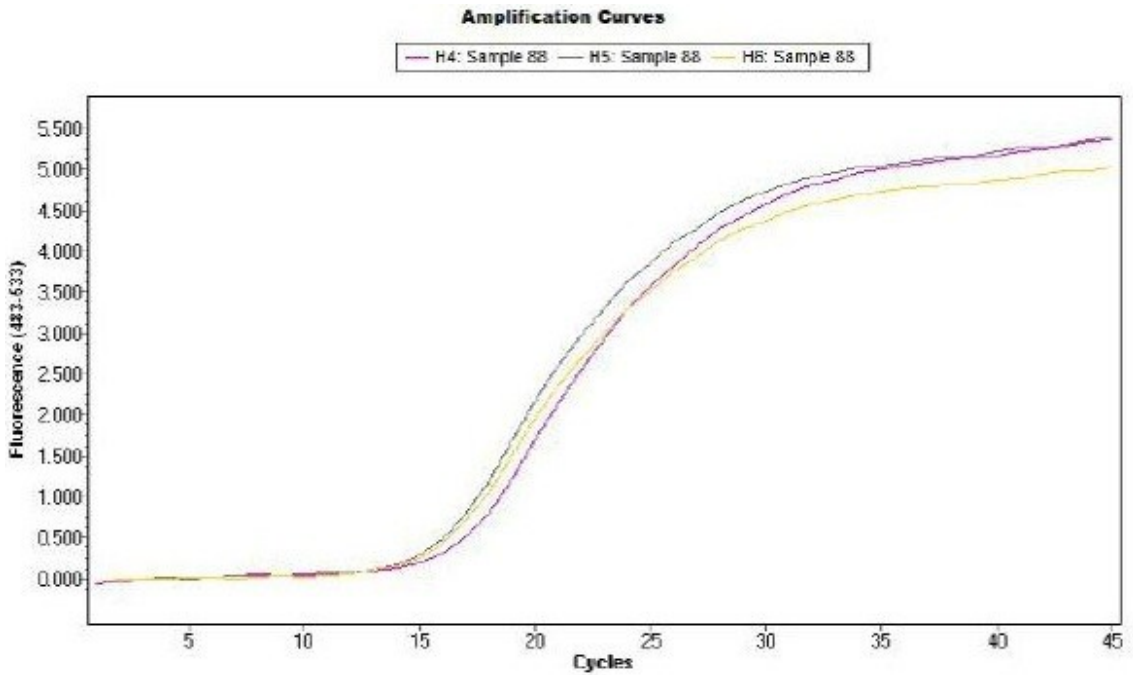

Figure 21. Amplification Curve - RiboS19.

Amplification curves in triplicate of housekeeping gene used for extrapolation of control and treated data for real time qPCR. 
media, but was significantly down regulated in the MCF-10A cells. ${ }^{39}$ The TNFRSF9 gene showed a 128-fold increase in a player in the TNF/TRAIL pathway. TNFRSF9 has been shown to be expressed in activated T cells (CD8 \& CD4), dendritic cells, natural killer cells, granulocytes and blood vessel inflammation. ${ }^{100}$ It has also been shown to stop tumors in mice. ${ }^{107}$ The Junction Mediating Protein (JMY) is a p53 cofactor that codes a tumor suppressor protein and is up regulated 4-fold in our validations. It is believed to be a key transcriptional regulator and controls DNA repair, cell cycle progression, angiogenesis and apoptosis. ${ }^{101}$ The loss of p53 function is thought to be a contributing factor in the majority of cancer cases. Caspase 4 (CASP4) is the caspase that is linked to ER Stress/UPR and it is up regulated 8-fold. ${ }^{102}$ Cyclin E2 (CCNE2) is down regulated 32-fold and has been shown to be elevated in tumor-derived cells and plays a role in the G1/S transition in the cell cycle. ${ }^{103}$ Hyaluronan-mediated motility receptor (HMMR) interacts with BRCA1 and other proteins to control key aspects of cell polarity and cell division and may hold answers to how to treat women with BRCA1 and BRCA2 mutations as its expression and overexpression has been linked to ras transformation, tumor progression and metastasis. ${ }^{104} \mathrm{HMMR}$ is down regulated 16 -fold on our validations. Chloride Intracellular Channel 4 (CLIC4) is a group of proteins who regulate cell membrane potential, transepithelial support, maintain $\mathrm{pH}$ and cell volume. Under expression or reduced CLIC4 alters the redox state of tumor cells and enhances tumor development. ${ }^{105}$ It is upregulated 8 -fold in our gene validations (Figure 22). Unpaired ttests were conducted on MDA-MB231 and MCF-10A gene validations (Table 4).

\section{DISCUSSION}

The initial cell growth studies found significant growth inhibition of the B16 murine melanoma and the MDA-MB231 human breast carcinoma while failing to show a growth inhibitory effect on the L929 mice fibroblasts and the MCF-10A breast epithelial cells. We conducted various experiments to see how long and under what conditions these effects were noted. The treated water alone appears to retain the ability to reduce cell proliferation of cancerous cells for up to 21 days. Once the treated water is combined with the components to make the growth media, the treated hypotonic saline solution appears to lose its effects on day 5 or 6 since cancerous cells were observed to show a significant increase in cell growth/proliferation at this time point. A possible explanation for this can be hypothesized and is discussed extensively in chapter 4 . The treated water appears to retain the effect created by treatment with the CETS system for a longer time period ( 21 days), as shown by growth inhibitory effects of cancerous cells when grown in media made with stored treated water, than does the treated growth media once it is made with the treated water as shown by the effect waning on day 5-6. This addition of other molecules/ions to the media could in effect, nullify or change the effects induced by the CETS system once added due to molecular changing/bonding that occurs between the various ions contained in the water and ions added with the growth media contents.

The cancerous cells also began to show a microscopic change of 'rounding up' after they were growing in the treated media for several days. The growth inhibitory effects and the 'rounding up' led us to cell cycle analyses, where we noted the cell cycle 


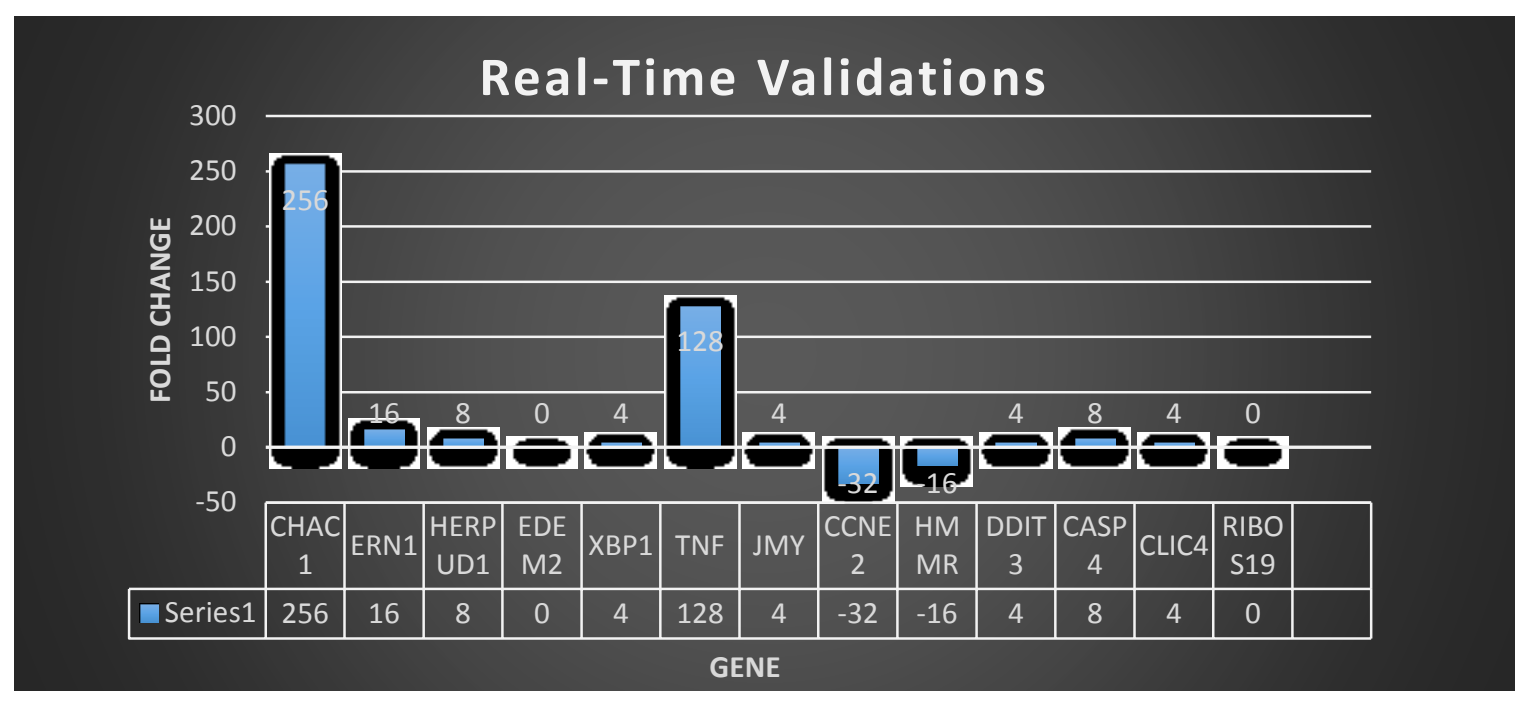

Figure 22. RT-qPCR Fold Change.

Table 4. Unpaired t-Tests of RT-qPCR.

\begin{tabular}{|c|c|c|c|c|c|}
\hline \multirow[b]{2}{*}{ Gene } & \multicolumn{3}{|c|}{ Unpaired t-Tests } & \multirow[b]{2}{*}{ Mean/Control } & \multirow[b]{2}{*}{ Mean/Treated } \\
\hline & df & ts & $\mathbf{p}$ & & \\
\hline \multicolumn{6}{|c|}{ MDA-MB231 } \\
\hline CHAC1 & 8 & 26.796 & .000000004 & 13.26134 & 6.184 \\
\hline HERPUD1 & 8 & 7.72534 & .0000561 & 7.53 & 5.1 \\
\hline EDEM2 & 8 & 1.1876 & .269047 & 9.3 & 9.8 \\
\hline XBP1 & 8 & 12.7308 & .00000136 & 5.74 & 4.34 \\
\hline TNFRSF9 & 8 & 26.7993 & .0000000004 & 13.55 & 8.05 \\
\hline JMY & 8 & 25.3296 & .000000000682 & 9.7 & 7.4 \\
\hline CCNE2 & 8 & 7.79364 & .000108 & 6.24 & 10.74 \\
\hline HMMR & 8 & 6.38892 & .000212 & 6.744648 & 10.32 \\
\hline DDIT3 & 8 & 8.75038 & .0000228 & 11.23 & 9.53 \\
\hline CASP4 & 8 & 7.6846 & .0000583 & 8.214653 & 5.63 \\
\hline CLIC4 & 8 & 11.0548 & .000004 & 5.17264 & 3.106 \\
\hline \multicolumn{6}{|l|}{ MCF-10A } \\
\hline DDIT3 & 8 & 0.05804 & .955142 & 12.668 & 12.678 \\
\hline $\mathrm{CHAC} 1$ & 8 & 12.0055 & .00000214 & 13.00 & 16.7 \\
\hline
\end{tabular}


arrest in the cancerous cells while the noncancerous cell lines, showed no change in the cell cycle in either the treated or control groups. We then proceeded to conduct the Annexin V-FITC Apoptosis assay on the cancerous cell lines where we were unable to quantify any differences between the stained and unstained treated groups due to an autofluorescence that was induced in all the treated cells when analyzing by flow cytometry. We then conducted fluorescence microscopy on the treated and control cancerous cells and could visualize the green fluorescence associated with annexin staining. This observation suggests the binding of the Annexin staining to phosphatidylserine and the early stages of apoptosis in the cancerous cells that had been grown for 3 days in treated media. The green fluorescence was not seen on fluorescent microscopy with the control cancerous cells which suggests the control cancerous cells were not undergoing apoptosis.

Due to the Vmem differences in cancerous and noncancerous cells, we decided to conduct membrane potential assays to determine if the treated media was causing a change in the membrane potential of the cells. The membrane potential findings suggest that the cells are initially hyperpolarized by exposure to the treated media and then begin to depolarize within the first 8 hours. By 24 hours the noncancerous cells have returned to their original baselines but the cancerous cells stay at a more polarized level than their original baseline. The CLIC4 gene is known to participate in membrane potential regulation and is a known tumor suppressor. ${ }^{105}$ CLIC4 is upregulated 4-fold in the treated MDA-MB231 cells in the RT-qPCR validation but was not upregulated in the noncancerous cells. This genomic change in expression in a gene in the cancerous cells that controls membrane potential regulation corresponds to the membrane potential assay testing. This suggests the treated media shows an effect in the regulation of membrane potential in cancerous cells who are known to possess a depolarized membrane when compared to a noncancerous cell.

The microarray and RT-qPCR validations on the MDA-MB231 cells showed the unfolded protein response (UPR) as the top pathway affected significantly by the CETS unit and this pathway was not upregulated in the microarray and the RT-qPCR of the MCF-10A cells. The UPR is a series of signaling events that occur due to intracellular stress from misfolded proteins in the lumen of the endoplasmic reticulum (ER). Certain pathologic stimuli can cause an interruption in the protein folding process and these include but are not limited to: calcium depletion, altered glycosylation, nutrient deprivation, oxidative stress, DNA damage or energy fluctuations. ${ }^{38}$ While no significant increase in protein synthesis was found with the BCA protein assay of human breast carcinoma, data showed a 2.5 fold increase in mRNA between the treated and control groups. The increase in mRNA indicates a possible increase in transcriptional affects may be initially occurring prior to the up regulation of ER stress/UPR pathways. The cell size appears to increase initially in our cell size data and the cells then begin to shrink which could suggest the halting of protein synthesis and the ER degradation/protein degradation that occurs with the UPR survival response. UPR has been shown to be activated by increased activation of ATF4 and increased transcription of its target $\mathrm{C} / \mathrm{EBP}$ homologous protein (CHOP), which is a pro-apoptotic factor. ${ }^{37}$ ATF4 is a strong upstream regulator in our microarray analysis. The known causes of UPR are energy 
fluctuations. This suggests a possible connection between the significant changes in the membrane potential of the cancerous cell lines and the upregulation of the UPR. The treated media did not illicit a growth inhibition in the noncancerous cells, which shows that growth arrest from UPR is likely not occurring in the noncancerous cells and also lends to the thought that other known causes of ER stress related to nutrient or calcium deprivation from the media are most probably not originating factors in the cancerous cell lines. The RT-qPCR validated that ER Stress/UPR gene expression was not up regulated and this corresponds to the experimental findings with the MCF-10A cells. The cell growth studies found cancerous cell lines significantly slowed mitosis and halted their cell cycles. In ER stress there is a struggle to balance adaptation and alarm/death. UPR is often highly activated in cancer cell to promote survival. In the RT-qPCR validations, ERN1 is upregulated 14-fold, which could suggest one mechanism for cell cycle arrest and DDIT3 (CHOP) is upregulated 4-fold, while CHAC1, which is downstream from CHOP is strongly upregulated 256-fold and could indicate that these cancer cells are headed down the apoptosis arm of the UPR after 3 days of exposure to the treated media. ${ }^{51} \mathrm{CHAC} 1$ is the pro-apoptotic component of the unfolded protein response pathway that mediates the pro-apoptotic effects of the ATF4-ATF3-DDIT3-CHOP cascade. ${ }^{39}$ Caspase 4 was significantly upregulated 4-fold as well in the RT-qPCR and this is the caspase that is linked to the UPR and could suggest a possible beginning to a cell death. ${ }^{49}$ An unsuccessful UPR can also be caused by an increase in TNF, which was also significantly upregulated 126-fold in the RT-qPCR and operates down the IRE1TRAF2-JNK pathway in ER stress. ${ }^{47}$ TRIB3 was shown to be a significant upstream regulator in our microarray, which is a known sensitizer of cells to TNF and TRAIL induced apoptosis. ${ }^{55}$

In our microarray, TP53INP1 is significantly upregulated gene that is involved in making a protein that has anti-proliferative and pro-apoptotic properties and acts as a regulator of transcription and autophagy. This gene plays a major role in the p53/TP53 oxidative stress response and was also validated with RT-qPCR as a 4-fold increase with JMY. It is possible that ER stress/degradation and anything that leads to the UPR could nonspecifically halt DNA replication leading to $\mathrm{p} 53$ activation and apoptosis. ${ }^{41,43}$ TP53INP1 can also reduce cell migration by regulating the expression of SPARC. ${ }^{44}$

The microarray found that TNFRSF9 was also found to be significantly upregulated downstream from the also significantly affected ER transmembrane protein: Inositol Requiring 1 (IRE1). Prolonged ER stress has been shown to activate the proapoptotic IRE1-TRAF2-JNK pathway. Tumor necrosis factor receptor superfamily, member 9 is a member of the TNF receptor superfamily that is implicated in the survival and development of T cells. It is a significant player in the 4-1BB Signaling in T lymphocytes pathway, which is known for eradication of established tumors, enhancing integrin-mediated cell adhesion and increasing T cell cytolytic potential. TNFRSF9 is also linked to the Death Receptor Signaling and NF-KB pathways. ${ }^{42}$ Even though tumor necrosis factors are not playing a role in these in vitro experiments, they could be a strong player in a future in vivo model. Also, CLIC4 codes for a diverse group of proteins that regulates cellular processes, such as stabilization of cell membrane potential. CLIC4 has been shown to participate in suppression of tumor growth and the absence of decreased 
levels of CLIC4 has been found to contribute to TGF-B resistance and enhances tumor development. ${ }^{45}$ Membrane potential assay results correlate with this finding. These significant changes of CHOP, CHAC1, JMY/P53, and CASP4 in the microarray/RTPCR, Annexin V fluorescent microscopy and the noted microscopic effects of nuclear fragmentation, blebbing and decrease in cell size suggest a possible apoptosis or other form of undetermined cell death may be occurring in these treated human breast carcinoma. Interestingly, the MCF-10A cell line did not show these experimental or genomic effects and show this could be a possible side-effect free adjunct therapy for cancer patients. More funding and research is needed to verify what is occurring in these cells.

\section{CONCLUSION}

Understanding how energy fluctuations can contribute to UPR and other genomic signaling offers a new opportunity to exploit the programmed balance of survival and cell death in order to catapult the cancerous cells past levels compatible with survival. Combining chemotherapeutic and pharmacologic treatments with this potentially known ER stressor from hyperpolarization in cancerous cells can potentially augment cell death and increase chemotherapeutic efficacy. Chemotherapeutic agents that cause ER stress such as brefeldin A, Velcade and geldanamycin, could be effective in enhancing UPR in order to promote apoptosis in cancer cells. ${ }^{40}$ To obtain ER homeostasis, eukaryotic cells have developed or evolved the UPR in order to have an adaptive intracellular signaling pathway that is essential when a response to metabolic stress, oxidative stress, inflammation, neurodegenerative disease or cancer is needed. UPR is a survival mechanism that is often used by cancerous cells. Could the hyperpolarization of the cell membrane in these cancer cells lead to an ER stress induced UPR that becomes too challenging for these cancer cells to overcome leading to a transition from the adaptive/protective stage to the pro-apoptotic/pro-death stage? The microarray and RTPCR validations show the cancer cells heading down several pro-apoptotic pathways related to ER stress/degradation, as well as the $\mathrm{p} 53$ oncogene activation pathway while these validations also show this effect is not occurring in the noncancerous cells. The mechanism of triggering p53 signaling during ER stress induced apoptosis is currently unknown but may possibly be associated with a hyperpolarized membrane according to both our experimental findings and the genomic analyses. Two of the top pathways delineated in our microarray according to our Ingenuity analysis were also shown to be serine biosynthesis and the super pathways of serine and glycine biosynthesis. The tumor suppressor p53 has been classically known to regulate DNA repair, cell-cycle arrest and apoptosis. In the process, these actions will upregulate metabolic targets and thereby upregulate these pathways of biosynthesis. ${ }^{52}$ The upregulation of serine and glycine biosynthesis is an essential reversal of how cancer cells can usually reprogram their metabolism by shifting from oxidative phosphorylation to aerobic glycolysis (Warburg effect) in order to achieve unchecked growth. ${ }^{53}$ The amplification of metabolic enzymes has been found in breast, liver, prostate and melanoma cancers due to the identified amplification of the gene encoding phosphoglycerate dehydrogenase (PHGDH) leading to increase flux through the serine/glycine pathway. ${ }^{60} \mathrm{PHGDH}$ increase has been linked 
to increased proliferation of cancerous cell lines. ${ }^{60}$ Our data suggest an increase in PHGDH and the serine/glycine super-pathways can also be possibly linked to decreased proliferation in cancerous cells lines under the right conditions, while conversely, this pathway was also upregulated in our noncancerous cell line, which did not show a halt in cell cycle or cell growth. In recent years, the study of metabolism has returned to the forefront of cancer research. Data now support that altered metabolism can possibly result from the reprogramming by altered oncogenes and tumor suppressors. Our data suggest that restoring the altered oncogene and tumor suppressor functions could return the cell to a normal metabolism. Altered metabolism as well as an altered immune response should continue to be considered two major hallmarks of cancer that is studied in future research.

Could hyperpolarization of the cell membrane hold the key to unlocking multiple mechanisms that lead to cancerous cells cell cycle arrest, increasing and then the abandoning of the UPR as a survival mechanism, becoming sensitized to TNF and TRAIL activation, and activation of p53, thereby causing eventual apoptosis or another type of cell death, while not illiciting the same response in a noncancerous cell? The cancer cells appear to have increased anabolic function with the upregulation of the serine/glycine super pathways (nucleotide formation), increased catabolic function with the upregulation of phenylethylamine degradation pathway (carbon and nitrogen source) and reprogramming of the UPR and p53 genomic apoptotic mechanisms. There are many forms of cell death that include but are not limited to apoptosis, entosis, mitotic catastrophe, necrosis, necroptosis, excitotoxicity, autophagic cell death, and pyrotosis. ${ }^{61}$ Dying cells are engaged in a process that is reversible until a "point of no return" is passed. ${ }^{61}$ The MDA-MB231 cells appear to be headed down a cell death pathway, while the MCF-10A cells do not. The cancerous cells that appear to survive the exposure to the treated media also appear to display different characteristics of slower cell growth when placed back in standard/non-treated media (Figure 13). This slower cell growth could suggest some form of change in cell metabolism/function. Many other associated gene expressions that are linked to control of tumorigenesis, tumor development, cell migration and cell differentiation have been shown significant in our microarray and warrant more research. The upregulation of IL1A (IL10) and TNF also have been linked to an unsuccessful UPR and could also lead to research in the autoimmune response to disease. There are also strong down regulatory changes that are linked to cell cycle check points as well as cell cycle progression. Hyperpolarization of the plasma membrane could in theory be a reprogramming of a cancer cell to behave like a normal cell that has lost its ability to function as a beneficial member to the organism; whereas a cell cycle arrest and eventual cell death cascade is initiated. Hyperpolarization of the noncancerous cell line does not appear to similarly affect these same pathways. There appears to be a slight down regulation of the ER Stress/UPR pathway, which could show promise for other chronic diseases such as neuro-generative diseases, organ fibrosis and diabetes that have also been linked to an aberrant UPR. There is a significant differential effect with regards to ER Stress/UPR and many other metabolic functions of the cell with the CETS treated water when one compares the cancerous cell versus noncancerous cell line responses. More research is warranted to further verify and validate these observed effects. 


\section{CHAPTER 3. HYPERPOLARIZATION OF PLASMA MEMBRANE ENHANCES WOUND HEALING}

\section{INTRODUCTION}

Wound healing is a critical process that, if impaired, can increase the risk for infections, complications, patient discomfort and slow the return to activities of daily living. Many of the biological mechanisms that both drive and prevent chronic wound healing are poorly understood. ${ }^{16,63}$ Cell migration plays a key role in both the spread of cancer cells and in wound repair. Some acute wounds are known to heal quicker with electric stimulation such as is used in orthopedics and sports medicine where an electrical signal can lead to an upregulation of cartilage matrix protein production and nitric oxide dependent chondrocyte proliferation from a bone growth stimulator ${ }^{64,67}$ On the contrary, chronic non-healing wounds that occur with diabetes, malnutrition, infection, chronic inflammation and aging currently have no effective therapy available and treatment for the biological impediments remain elusive. ${ }^{62}$ Thus, chronic wound care generates a very challenging and significant economic burden to our health care system. ${ }^{68}$

One hundred and sixty years ago, Du-Bois Reymond, founder of electrophysiology, identified electromagnetic fields on a hand wound. ${ }^{68}$ Electromagnetic fields were recently shown to activate multiple signaling pathways that are instrumental in wound healing. Unlike other wound treatments, electromagnetic fields have the intrinsic property of being directional (polarized). ${ }^{9,14}$ Cell migration (electrotaxis/galvanotaxis) appears to be driven by electromagnetic induced polarized signaling of epidermal growth factor receptors, integrins, and phosphoinositide 3 kinase/Pten, and some research also points to involvement of protein kinase $\mathrm{C}$, intracellular calcium, and cyclic adenosine monophosphate. ${ }^{63}$ Electromagnetic fields have also been found to override other signaling cues of cell migration such as: chemoattractant gradients, injury stimulation, contact inhibition, wound void and population pressure..$^{65,66,2}$ When an electromagnetic field of physiological strength is applied in the opposite direction of these signaling cues, cell migration begins to follow the direction of the electromagnetic field. ${ }^{63}$ Plasma membrane potential (Vmem) differences have been found in injured and proliferating cells. ${ }^{12,13}$ Injured and proliferating cells have a measurable depolarized membrane potential of approximately $<$ $-30 \mathrm{mV}$, while healthy and non-proliferating cells have a resting potential of approximately $>-70 \mathrm{mV} \cdot{ }^{12,17}$ Cells have been shown to respond to different electromagnetic signals when undergoing division, migration and differentiation. ${ }^{63}$ It has been found that magnetic fields involve the changing gradients of Vmem that are produced and sensed by non-excitable cells in living organisms. ${ }^{17,18}$ Therefore, bioelectricity shows an effect well beyond excitable cells and has been shown to affect wound healing, cell migration, nerve growth and limb regeneration. ${ }^{3,4,24}$

Previous basic and clinical electromagnetic therapy wound care research has historically been conducted with a vibrating probe technique that places a flow of positive charge directed toward the wound both in vitro and in vivo. This probe technique 
has shown great promise with affecting not only the motility of the cells but also the directional migration of the cells in vitro. ${ }^{63}$ Impaired cell migration is characteristic of chronic wounds and in order to heal, cells must migrate directionally and in an organized fashion. ${ }^{65}$ Unfortunately, extrapolation and translation of the use of these applications that are successful in vitro have major challenges to overcome in vivo. ${ }^{63}$ To date, the exogenously applied electromagnetic probe stimulations in patients have generated highly variable current density and voltage distributions that have led to high discrepancies in the reported clinical trials. Currently, electromagnetic stimulation is being utilized in some non-healing chronic wounds but there are no FDA-approved devices for the indication of chronic skin wounds due to the lack of significant wellcontrolled randomized clinical trials and standardization of the devices used for electrical stimulation. Currently, scientists remain baffled as to how cells actually sense electromagnetic fields. ${ }^{8,9}$

We will discuss our experiments that have been conducted to show how the treatment with a device called the Cellular Energy Transfer Science (CETS) system that uses an electromagnetic field could open the door for future wound care applications. The CETS system has been used across the globe for 20 years in holistic markets and administered in the form of footbaths and baths with reports of pain relief, increased stamina, improvements in renal and hepatic function, support in cancer treatment recovery, decreased recovery time from illness and injury and many other health applications. ${ }^{15}$ Users of this device have also reported faster or improved wound healing after immersing part or all of their body in the water for 20-35 minutes every other day. In chapter 2 I showed that the noncancerous cell lines did not exhibit a growth inhibition when exposed to the CETS treated growth media and this along with the anecdotal testimonials from across the globe led us to conduct cell migration experiments. We will discuss the scratch assay, membrane potential assay and microarray analyses that when coupled with anecdotal reports from across the globe, offer a strong argument for future translation to chronic wound clinical trials. We hypothesized that there would be a differential effect on cell migration between treated and control groups of murine fibroblasts (L929 cells).

\section{METHODS}

Murine Fibroblasts (L929 cells), treated $\left(5 \times 10^{5}\right)(\mathrm{n}=18)$ and control $\left(5 \times 10^{5}\right)$ L929 ( $\mathrm{n}=18)$ were cultured in $60 \mathrm{~mm}$ petri dishes in standard Dulbecco's Modified Eagles Medium (DMEM) with 10\% fetal bovine serum (FBS) and allowed to grow to $90 \%$ confluence; then, a $3 \mathrm{mM}$ hypotonic saline solution that had been treated with the CETS system was used to prepare treated media. DMEM 10X from Sigma Aldrich Laboratories was diluted 9:1 with CETS treated water and glucose, sodium bicarbonate, folic acid, glutamine and fetal bovine serum (10\%) were added to achieve a high glucose DMEM- 10 high glucose concentration (See Chapter 2). DMEM 10x was also diluted 9:1 with 9 parts of a $3 \mathrm{mM}$ hypotonic saline solution that had not been treated with the CETS unit to 1 part DMEM 10X to achieve a DMEM-10 with high glucose concentration. The standard DMEM-10 that the cells were initially cultured in was aspirated and replaced 
with control and treated media in the respective plates. Then, a "scratch" in the cell monolayer was made with a p200 pipet tip that was attached to low suction. It is important to create scratches of approximately similar size in the cells to minimize possible variation by the difference in the width of the scratches. Three scratches in parallel were made on each $60 \mathrm{~mm}$ dish along with 2 reference points that consisted of two perpendicular lines to the scratch lines made with a permanent marker on the bottom of the dishes. These reference points are critical to ensure consistent orientation to the same microscopic field when taking pictures and to insure accuracy of these measurements. We made sure we kept the reference lines in the picture for a reference point in each scratch to insure we were photographing the same cell growth point of each photograph at each time interval.

Pictures were taken along each scratch/wound at the time of scratch and then at 3 hour intervals until confluence in the treated group was reached at 12 hours with a 10x eye piece and 40x objective utilizing AxioVision Imaging System. This time interval was based on known doubling times of this cell line. The cells were placed in a $37^{\circ} \mathrm{C} / \mathrm{CO} 2$ incubator between picture time points.

Quantification of cell migration rate can be reported by the percentage change in area over time (Equation 1):

$$
M(t)=\frac{A(t)-A(0)}{A(0)} \times 100
$$

Where $A(0)$ is the initial area enclosed by the population of cells, $A(t)$ is the area enclosed by the population of cells at time $t$, and $M(t)$ is the percentage change in area at time $t$. Estimates of cell migration rates using this equation are often obtained by hand tracing that area enclosed by the leading edge of a spreading cell population and this can be subjective. To overcome this limitation, we used an automated image analysis software, ImageJ to outline the leading edge of the cell migration. ImageJ is a public domain, Java-based image processing program developed at the National Institutes of Health. It performs standard image processing functions such as logical and arithmetical operations between images outlined by sharpening, smoothing, edge detection and median filtering in order to develop geometric transformations and accurate measurement of the area of the wound. This accurate measurement of the wound area can then be used to calculate percent change in area of wound over time.

\section{RESULTS}

After analysis with ImageJ software to obtain the percent area of wound healed over time, we conducted Student's t-test between the percent change in area at the time points of 3 and 9 hours. There was a significant difference in percent area of wound healed over time in the treated versus the control groups (Figure 23). On observation of the wound picture that was taken at the 9-hour time point in the treated wound (Figure 24), healing appears to be in an upward fashion from the bottom or an upward directional 


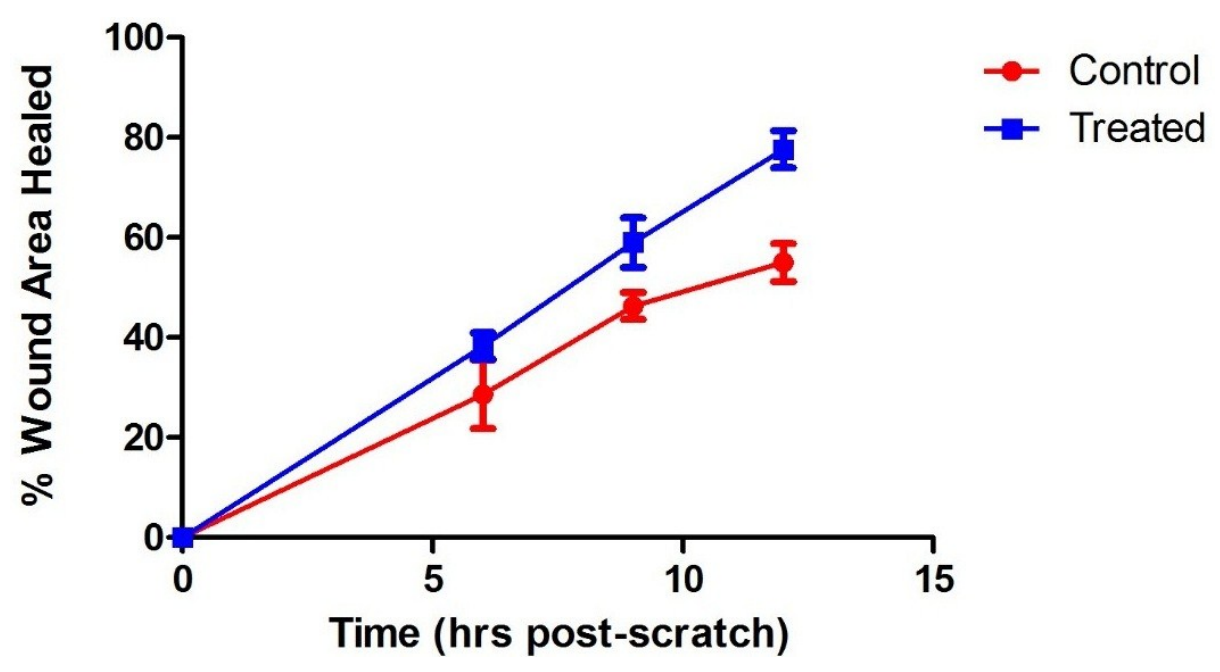

Figure 23. L292 Cells Scratch Assay- Percent Area Healed/Time.

L929 cells Scratch Assay; mean (C)-152057; mean (T)-78198.22; df = 16; ts = 5.577858; $\mathrm{p}=0.0000416$.

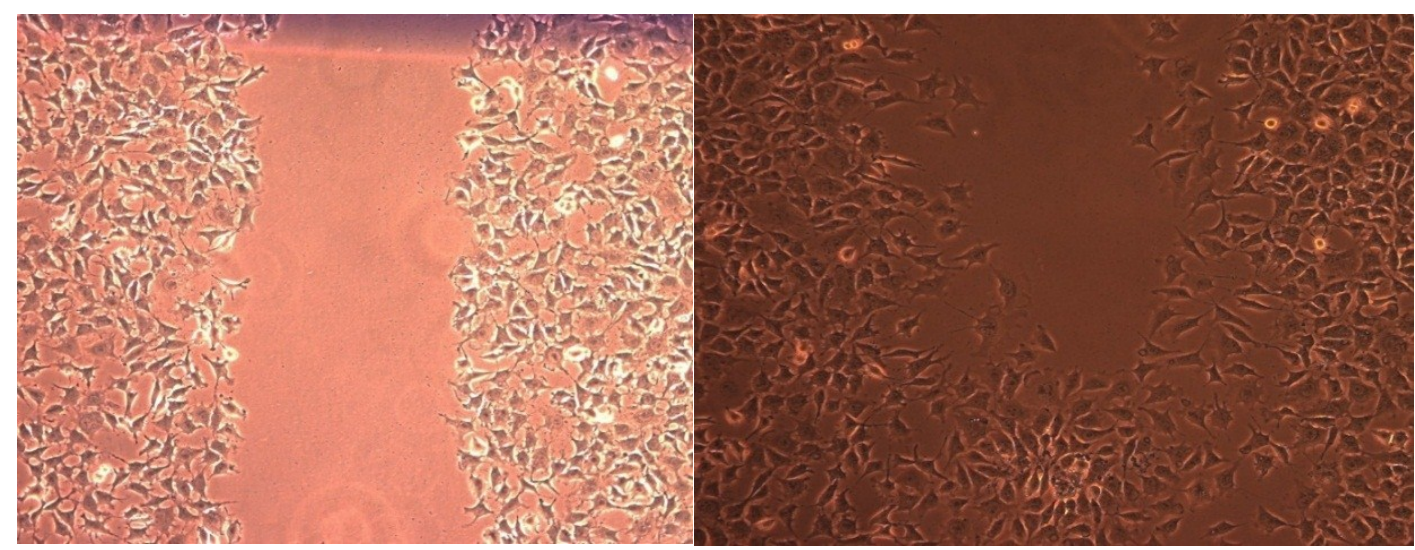

Figure 24. L292 Treated Cells Scratch Assay. Baseline (left) and 9 hours (right). 
migration. The control wound (Figure 25) appears to lack directional migration (9-hour time point) and has few cells that have migrated into the wound as compared to the treated wound at the same time point of 9 hours.

\section{DISCUSSION}

The CETS treated media appears to hyperpolarize the membrane of the murine fibroblast when compared to the control group as discussed in Chapter 2 in our membrane potential analyses. The treated media also shows increased wound healing similar to what is described with the voltage pulsed currents of AC and DC that are applied with the probes in vitro. ${ }^{64}$ The pulsed probed applications have not been effective to date in clinical trials. ${ }^{64}$ The treated wound in Figure 24 shows the treated murine fibroblast migrating more quickly, while Figure $\mathbf{2 5}$ shows the murine fibroblasts migrating sparsely and randomly. We know that injured and proliferating cells have a depolarized membrane when compared to non-proliferating cells. ${ }^{19}$ The CETS treated L929 cells show a hyperpolarization or an increase in membrane potential in our assays from baseline to 72 hours post treatment.

An Affymetrix microarray was conducted on human breast carcinoma (MDAMB231) and human breast epithelial cell (MCF-10A) that had also been grown in the CETS treated media and a significant upregulation of genes related to wound healing and cancer were found. Two major genes that are associated with multiple pathways are vascular endothelial growth factor (VEGF) and Amphiregulin (AREG). VEGFA is a member of the PDGF/VEGF growth factor family and encodes a protein that is a glycosylated mitogen that acts on endothelial cells and affects angiogenesis, vasculogenesis, as well as endothelial cell growth, through the promotion of cell migration, cell growth and inhibition of apoptosis. It is associated with 9 different significant pathways. ${ }^{63}$ AREG encodes a member of the epidermal growth factor family, which is an autocrine growth factor as well as a mitogen for astrocytes, Schwann cells and fibroblasts. AREG is related to epidermal growth factor EGF and transforming growth factor (TGF-alpha). ${ }^{69}$ This protein associates with the EGF/TGF-alpha receptor to promote the growth of normal epithelial cells while inhibiting the growth of certain aggressive carcinoma cell lines. ${ }^{70}$ Since these genes are strongly implicated in the literature as significant targets for wound care treatment and they have been found to be significantly upregulated in our microarray analysis of treated versus control human breast carcinoma cells and treated human epithelial cells, future plans include QRT-PCR validation of these genes in these cell lines is warranted. If validations of the same genes are found in these cell lines, hyperpolarization with the CETS system may offer an electromagnetic application that could unlock the mystery of electromagnetic signaling of cells in vivo that could offer a new wound care treatment. 


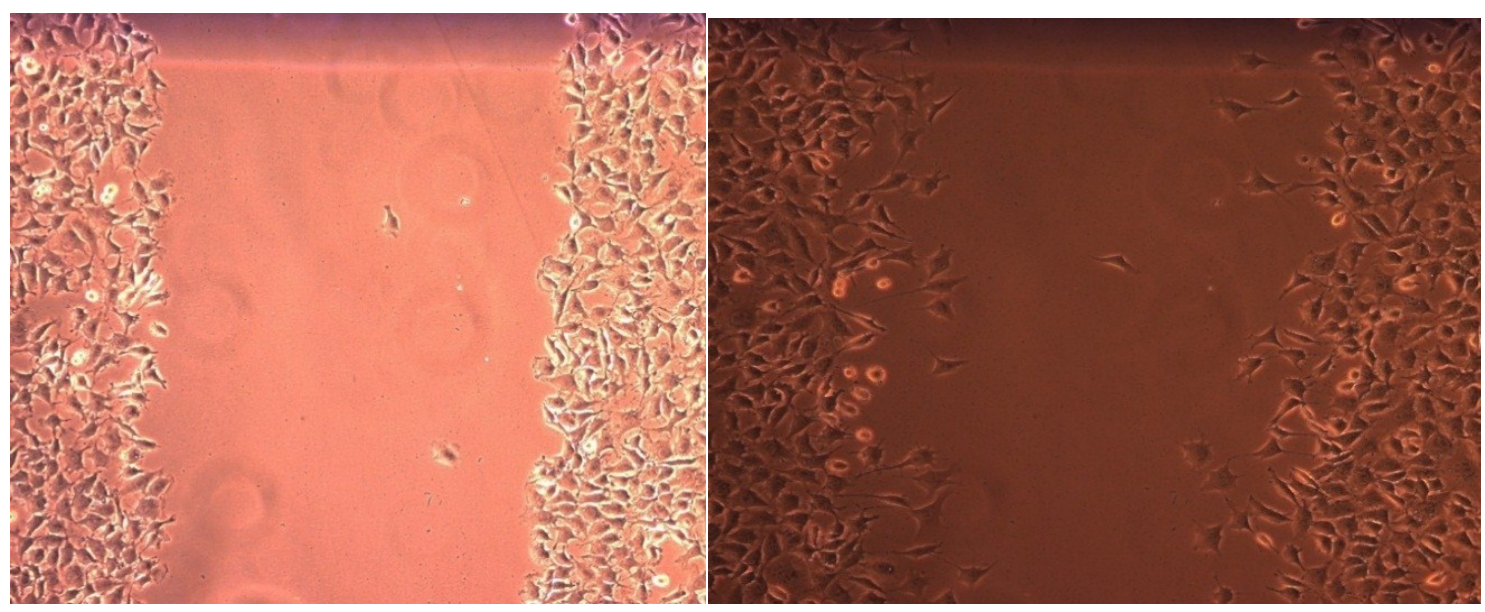

Figure 25. L292 Control Cells Scratch Assay. Baseline (left) and 9 Hours (right). 


\section{CONCLUSION}

Wound care presents significant challenges to our health care system. Some success has been found in vitro with voltage pulsed currents of AC or DC as well as with electrical stimulation of acute wounds in vivo. The CETS system has been shown to hyperpolarize the cell membrane and data suggest improved wound healing through faster cell migration. The microarray data in our MDA-MB231 and MCF-10A cells suggest mechanisms occurring with CETS use may be similar to what has been observed in vitro with previous wound care research. ${ }^{63,64}$ Anecdotal reports of improvements in patients with chronic and acute wounds following the use of the CETS are also consistent with these in vitro studies. ${ }^{15}$ Because muscle is also built by the breakdown and rebuilding/repair of the muscle cells and fibers as is done by athletes in weight training etc., it could be inferred that applications of the CETS might extend beyond acute/chronic would care. For example, when a cell membrane can be safely hyperpolarized, the damage/breakdown of the muscle fibers that occurs from an athlete with training and performance in athletic events could be restored to health more quickly just as the acute/chronic wounds appear to respond. This could lead to decreased recovery time as well as enhanced performance of athletes as well as expand the application from repair of wounds of chronicity to repair of high performance wounds. AREG has been shown to participate in certain EGFR and STAT3 signaling, cell cycle progression and in tumorigenicity in certain cancers. ${ }^{69,70}$ AREG has also been shown to be overexpressed in wounds that are healing. ${ }^{69,70}$ Hyperpolarization could be differentially affecting the same pathways that are used by both cancerous cells for invasion and proliferation and noncancerous cells for migration and healing. Hyperpolarization of the cell membrane could be affecting the poorly understood endogenous electrical cues of the cell that ultimately lead to the guiding of the cell in ways that are most beneficial to the organism. Further bench work and clinical trials are needed to verify the potential beneficial effects of the CETS system on cell migration, wound healing and tissue repair. 


\section{CHAPTER 4. CELLULAR ENERGY TRANSFER SCIENCE SYSTEM MODULATES MAGNETIC IONS IN WATER}

\section{INTRODUCTION}

The Cellular Energy Transfer Science (CETS) system is a device that generates an electromagnetic field in water. This device was developed in Australia in 1996 by Terry Skrinjar as a water apparatus that was originally designed to affect plants, animals and humans by increasing conductivity and water tension is such a way that it positively affects ion exchange at the cellular level. This device was one of two devices that conformed to the original device and this one which was tested was brought to the United States for manufacturing and marketing in Robertsdale, Alabama in 2001. It has been marketed in alternative health markets as the Aqua Chi and the Total Charge. This device consists of a power pack and a module. The power pack converts alternating current (AC) to direct current (DC) and delivers 2.5 amperes of DC to the module that is submerged in water. The module is comprised of a set of spaced, electrically conductive stainless steel rings that are arranged in parallel on a common axis and with two plates being charged, one positively and one negatively and 4 opposing electrically conductive plates (Figure 26). The center ring/plate is composed of copper and is not part of the circuit since it does not have current flowing through it due to the fact it is a non-magnetic metal. The module is designed to affect any living organism that comes in contact with the water that has been treated with the CETS system. This living organism can be in contact with the water in a footbath/bath while the DC is actively running to the module to achieve a direct "effect," or can be placed in the water after the DC has run through the module in the water for 30 minutes to achieve an indirect "effect." People and animals have been taking footbaths across the globe with this original design for 20 years to achieve a direct effect and we have conducted in vitro experiments where an indirect effect has been scientifically tested.

\section{BACKGROUND}

\section{Magnetic Properties of Metal Ions}

Every material is known to be influenced in some way by magnetic fields. ${ }^{74}$ The water that was used in these laboratory experiments is de-ionized water that has been made to a $3 \mathrm{mM} \mathrm{NaCl}$ by the addition molecular grade $5 \mathrm{M} \mathrm{NaCl}$ to supply ions in the water so it can carry a measurable current. The rings in the CETS system consist of stainless steel and a copper ring. The stainless steel rings contain chromium, nickel and molybdenum. Materials can be classified by their response to externally applied magnetic fields as diamagnetic, paramagnetic, ferromagnetic and/or anti-ferromagnetic and their magnetic responses differ vastly in strength. ${ }^{75}$ The actual classification of a material's magnetic properties is based on its magnetic susceptibility $(X)$ which is the ratio of the induced magnetization $(\mathrm{M})$ to the applied field $(\mathrm{H}) .{ }^{74}$ The magnetic moments of 


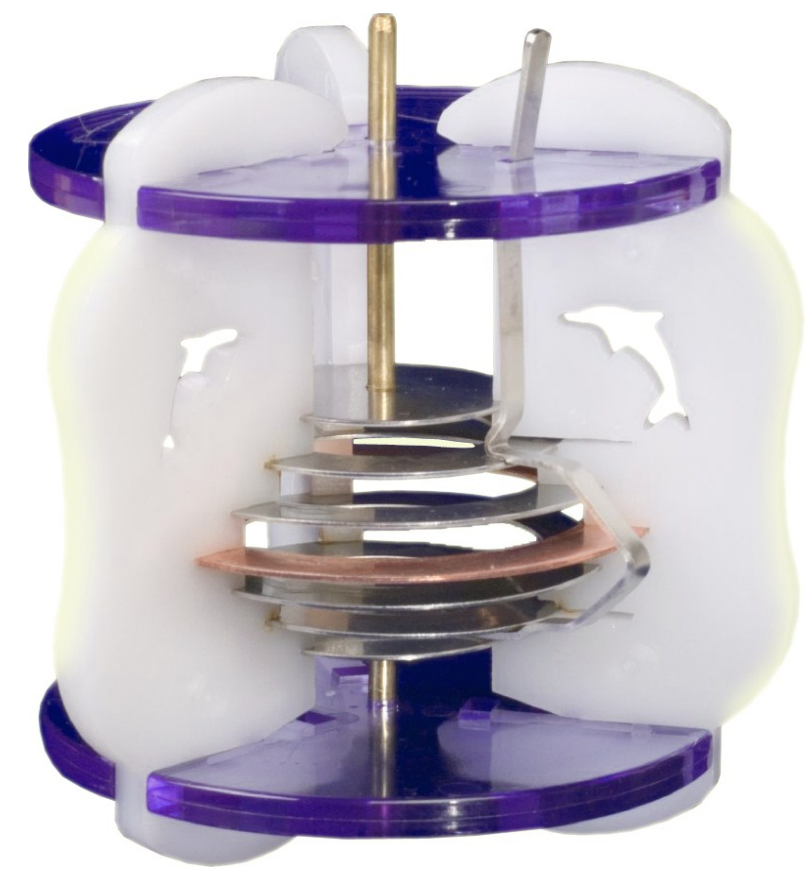

Figure 26. CETS Module. 
ferromagnetic materials align parallel to $\mathrm{H}$ and this allows for the coupling interactions between electrons of the material leading to very ordered magnetic states. ${ }^{74}$ The factors involved in this process depend on temperature, external field $(\mathrm{H})$ and the atomic structures. ${ }^{74}$ Chloride and copper's atomic structures lend them to the classification of diamagnetic metals. ${ }^{71}$ Diamagnetism is a very weak magnetism that is nonpermanent and persists only when an external magnetic field is being produced. These metals create an induced magnetic field in a direction opposite to an externally applied magnetic field and are actually repelled by the magnetic field. ${ }^{71}$ Molybdenum and sodium are paramagnetic metals, which are attracted by an externally applied magnetic field and form a magnetic field in the same direction of the magnetic field and the strength of this magnetism is in proportion to the applied field. Both diamagnetic and paramagnetic metals are considered to be nonmagnetic, because they only display magnetism when in the presence of an external field. ${ }^{71,76}$ Nickel is a ferromagnetic metal, which continues to display a permanent magnetism with or without a presence of a magnetic field. Magnets are an example of ferromagnetism because they retain their magnetic properties. Ferromagnetic effects are very large and are considered the strongest form of magnetism and often produce magnetism of greater magnitude than an applied field. ${ }^{71,76} \mathrm{Chromium}$ is one of the few (2) known anti-ferromagnetic metals in our periodic table. In antiferromagnetic materials, the magnetic dipole moments (behaves like tiny magnets) of atoms align in opposing directions of the ordered magnetism of ferromagnetic atoms. ${ }^{76}$ This leads to parallel spin of electrons (ferromagnetism), which creates a magnetic moment (polarity), and antiparallel spin of electrons (anti-ferromagnetism) which creates an opposing magnetic moment (opposing polarity). ${ }^{82,83}$ The combination of the ferromagnetism and the anti-ferromagnetism greatly strengthens the magnetic field produced by the spin/current of the electrons in the water. ${ }^{76}$

\section{Magnetic Spin, Magnetoresistance and Lorenz Force}

All atoms have inherent sources of varying strengths of magnetism because electron spin produces a magnetic moment and the electron orbits act as current loops, which produce a magnetic field. ${ }^{81}$ As stated above, the strength of a field is enhanced, when there are both parallel and anti-parallel spinning in electrons from the combination of ferromagnetic and anti-ferromagnetic metals that are exposed to that field. ${ }^{82}$ Giant Magnetoresistance (GMR) is a quantum mechanical magnetoresistance effect observed in thin-film objects that are composed of alternating ferromagnetic, anti-ferromagnetic and non-magnetic conductive layers. ${ }^{83}$ The 2007 Nobel Prize was awarded to Albert Fert and Peter Grunberg for the discovery of GMR where the main application of GMR is a magnetic field sensor that is used to read data in hard disk drives, biosensors, microelectromechanical systems and other types of devices. ${ }^{72}$

Magnetoresistance (MR) occurs when the electrical resistance of a material changes when a magnetic field is applied to this material. ${ }^{73}$ When an electromagnetic field is applied, the magnetic moments of the different magnetic compounds align with respect to each other and their magnetizations are parallel. This increased alignment/polarity leads to an actual decrease or drop in electrical resistance of the material due to the 
organizational or uniform spin of the molecules. ${ }^{73}$ The MR and/or GMR are initiated from the interaction of the current carrying the electrons and the magnetization of the host magnetic material. ${ }^{73}$ When electrons have not been exposed to a strong magnetic field, the spin-dependent electrons are often scattered and spinning with no organization or without the unity of direction that is derived from polarity. In the presence of a magnetic field, the spin-dependent electron scattering within the substance will be reduced and the electrical resistance will decrease once order is established in the organized and unified directional spin of the electrons. ${ }^{73}$ The parallel (ferromagnetism) and the anti-parallel (anti-ferromagnetism) spin induced by the nickel and chromium in solution will ultimately order the electrons to spin in a bi-directional fashion. This parallel/anti-parallel spin greatly increases the effectiveness and the strength of the magnetic field. ${ }^{82}$ While GMR has been historically applied to solid state materials, many chemical, biological, and biophysical reactions occur in liquid environments. ${ }^{73}$ The chips or biosensors that are often used in these processes are microfluidic devices. These biosensors are used to detect a bioanalyte's ability to possess biological recognition of a component that acts as a transducer that can measure an electrical output signal. ${ }^{73}$ Bruce Lipton has referred to the cell membrane as an actual microchip that can be considered to have the properties of a liquid crystal semiconductor with gates. ${ }^{6}$ The DNA can be considered to be an electromagnetic antennae which is a powerful receiver, transmitter and amplifier of frequencies. ${ }^{6}$ All of these concepts combined with water being the major component of life leads to a possible application of magnetism and water as being a powerful driver of many chemical and electrical mechanisms in living organisms.

Our in vitro experiments have been conducted with a hypotonic saline solution that is exposed to diamagnetic (copper), ferromagnetic (nickel), anti-ferromagnetic (chromium) and paramagnetic (sodium and molybdenum) metals that are known components of the stainless steel and copper rings in the CETS module, in the presence of a magnetic field. A possible hypothesis is that the theoretical parallel and anti-parallel spins of the ferromagnetic and anti-ferromagnetic metals could offer a decreased bidirectional resistance and increased efficiency in the membrane allowing the membrane to be more easily gated in order to conduct more work of the cell. In other words, ferromagnetic materials retain highly ordered magnetic states when magnetic moments are aligned in the presence of a field. ${ }^{4}$ The Lorenz force and the right hand rule can be used to explain how the electrons will react and the directional movement or the spin they will exhibit in relation to the magnetic field and the applied charge.$^{80}$ The Lorenz force is a force that is exerted by a moving external electric field $(\mathrm{E}){ }^{80}$ The force $(\mathrm{F})$ or direction of the spin will always occur perpendicular (either up or down) to both the velocity (v) of the charge (q) and the magnetic field (B) (Equation 2).

$$
\mathbf{F}=q(\mathbf{E}+\mathbf{v} \times \mathbf{B})
$$

Eq. 2

To further explain the ferromagnetism and anti-ferromagnetic spins of the nickel and chromium in the presence of a magnetic field, the ferromagnetic metals spin would travel upwards and the anti-ferromagnetic spin would travel downward. If the charge is applied in the same direction as the magnetic field, then the magnetic field will be zero and non-existent. ${ }^{85}$ Magnetic fields are very different from electric fields in that they exist 
only in a three-dimensional fashion. The units of a magnetic field are Newton seconds (Coulomb meter) or Newtons per Ampere meter. This unit is named the Tesla. ${ }^{84}$

\section{Metal Ions in Aqueous Solution and Proteins}

In aqueous solutions, the water molecules that are attached to the metal ions are classified as belonging to the first coordination sphere or the first shell. ${ }^{86,87}$ The first sphere refers to the central atom or ion and the array of molecules or anions that are attached around with a dative covalent bond. ${ }^{86,87}$ The second coordination sphere includes molecules that are attached non-covalently to the ligands by hydrogen bonding. ${ }^{86,87}$ When metal ions are in aqueous solution they are called aqua ions. Aqua ions are in most natural waters and are major constituents of seawater. Interestingly, blood also has concentrations of aqua ions similar to seawater. ${ }^{87,88,89}$ When one examines the two coordination spheres of the aqua ion, it is known that the second coordination sphere is essential in understanding the reactions of this metal complex (metal ion and water) because this second complex consists of hydrogen bonding and is involved in mechanisms of ligand exchange and catalysis. ${ }^{87,89}$ These aqua ions play a role in the building of many intracellular proteins by serving as a coenzyme or cofactor. Metalloproteins are proteins that contain a metal ion cofactor or coenzyme. ${ }^{90,91} \mathrm{~A}$ large number of proteins fall into this category. It has been estimated that half of all proteins contain a metal, while one third of all proteins may also require metals to carry out their functions. ${ }^{90}$ Metalloproteins have been associated with storage and transport of proteins, enzymes and signal transduction proteins. ${ }^{90}$

Due to the relatively unknown and poorly understood mechanisms that could be occurring in the water to lead to these interesting experimental effects, we will discuss the different water analyses we conducted and the metal ion changes we found between the $3 \mathrm{mM}$ hypotonic saline solution that had been treated with the CETS unit as compared to the control. The various aqueous metal ions that were found are known to have differing magnetic properties. These aqueous metal ions and their known magnetic differences became the basis for our experiments in this chapter.

\section{METHODS}

\section{Water Analysis of Metal Ions}

In order to determine the basis for the biological effects induced by the CETS system, we examined the ionic composition of the water before and after treatments and after filtering of the treated water by performing a water analysis (Table 5). Eight liters of de-ionized water were placed in a 12 liter foot tub plastic wash basin and $5.5 \mathrm{ml}$ of $5 \mathrm{M}$ $\mathrm{NaCl}$ were added from which $500 \mathrm{ml}$ were removed and placed in a clean plastic container to serve as the 'control' saline solution (per request of A \& L). The CETS module was then placed in the plastic wash basin and 2.0 amps of current applied for 30 
Table 5. Analysis of CETS-Treated and Untreated Dilute Saline.

\begin{tabular}{lccc}
\hline Ion/Element & $\begin{array}{c}\text { Control } \\
\text { (Unfiltered) } \\
\text { Concentration }\end{array}$ & $\begin{array}{c}\text { Treated } \\
\text { (Unfiltered) } \\
\text { Concentration }\end{array}$ & $\begin{array}{c}\text { Treated } \\
\text { (Filtered) } \\
\text { Concentration }\end{array}$ \\
\hline Chloride & $205 \mathrm{mg} / \mathrm{L}$ & $128 \mathrm{mg} / \mathrm{L}$ & $* \mathrm{NR}$ \\
Chromium & $1.13 \mu \mathrm{g} / \mathrm{L}$ & $\mathbf{2 2 . 7} \boldsymbol{\mu g} / \mathbf{L}$ & $\mathbf{1 8 . 8} \boldsymbol{\mu g} / \mathbf{L}$ \\
Copper & $4.89 \mu \mathrm{g} / \mathrm{L}$ & $1600 \mu \mathrm{g} / \mathrm{L}$ & $2.69 \mu \mathrm{g} / \mathrm{L}$ \\
Iron & $<100 \mu \mathrm{g} / \mathrm{L}$ & $<100 \mu \mathrm{g} / \mathrm{L}$ & $<100 \mu \mathrm{g} / \mathrm{L}$ \\
Lead & $<0.5 \mu \mathrm{g} / \mathrm{L}$ & $<0.5 \mu \mathrm{g} / \mathrm{L}$ & $<0.5 \mu \mathrm{g} / \mathrm{L}$ \\
Molybdenum & $<1 \mu \mathrm{g} / \mathrm{L}$ & $\mathbf{2 . 5 8} \boldsymbol{\mu g} / \mathbf{L}$ & $\mathbf{2 . 4} \boldsymbol{\mu g} / \mathbf{L}$ \\
Nickel & $<0.5 \mu \mathrm{g} / \mathrm{L}$ & $\mathbf{1 2 . 1} \boldsymbol{\mu g} / \mathbf{L}$ & $\mathbf{7 . 4 9} \boldsymbol{\mu g} / \mathbf{L}$ \\
Sodium & $128 \mathrm{mg} / \mathrm{L}$ & $82.8 \mathrm{mg} / \mathrm{L}$ & $83.3 \mathrm{mg} / \mathrm{L}$ \\
Titanium & $<1 \mu \mathrm{g} / \mathrm{L}$ & $<1 \mu \mathrm{g} / \mathrm{L}$ & $<1 \mu \mathrm{g} / \mathrm{L}$ \\
\hline
\end{tabular}

$* \mathrm{NR}$-none registered/measured. 
minutes. Next, $500 \mathrm{ml}$ of the 'treated' saline solution was removed and placed in a clean plastic container. A separate $500 \mathrm{ml}$ of the 'treated' saline solution was run through a 0.45 micron filter and placed in a clean plastic container. The three containers of the control, treated and treated-filtered saline solution were immediately transported for the water ion analysis to A \& L Analytical Laboratories in Memphis, TN.

\section{Comparison Water Analysis with Metal Ions}

In order to determine if the biological effects induced by the CETS system could be replicated without running DC through the CETS system and by simply adding the metal salts noted in the first water analysis in Table 5, we examined the ionic composition of the water before and after adding the metal salts to the same concentrations (treated) and after filtering of the metal salt water (treated filtered) (Table 6). Eight liters of de-ionized water were placed in a 12.6 liter foot tub plastic wash basin and $5.5 \mathrm{ml}$ of $5 \mathrm{M} \mathrm{NaCl}$ were added. Then the microgram/liter concentrations of molybdenum, chromium and nickel were added to the $3 \mathrm{mM}$ hypotonic saline solution. Then $500 \mathrm{ml}$ were removed and placed in a clean plastic container and $500 \mathrm{ml}$ were removed and run through a 0.45 micron filter (Corning) and placed in a clean plastic container. The filtered and unfiltered saline/metal salt solution were immediately transported for the water ion analysis to A \& L Analytical Laboratories in Memphis, TN.

\section{Cell Growth with Metal Salts}

We cultured B16, L929 and MDA-MB231 cells in the DMEM-10 with media that was reconstituted with a hypotonic saline solution that had chromium, nickel and molybdenum salts added to the same concentrations as found in the water analysis (Table 6) and the control groups of each of the three cell lines were cultured in media that was reconstituted with the same hypotonic saline solution that had not been treated with the CETS system (See Chapter 2). The treated group of MCF-10A cells was cultured in the DMEM/F12-5 media that had been reconstituted with a hypotonic saline solution that had chromium (Aldrich Chromium (111) chloride hexa-hydrate, lot \# BCBM86667V), nickel (Sigma Nickel (11) chloride hexa-hydrate, lot \# 054M0001V) and molybdenum (Aldrich Molybdenum powder, lot \# MKBT3128V) salts added to the same concentrations as found in the water analysis (Table 5) and the control group was cultured in media that was reconstituted with a hypotonic saline solution that had not been treated with the CETS system. On day one, aliquots of 10,000 cells were plated in three 6-well plates for each of the two groups in each of the four cell lines. They were plated in their standard DMEM-10 or DMEM/F12-5 media on day 1. On day 2, the treated $(n=18)$ and control $(n=18)$ media for each of the four cell lines were made and the original standard media was replaced in each of the wells with the newly prepared treated and control media. On days 3 through 7, wells from the control group and treated group of each cell lines were trypsinized, removed from 3 wells of each group and counted using a Scepter Automated 
Table 6. Comparison of Metal Ions in CETS Treated Filtered and Metal Salt Filtered Water.

\begin{tabular}{llcc}
\hline Ion/Element & \multicolumn{1}{c}{ Magnetism } & CETS Treated & Metal Salts \\
\hline Chloride & Diamagnetic & $\downarrow 100 \%$ & $\uparrow 33 \%$ \\
Copper & Diamagnetic & $\downarrow 99 \%$ & Not added \\
Chromium & Anti-ferromagnetic & $\downarrow 17 \%$ & $\downarrow 32 \%$ \\
Nickel & Ferromagnetic & $\downarrow 38 \%$ & $\downarrow 02 \%$ \\
Sodium & Paramagnetic & $\downarrow 00 \%$ & $\uparrow 21 \%$ \\
Molybdenum & Paramagnetic & $\downarrow 06 \%$ & $\downarrow 58 \%$ \\
\hline
\end{tabular}


Cell Counter (Millipore). Remaining wells had the control and treated media replaced daily.

\section{Cell Growth with Autoclaved CETS Treated Water}

We cultured the treated MDA-MB231 cells in the DMEM-10 with media that was reconstituted with a hypotonic saline solution that had been treated with the CETS system for 30 minutes and was then placed in the autoclave at $120^{\circ} \mathrm{C}$ for 40 minutes prior to making the growth media and the control group was cultured in media that was reconstituted with the same hypotonic saline solution that had not been treated with the CETS system and autoclaved. On day one, aliquots of 10,000 cells were plated in three 6well plates for each of the two groups. They were plated in their standard DMEM-10 media on day 1 . On day 2 , the treated $(n=18)$ and control $(n=18)$ media for each of the four cell lines were made and the original standard media was replaced in each of the wells with the newly prepared treated/autoclaved and control media. On days 3 through

7, wells from the control group and treated group were trypsinized, removed from 3 wells of each group and counted using a Scepter Automated Cell Counter (Millipore). Remaining wells had the control and treated media replaced daily.

\section{Cell Growth with CETS Treated Water and Magnet}

We cultured the MDA-MB231 cells in the DMEM-10 with media that was reconstituted with a hypotonic saline solution that had been treated with the CETS system for 30 minutes and was then placed in test tubes that were placed next to a magnet for 24 hours prior to making the growth media and the control groups were cultured in media that was reconstituted with the same hypotonic saline solution that had not been treated with the CETS system and had been both exposed to magnet and not exposed to magnet. On day one, aliquots of 10,000 cells were plated in three 6-well plates for each of the two groups. They were plated in their standard DMEM-10 media on day 1. On day 2, the treated $(n=18)$ and control $(n=18)$ media for each of the four groups were made and the original standard media was replaced in each of the wells with the newly prepared treated/magnet and control/magnet media. On days 3 through 7, wells from the control group and treated group were trypsinized, removed from 3 wells of each group and counted using a Scepter Automated Cell Counter (Millipore). Remaining wells had the control and treated media replaced daily.

\section{RESULTS}

\section{Metal Ions in the CETS treated Water Analysis}

Analysis of water samples found differences in chromium, copper, molybdenum, nickel and sodium between treated samples and control (Table 6). In the control water, 
there is a measurable concentration of chloride, chromium, copper and sodium. The chloride and sodium can be attributed to the addition of the molecular grade $\mathrm{NaCl}$ to the de-ionized water. The chromium and copper are either naturally in the water or are deposited from the water pipes etc. The treated water prior to filtering through a 0.45 micron filter for sterilization with the in vitro experiments, contains more chromium, copper, molybdenum and nickel and less sodium and chloride than the control. After filtering the treated water, the majority of the chromium, molybdenum, nickel and sodium remains, while the copper and chloride appear to be retained by the filter.

\section{Metal Ions in Metal Salt Water Analysis}

When examining the results of the metal salt water analysis, chloride does not remain in solution with filtering after exposure to the magnetic field from the CETS system. Chloride does remain in solution after the water is reconstituted with the metal salts. Copper also does not remain in solution after filtering once exposed to the magnetic field of the CETS system. These are both diamagnetic metals. Chromium is an antiferromagnetic metal and the data suggest it remains in solution at a higher concentration after exposure to a field than when added as a metal salt. Nickel is a ferromagnetic metal and appears to remain in solution in higher levels when added as a metal salt as opposed to when exposed to the magnetic field of the CETS. Sodium and molybdenum are paramagnetic metals and appear to remain in solution in higher concentrations once exposed to the magnetic field of the CETS system.

\section{Cell Growth with Metal Salts}

To determine if the growth inhibition was due to the metals that are found in the treated filtered water, growth media was made with control water with the same concentrations of chromium, molybdenum and nickel salt that was made to correspond to the same concentrations as noted in the water analysis of the treated filtered water. We found that the doubling time in the metal salt supplemented media has the opposite effect seen with the CETS treated water (Figure 27) e.g. the cells grew at the same rate equal to that of the non-treated control media.

\section{Cell Growth with Autoclaved CETS Treated Water}

To determine if heating the water would change the effects of the treated water/media on the growth inhibition, we autoclaved treated water autoclaved at $120^{\circ} \mathrm{C}$ and 1.1 bars for 40 minutes prior to making the media to see if it would have a differential effect on the growth of cancerous cells compared to non-autoclaved water. We did not observe a change in the appearance (e.g. color, precipitate etc.) in the autoclaved treated water. We then plated the human breast carcinoma and prepared and changed the media daily over 6 days. The doubling times suggests the effects are negated with heating the treated water (Figure 28). The heating of metal aqueous ions affects the 

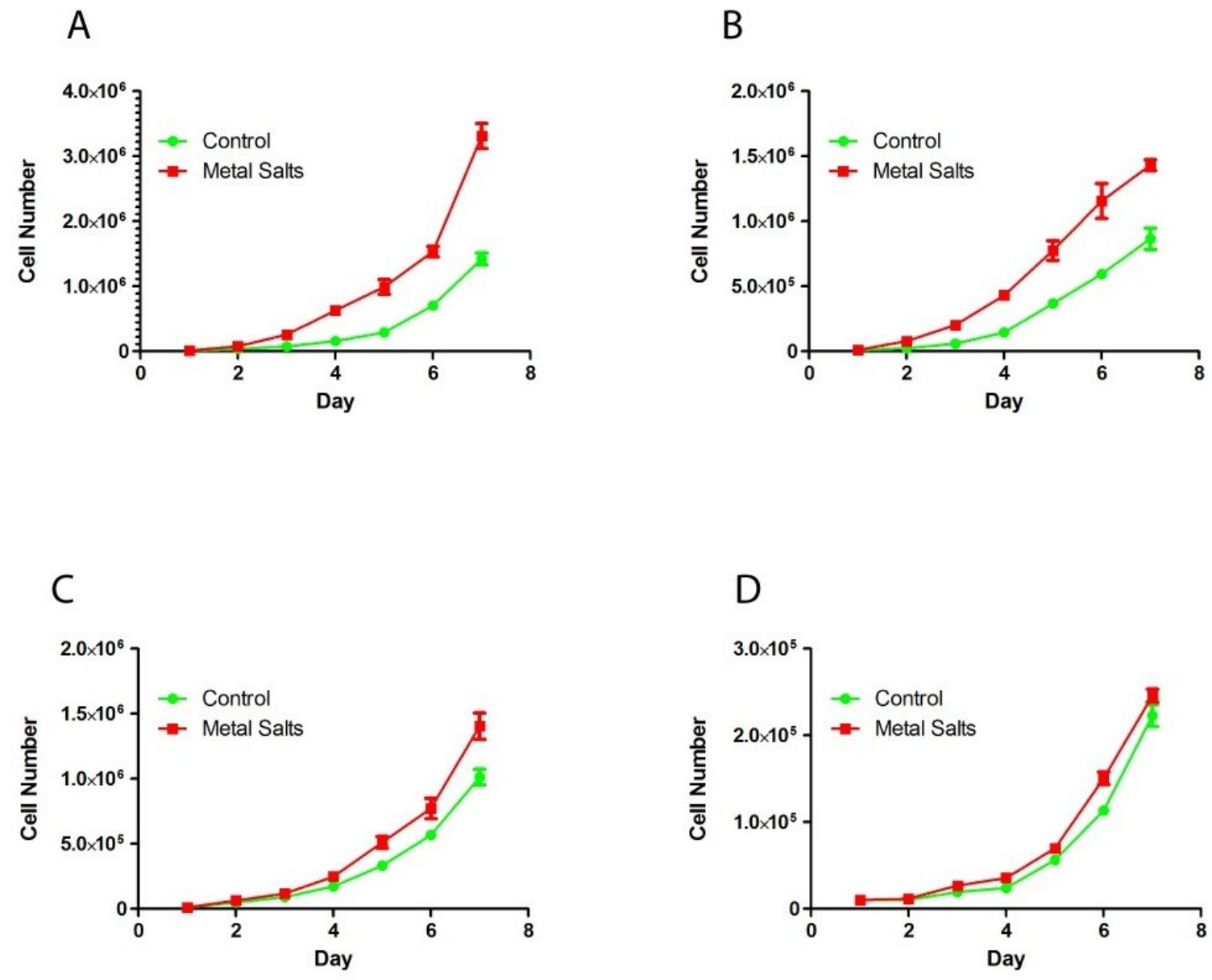

Figure 27. Metal Salt Experiments.

A $3 \mathrm{mM}$ saline solution that was identical to the solution used in all the previous experiments was made. Instead of treating with the CETS system, nickel, chromium and molybdenum salts were added to the hypotonic saline solution in order to achieve their same concentrations as found in the CETS treated-filtered water by the analysis of an independent laboratory. All four cell lines were cultured in standard media and the control and metal salts media were added to the wells on Day 2 and the media was made and replaced daily. Wells were also counted in triplicate daily. Data were analyzed with unpaired two-tailed t-tests.

(A) Murine melanoma; mean control 385536.2; mean treated 973811.4; $\mathrm{df}=40$; ts $=-2.21586 ; \mathrm{p}=0.032455$. (B) Murine fibroblasts; mean control 295167.1; mean treated 583794.8; $\mathrm{df}=40 ; \mathrm{ts}=-2.13383 ; \mathrm{p}=0.03904$. (C) Human breast carcinoma; mean control 319071.4; mean treated 446895.2; $\mathrm{df}=40 ; \mathrm{ts}=-0.98762 ; \mathrm{p}=0.329275$. (D) Human epithelial cells; mean control 65259.52; mean treated 78675.19; df $=40$; ts $=-0.54548 ; \mathrm{p}=0.588451$. 


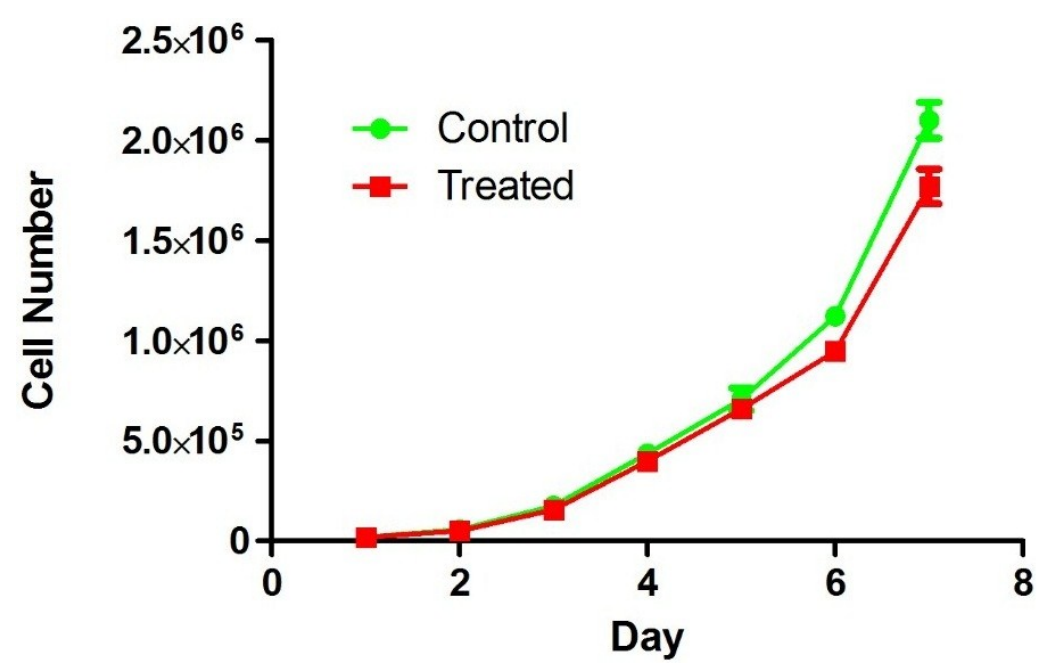

Figure 28. MDA-MB231 Cell Autoclave Experiment.

MDA-MB231 cells plated in media made with treated CETS saline after autoclaving. Data were analyzed with unpaired t-tests; mean control 659690.5; mean treated 571904.8; $\mathrm{df}=40 ;$ ts $=0.433124 ; \mathrm{p}=0.667251$. 
magnetic behavior of these metal ion complexes and is known to exhibit this phenomena from $25^{\circ} \mathrm{C}$ and 1 Bar to $5000^{\circ} \mathrm{C} .{ }^{28}$ The data suggests that heating in the autoclave to $120^{\circ} \mathrm{C}$ and 1.1 bar could be leading to a change in the magnetic behavior of the metal aqueous ions thereby negating their effects.

\section{Cell Growth with CETS Treated Water and Magnet}

To determine if the effect is due to magnetism, we hypothesized that treated water exposed to the magnet for 24 hours prior to making the media would have a differential effect on the growth of cancerous cells compared to the control water exposed to the magnet for 24 hours. We exposed both control and treated media placed in a test tube to a magnet. We found that there was a significant difference between the treated group exposed to the magnet and the treated group that was not exposed to the magnet, while no difference in the growth was noted between the control groups when the control water was exposed or not exposed to the magnet (Figure 29). This suggests the CETS induced effect in the water that has contributed to growth inhibition, cell cycle arrest, membrane potential change and genomic effects noted in our experiments is affected by exposure to another magnetic field and this field was generated by the magnet.

\section{DISCUSSION}

The CETS system uses a Lorenz force with DC that is applied through a cathode and an anode in a perpendicular fashion to a set of metal rings that consists of diamagnetic, paramagnetic, ferromagnetic and antiferromagnetic metals. These rings are placed in water where they create an electromagnetic field in the presence of this current. The copper or diamagnetic ring sits in the center of the stainless steel rings which separates the field traveling through the anode and cathode pathways and helps to create the perpendicular field to the current. Lorenz force is being produced by current being applied in perpendicular fashion to the magnetic field. The persisting and possible permanent change in the ferromagnetism and its associated parallel spin that is displayed by the nickel, and the change in the anti-ferromagnetism and its associated anti-parallel spin that is displayed by the chromium, leads to the increased strength of the magnetic field (GMR) and organizational polarity. These concepts suggest that it is possible that a magnetic change in the saline/metal ion solution is being induced by applying an electromagnetic field to these metals in the presence of this water. Since ferromagnetism persists in the absence of a field, this would suggest that the parallel spin (nickel) and anti-parallel spin (chromium) of electrons would persist in the growth media (that was made with the treated hypotonic saline solution) when it is used to grow the cancerous and noncancerous cells in vitro in our experiments. The bi-directional spin of metal ions, induced by a strong parallel, anti-parallel spin of the magnetic metals, could decrease the electrical resistance in the cell membranes that is exhibiting increased electrical resistance due to the lack of ordered spin that could be occurring in the depolarized cancerous and/or proliferating cells. This cell membrane or microchip is known to be gated with cell signaling mechanisms and it is known to carry a charge. ${ }^{8}$ The organized 

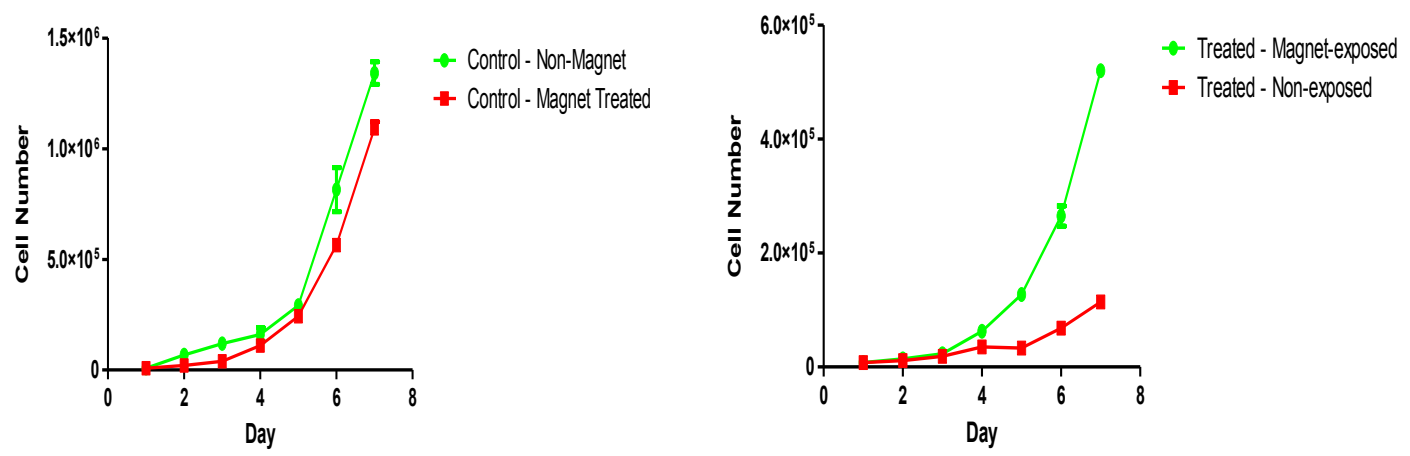

Figure 29. MDA-MB231 Magnet Experiment.

Control magnet exposed and non-magnetic exposed water was used to make the growth media. This suggests the CETS induced effect in the water that has contributed to growth inhibition, cell cycle arrest, membrane potential change and genomic effects noted in our experiments is affected by exposure to another magnetic field and this field was generated by the magnet. Data analyzed with unpaired t-tests and showed no significant difference in growth; control magnetic exposed mean 659690; control non-magnetic exposed mean 571904.8; ts $=0.781225 ; \mathrm{df}=40 ; \mathrm{p}=0.43927$. Treated magnet-exposed and treated non-exposed showed a significant difference in growth; treated magnetic exposed mean 145748.6; treated non-magnetic exposed mean 41152.38; ts $=2.61961$; $\mathrm{df}=40 ; \mathrm{p}=0.012379$. 
nature of the magnetic resistance could in fact be decreasing the electrical resistance and allowing a more organized flow of ions through the liquid crystal semiconductor membrane. Movement of charges due to lateral diffusion within a plasma membrane is essentially a rotating magnetic field. ${ }^{97}$ The parallel and anti-parallel spins, as well as the accompanying paramagnetic changes in organizational spin, could offer a decreased bidirectional resistance in the membrane, allowing the membrane to be more easily gated in order to conduct more work of the cell. These metal ions that are formed after exposure to the electromagnetic field that is applied to the hypotonic saline solution by the CETS system may also be a factor in protein synthesis in the intracellular matrix due to the interaction with the cell membrane. The charged ions could possibly be developing dative covalent bonds with the water molecule in the presence of the electromagnetic field in the first coordination sphere. ${ }^{92,93,94}$ These bonds create the spins that are known to occur with the magnetism of the specific metals. This will then offer an opening for second coordination sphere non-covalent hydrogen bonding that can lead to the development of metal ion cofactors that can be used for the initiation of protein synthesis. ${ }^{92,93}$ A major site of the interaction of a divalent metal ion and a nucleotide has been shown to be between the cation and the phosphate chain. ${ }^{77} \mathrm{~A}$ major complex of divalent cations and nucleotides is known to consist of ATP. ${ }^{77}$ There is an interaction of divalent ions with the ring of nitrogen atoms in nucleotides and this interaction has been studied with the use of paramagnetic and ferromagnetic ions showing significant changes in the proton magnetic resonance spectra of these nucleotides. ${ }^{92}$ It has also been noted that complexes of magnesium (paramagnetic) with nitrogenous ligands are considerably weaker than the complexes of nickel (ferromagnetic) and this corresponds to the strength of the magnetism associated with these metal ions. ${ }^{77,24}$ The factors that govern metal binding affinity and selectivity in proteins range from: 1) intrinsic properties of the metal, 2) primary coordination sphere, 3) secondary coordination sphere, 4) protein matrix, 5) bulk solvent, 6) competing non-protein ligands from the surrounding biological environment. ${ }^{95}$ Once the field is created and the metal ions begin to attach to the water molecules in the first coordination sphere, they can then also begin to interact with the cell membrane and become a possible cofactor or catalyst for the initiation of metalloproteins in the membrane proteins and intracellular matrix through hydrogen (non-covalent) bonding that occurs in the second coordination sphere. ${ }^{89}$

The differing concentrations of the different metal ions that remain in solution after the filtering process once they have been exposed to the magnetic field by the CETS system, when compared to the concentration that remain in solution after the addition of the metal salts, could be a possible mechanism that may have a magnetic basis. When the treated water that contained the metal ions was immediately heated in an autoclave, our experiments show this heating decreased the growth inhibitory effect of the treated media. The growth inhibitory effect was also decreased after the treated water was exposed to a magnet and its magnetic field prior to making the growth media for culturing. The growth inhibitory effects was also reduced once the media was made with the treated water while the treated water appears to hold the effect when left unexposed to high temperatures, other magnetic fields and other metal ions. We know that the magnetic properties of metal ions are sensitive to temperature and magnetic fields. ${ }^{96}$ 


\section{CONCLUSION}

The concept of magnetic drug targeting has been around for over 30 years and magnetic nanoparticles are a class of engineered particulate materials of $<100 \mathrm{~nm}$ that can be influenced or manipulated by an external magnetic field. ${ }^{79}$ Targeting of drugs by nanoparticles is intended to decrease drug waste, frequency of administration, reduce side effects, and increase sustained delivery to desired organ target. ${ }^{74}$ There has been limited success due to magnetic forces generally being short ranged and underwhelming to the hydrodynamic forces in the body. ${ }^{74,79}$ Magnetic nanoparticles consist of magnetic compounds, such as iron, nickel, cobalt and their oxides. My experimental data suggest significant effects on cell growth, cell cycle, membrane potential, cell migration and genomic expression with the CETS treated water. Could the electromagnetic field be inducing a modulation in the magnetic structure of the water? When one examines these metal ions that remain in the treated-filtered water, the concentrations of these metal ions (chromium, nickel, sodium and molybdenum) is strikingly similar to their concentrations in seawater and blood. These similar concentrations make an interesting correlation to the concept of how we are connected to the naturally occurring water that is said to be the 'staff of life.'

The effects in our experiments appear to also be differentially expressed with the observations of growth inhibition of cancerous cells and lack of growth inhibition in noncancerous cells. Increased cell migration was also observed in the mouse fibroblasts with wound care data which shows an application for wound healing. Quantification of the possible magnetic nanoparticle effects, if any, warrant further investigation. The CETS system could offer a form of magnetic nanoparticle augmentation that utilizes a hypotonic saline solution that is exposed to a carefully designed set of metal rings in the presence of an electromagnetic field and that produces metal aqueous ions that interact with the cell membrane and significantly affect cell behaviors. Due to the fact that the addition of the metal salt/ions to exact molar concentrations found in the treated filtered water analysis did not yield the same differential cell growth results in our laboratory experiments; the data suggest the metal ions may only form a divalent covalent bond in water in the presence of an induced electromagnetic field. Therefore, DC, metal rings, water (with ions) and electromagnetic field may be all needed to produce the aqueous metal ion solution that is needed to achieve the biological effects noted in these experiments and quite possibly in the anecdotal reports that have occurred across the globe over the last 20 years with use of the CETS system. When we review the susceptibilities or criteria for inducing magnetic moments into materials, they are: temperature, external field $\mathrm{H}$ and atomic structure. The in vitro experiments were conducted with an aqueous solution that had previously been exposed to the external field $\mathrm{H}$ but was not actively present during the cell culturing and growth phases. We also conducted these experiments after exposing the treated aqueous solution to high temperatures of the autoclave. It is known that at sufficiently high temperatures (blocking temperature) thermal energy is the catalyst that induces free rotation of the particle resulting in a loss of net magnetization in the absence of an external field. ${ }^{78}$ The data suggest that the metal ions are only catalysts or cofactors for metalloproteins, when they are formed in the presence of current through a magnetic field in the medium of water. If 
these metal ions are forming covalent bonds, the dissociation of these bonds explain the nullification of the effects seen with heating the treated water in the autoclave due to the high temperature negating effects. Lastly, the exposure of the treated water to the magnetic field of the magnet also appeared to reduce the effects of the treated water on the cell growth. If magnetism was involved in the effects seen in our experiments, then the exposure to a field could be a factor in influencing the directional spins induced by the CETS system. These results suggest our experiments may be possibly showing effects that are known to exist in the magnetic nanoparticle world but have remained elusive in their application for health. Due to the fact that the CETS has shown many anecdotal health benefits across the globe and that this work is showing significant experimental effects that appear to correspond to these phenomena, future research into responsible mechanisms are warranted. 


\section{CHAPTER 5. DISCUSSION}

These experiments have been conducted in this dissertation research to test whether there are differential growth effects when cancer cells are maintained in media reconstituted with the water treated by the CETS system. Experimental data showed cancerous cell growth inhibition while not affecting noncancerous cell growth. This cancer cell growth inhibition also showed cell cycle arrest, hyperpolarization of plasma membranes, annexin staining and genomic upregulation of ER stress/UPR as well as the p53 oncogene. This CETS treated water analyses also suggests a possible modulation of the magnetic behavior of metal aqueous ions.

Our experiments show a correlation to the Rogerian theoretical framework that suggests that bioelectrodynamics can utilize an electrical energy source that affects not only the organism but the field immediately surrounding the organism. The tertiary interaction of these three components: 1) energy source (DC), 2) environment (water), and the 3) organism (cells) are all involved in the process of bioelectrodynamics. This data gives quantitative measurements of a previously abstract concept that has often failed to obtain data that is readily accepted by the scientific community. The microarray and genomic validations revealed some interesting results that while unexpected, show some interesting possibilities for future work with many chronic co-morbidities. The UPR is linked to many chronic co-morbidities in the literature that include but are not limited to: cancer, hyperlipidemia, allergies, asthma, COPD, cystic fibrosis, autism, ALS, Parkinson's disease, Huntington's disease, organ fibrosis, diabetes and many more. Proteins must be folded in appropriate fashion in order to be able to be used by the cell and ultimately an organism. It has been estimated that if we took a penny to represent every cellular protein, it would fill up the Pacific Ocean with these pennies. The number of proteins a cell must properly fold is vast. If the proteins are not properly folded, this can lead to toxicity in the cell/organism. Cancer cells hijack the UPR and exploit the pathway in order to survive and avoid programmed cell death. Neurons in the brain enter into programmed cell death when unfolded proteins begin accumulating in patients leading to amyloid fibrils that contribute to the development of the neurodegenerative diseases of ALS, Parkinson's disease and Huntington's disease. Many allergies are caused by an incorrect folding of some proteins leading to a failure of the immune system's production of antibodies for certain protein structures. Misfolding and excessive degradation of proteins are linked to cystic fibrosis and lysosomal storage disease. Our experiments show that external factors of high temperatures of the autoclave and external fields (electric, magnetic), have an effect on protein folding. Folding is a process that can require ATP energy for recruitment of chaperones or occur spontaneously with inputs from the nucleoside triphosphates. The folding of proteins is believed to be enhanced by intramolecular hydrogen bonds and is opposed by an energy deficit. In theory, the hyperpolarization of the cell membrane in our experiments could be reducing factors that lead to ER stress and problems with protein folding. The genomic analyses with the MDA-MB231 and MCF-10A cells suggest that a change in the magnetic behavior of the aqueous metal ions may prevent the cancer cell from hijacking the UPR for survival. The data from the genomic analyses from the MCF-10A cells also suggests that it may help 
relieve the ER stress and therefore prevent programmed cell death in noncancerous cells. Also, the upregulation of Amphiregulin (AREG) in the MCF-10A cells microarray could offer a genomic link to spark wound care clinical trials. The TNFRSF9 gene upregulation could help with the internal immune response activation in the fight against the cancerous, inflamed and injured cells.

Magnetic nanoparticle therapies have been widely used in drug delivery and hyperthermia treatments for cancer. Recent applications of magnetic nanoparticles have shown great promise towards decreasing infections and tissue growth. To continue to build this science, much future research is warranted in order to translate this application more fully to mainstream medicine. ${ }^{98}$ These magnetic nanoparticles have been used to augment chemicals that are foreign to the body. When one looks at the building block of the body, the cell, it is known that they are composed of water, inorganic ions and carbon-containing molecules. Water is the most abundant molecule in cells. Therefore, our understanding of water and the other constituents and how they act and interact together are paramount in the study of biology. Because of the polar nature of water molecules, they can form hydrogen bonds with both other polar molecules and well as with positively and negatively charged ions. The study of proteolysis could also provide answers to the wide range of conditions under which this protein folding could be analyzed. Water may be the essential component to bridge the magnetic nanoparticle world to living organisms that warrants further experimental testing. Chapter 4 delves into the key components of the water structure that undergo change with the CETS treatment. We have much to learn about how these magnetic ions and their solubility and other behavioral changes in the CETS treated water are actually driving or changing the behavior of the cells with regards to cell growth, cell migration, cell cycle progression, cell size, membrane potential, cell death and genomic level changes. The mechanisms may be occurring quickly and in multiplicity and will take many experimental studies to begin to piece together the puzzle as to how these cellular behaviors become so significantly altered.

Cancer will affect one in three individuals over their lifetime. Drugs that treat cancer and wounds are so expensive, the costs are affecting the care of patients with these chronic co-morbidities and our health care system. ${ }^{99}$ Mayo Clinic recently introduced seven actions that could reduce the cost of cancer drugs and improve the ability for patients to receive adequate treatment. One action they considered is allowing the Patient-Centered Outcomes Research Institute-which the Affordable Care Act initiatives created to evaluate the benefits of new treatments. They recommend similar organizations include pricing in their assessment of treatment value. The financial burdens placed on the health care system for treatment of cancer and wounds have to be addressed as we progress into future options for these patients. The CETS system can offer an adjunct that is affordable to our health care system. It appears that CETS system needs to be taken to both animal models and to clinical trials to evaluate the effectiveness of this as a future adjunct treatment for cancer, wounds and other chronic co-morbidities. We have seen the toxicity and failure of many current cancer and wound care treatments for decades. When done in combination with chemotherapy and radiation, the upregulation of both UPR and the JMY/p53 oncogene by the CETS treated water could help decrease the toxicity of 
these treatments allowing for the patients to complete the standards of care that are currently FDA approved and in oncological practice. Clinical trial testing with the CETS system could offer hope and improved outcomes to mankind.

We have a phase 1 safety trial for the CETS system approved by the UTHSC IRB and will be conducting the study in early 2016. This safety trial along with the experimental data and case study data we are collecting from anecdotal reports, will provide critical and essential data that could allow the CETS system to be used in patients in the areas cancer and wound care and lay the foundation for additional studies in other chronic co-morbidities that are connected to the UPR. These actions could help lead to a future paradigm shift in how we address life, health and wellness. There are many policy obstacles to overcome in the future in order to bring this device to market. Due to the transition from a Newtonian Physics based application to a quantum physics based application of the CETS system, great efforts will be needed to overcome provider bias and skepticism. The experimental, animal models and clinical trial data will be critical to establish the scientific basis in order to gain scientific credibility and validity. There will also be obstacles to overcome that favor medication reimbursement for cancer therapies. Ultimately all the stakeholders will need to see the safety, efficacy and profitability with use of the CETS for future treatments in order for this to move forward in the marketplace and for the benefit of mankind. Research funding is warranted for in order to pursue the possibilities from the significant experimental, anecdotal and genomic results presented in this work. 


\section{LIST OF REFERENCES}

1. Zhou SA, Uesaka M. Bioelectrodynamics in living organisms. International journal of engineering science. 2006;44(1), 67-92.

2. McCaig CD, Song B, Rajnicek AM. Electrical dimensions in cell science. J Cell Sci. 2009;122: 4267-4276.

3. McCaig CD, Rajnicek AM, Song B, Zhao M. Controlling cell behavior electrically: current views and future potential. Physiol Rev. 2005;85(3), 943-978.

4. Funk RH, Monsees T, Ozkucur N. Electromagnetic effects - From cell biology to medicine. Prog Histochem Cytochem. 2009; 43(4), 177-264.

5. Goodman R, Blank M. Insights into electromagnetic interaction mechanisms. Journal of Cellular Physiology. 2002; 192: 16-22.

6. Lipton BH. The Biology of Belief. Carlsbad California: Hay House, Inc; 2008.

7. Rubik B. Energy Medicine and the Unifying Concept of Information. Alternative Therapies in Health and Medicine. 1995;1:34-39.

8. Panagopoulos DJ, Messini N, Karabarbounis A, Philippetis AL, Margaritis Mechanism for action of oscillating electric fields on cells. Biochem Biophys Res Commun. 2000; 272(3), 634-640.

9. Tseng A, Levin M. Cracking the bioelectric code: Probing endogenous ionic controls of pattern formation. Commun Integr Biol. 2013; 6(1), e22595.

10. Kuhn TS. Black Body Theory and Quantum Discontinuity. New York: Oxford University Press. 1978.

11. Hackermuller L, Uttenthaler S, Hornberger K, Reiger E, Brezger B, Zeilinger A, Arndt, M. Wave nature of biomolecules and fluorofullerenes. Phys Rev Letters 2003;91(9): 090408-1.

12. Levin M. Molecular bioelectricity: how endogenous voltage potential control cell behaviors and instruct pattern regulation in vivo. American Society for Cell

Biology; 2014;25: 3835-3850.

13. Barry P. It's the network, stupid, Science News. 2008; 173.

14. Skrinjar T, Walker S. Q Mechanics. Toowomba, Queensland, Australia: Terry J. Skrinjar \& Steven T. Walker:1996. 
15. Marsh R. A preliminary report on the new BEFE: Bioelectric Field Enhancement. Explore. 2001;10(6).

16. Maret K. Energy Medicine in the United States: Historical Roots and Current Status. July 2009. www.faim.org/energymedicine-/energy-medicine-united-stateshistorical-roots-current status.html: accessed March 2, 2015.

17. Zimmerman JW, Pennison MJ, Brezovich I, Yi N, Yang CT, Ramaker R, ... Pasche B. Cancer cell proliferation is inhibited by specific modulation frequencies. Br J Cancer. 2012;106(2), 307-313.

18. Cone CD. Variation of the transmembrane potential level as a basic mechanism of mitosis control. Oncology. 1970;4(6), 438-470.

19. Yang M, Brackenbury WJ. Membrane potential and cancer progression. Front Physiol. 2013; 4, 185.

20. Lobikin M, Chernet B, Lobo D, Levin M. Resting potential, oncogene-induced tumorigenesis, and metastasis: the bioelectric basis of cancer in vivo. Phys Biol. 2012; 9(6), 065002.

21. Levin M. Large-scale biophysics: ion flows and regeneration. Trends Cell Biol. 2007; 17(6), 261-270.

22. Nishiyama M, von Schimmelmann MJ, Togashi K, Findley WM, Hong K. Membrane potential shifts caused by diffusible guidance signals direct growthcone turning. Nat Neurosci. 2008; 11: 762-771.

23. Sundelacruz S, Levin M, Kaplan DL. Membrane potential controls adipogenic and osteogenic differentiation of mesenchymal stem cells. PLoS One. 2008; $3: \mathrm{e} 3737$.

24. Reddien PW, Sanchez Alvarado A. Fundamentals of planarian regeneration. Annu Rev Cell Dev Biol; 2004;20: 725-757.

25. Marder E. Electrical synapses: rectification demystified. Curr Biol. 2009;19:R3435 .

26. Rather LJ. Disturbance of function: the legendary fifth cardinal sign of inflammation, added by Galen to the four cardinal signs of Celsus. Bull NY Acad Med. 1971; 47(3): 303-322.

27. McMakin CR, Oschman JL. Visceral and somatic disorders: tissue softening with frequency-specific microcurrent. J Altern Complement Med. 2013;19(2), 170-177. 
28. Chen K. Inhibitory Effects of Bio-Energy Therapies on Cancer Growth. Center for Integrative Medicne, University of Maryland School of Medicine: www.qigonginstitute.org/html/papers/Chen_Bioenergy_Cancer.pdf. published 2008: accessed March 2, 2015.

29. Levin J, Mead L. Bioenergy Healing: A Theoretical Model and Case Series. Explore. 2008: 4 (3): 201-209.

30. Mackey B. Massage Therapy and Reflexology Awareness, The Nursing Clinics of North America; 2001; 36 (1): 159-170.

31. Facco E, Liguori A, Filomena P, Gastone Z, Coluzzi F, Nardin M, Mattia C. Traditional Acupuncture in Migraine: A Controlled Randomized Study; Headache; 2008; 48:398-407.

32. Habal M. Effect of applied dc currents on experimental tumor growth in rats. Journal of Biomedical Materials Research; 1980. 14(6): 789-801.

33. David S, Absolom D, Smith C, Gams J, Herbert M. Effect of Low Level Direct Current on in Vivo Tumor Growth in Hamsters. Cancer Research. 1985; (45)5625-5631.

34. Karnick PM. The science of unitary human beings continues to flourish. Nurs Sci Q. 2014; 27(1):29.

35. Rogers ME. Nursing science and the space age. Nursing Science Quarterly; 1992; $5: 27-34$.

36. Purnell M, Cowan P, Whitt M. The Effects of Bioelectrodynamics on Cancerous and Noncancerous Cells. http://www.resourcecenter.net/images/SNRS/Files/2014/AnnMtg/AbstractProcee dings/data/papers/E4-6.html. February 15, 2014. Accessed March 2, 2015.

37. Nogalska A, D’Agostino C, Engel WK, Cacciottolo M, Asada S, Mori K, Askanas V. Activation of the Unfolded Protein Response in Sporadic InclusionBody Myositis but Not in Hereditary GNE Inclusion-Body Myopathy; $J$ Neuropathol Exp. Neurol. 2015; 74 (6): 538-46.

38. Li X, Zhang K, Li Z. Unfolded protein response in cancer: the physician's perspective. J Hematol Oncol. 2011; 23 (4).

39. Mungrue IN, Pagnon J, Kohannim O, Gargalovic PS, Lusis AJ. $\mathrm{CHAC} 1 / \mathrm{MGC} 4504$ is a novel proapoptotic component of the unfolded protein response, downstream of the ATF4-ATF3-CHOP cascade. J Immunology. 2009; 182 (1): 466-476. 
40. Wang S, Kaufman RJ. The impact of unfolded protein response on human disease. J Cell Biology. 2012; 197 (7): 857-867.

41. Stavridi E, Halazonetis T. P53 and stress in the ER. Genes \& Dev. 2004; 18: 241244.

42. Schwartz H, Tuckwell J, Lotz M. A receptor induced by lympocyte activation (ILA): a new member of the human nerve-growth-factir/tumor-necrosis-factor receptor family. Gene 1993. 134:295-298.

43. Yoshida K, Liu H, Miki Y. Protein kinase C delta regulates Ser46 phosphorylation of p53 tumor suppressor in the apoptotic response to DNA damage. J. Biol. Chem. 2006; 281: 5734-5740.

44. Thomas SL. Loss of SPARC in p53-null Astrocytes Promotes Macrophage Activation and Phagocytosis Resulting in Decreased Tumor Size and Tumor Cell Survival. Brain Pathol. 2015; 25(4): 391-400.

45. Suh KS, Malik M, Shukla A, Ryscavage A, Wright L, Jividen K, Crutchley JM, Dumont RA, Fernandez-Sales E, Webster JD, Simpson RM, Yuspa SH. CLIC4 is a tumor suppressor for cutaneous squamous cell cancer. Carcinogenesis 2012; 33 (5): 986-995.

46. Logue SE, Gorman AM, Cleary P, Keogh N, Samali A. Current Concepts in ER Stress-Induced Apoptosis. J Carcinogene Mutagene. 2013; S6:002.

47. Colbert RA, Delay ML, Klenk EI, Layh-Schmitt G. From HLA-B27 to spondyloarthritis: a journey through the ER. Immunol Rev. 2010; 233(1):181-202.

48. Nakayama Y, Endo M, Tsukano H, Mori M, Oike Y, Gotoh T. Molecular mechanisms of the LPS-induced non-apoptotivc ER stress-CHOP pathway. $J$ Biochem. 2010; 147 (4): 471-483.

49. Hitomi J, Katayama T, Eguchi Y, Kudo T, Taniguchi M, Koyama Y, Manabe T, Yamagishi S, Bando Y, Imaizumi K, Tsujimoto Y, Tohyama M. Involvement of caspase-4 in endoplasmic reticulum stress-induced apoptosis and Abeta-induced cell death. J Cell Biol. 2004; 165 (3): 347-56.

50. Mungrue IN, Pagnon J, Kohannim O, Gargalovic PS, Lusis AJ. CHAC1/MGC4504 is a novel proapoptotic component of the unfolded protein response, downstream of the ATF4-ATF3-CHOP cascade. J Immunol. 2009; 182 (1): 466-476.

51. Brewer JW, Diehl JA. PERK mediates cell-cycle exit during mammalian unfolded protein response. Proc Natl Acad Sci USA 2000; 97 (23): 12625-30. 
52. Tavana $\mathrm{O}, \mathrm{Gu} \mathrm{W}$. The Hunger Games: p53 Regulates Metabolism upon Serine Starvation. Cell Metabolism 2013; 17 (2): 159-161.

53. Ward PS, Thompson CB. Metabolic Reprogramming: a cancer hallmark even warburg did not anticipate. Cancer Cell 2012; 21: 297-36.

54. Farook JM, Shields J, Tawfik A, Markand S, Sen T, Smith SB, Brann D, Dhandapani K, Sen N. GADD34 induces cell death through inactivation of Akt following traumatic brain injury. Cell Death and Disease 2013; 4:e754.

55. Fang N, Zhang W, Xu S, Lin H, Wang Z, Liu H, Fang Q, Li C, Peng L, Lou J. TRIB3 alters endoplasmic reticulum stress-induced B-cell apoptosis via the NFkB pathway. Metabolism 2014; 63 (6): 822-30.

56. Stehlik C, Hayashi H, Pio F, Godzik A, Reed JC. CARD6 is a modulator of NFkappa-B activation by Nodl- and Cardiak-mediated pathways. J Biol Chem. 2003; 278: 31941-31949.

57. 2015 Recharge Your Body's Battery with the Q2 Energy Water System. Retrieved from: http://www.drdemarco.com/prod/prod-03.htm.

58. Bolstad B, Irizarry R, Astrand M, Speed T. A comparison of normalization methods for high intensity oligonucleotide array data based on variance and bias. Bioinformatic. 2003; 19 (2): 185-193.

59. Sverjensky D, Shock E, Helgeson H. Prediction of the thermodynamic properties of aqueous metal complexes to $1000^{\circ} \mathrm{C}$ and $5 \mathrm{~kb}$. Geochimica et Cosmochimica 1997; 61 (7): 1359-1412. U.S.A., Elsevier Science Ltd.

60. Locasale J, Grassian A, Melman T, Lyssiotis C, Mattaini K. Phosphoglycerate dehydrogenase diverts glycolytic flux and contributes to oncogenesis. Nature Genetics 2011: 43: 869-874.

61. Kromer G, Galluzze L, Melino G. et al. Classification of cell death, recommendations of the Nomenclature Committee on Cell Death. Cell Death Diff. 2009; 16 (1): 3-11.

62. Kantor J, Margolis DJ. Expected healing rates for chronic wounds. Wounds 2000; 12:155.

63. Zhao M, Penninger J, Isseroff R. Electrical Activation of Wound-Healing Pathways. Advances in skin \& wound care 2010; 1: 567-573.

64. Fitzsimmons R, Gordon S, Kronberg J, Gancy T, Pilla A. Pulsing electric field (PEF) increases human chondrocyte proliferation through transduction pathway involving nitric oxide signaling. J Orthop Res. 2008; 26:854. 
65. Gurtner G, Werner S, Barrandon Y, Longaker M. Wound repair and regeneration. Nature. 2008; 453:314.

66. Zhao M, Song B, Pu J, Wada T, Reid B, Tai G, Wang F, Guo A, Walczysko P, Gu Y, Sasaki T, Suzuki A, Forrester J, Bourne H, Devreotes P, McCaig C, Penninger J. Electrical signals control wound healing through phosphatidylylinositol-3-OH kinase-gamma and PTEN. Nature 2006; 442: 457.

67. Brighton C, Wang W, Clark C. The effect of electrical fields on gene and protein expression in human osteoarthritic cartilage explants. J Bone Joint Surg. 2008; 90:833.

68. Chandan K, Gordillo G, Longaker M. Human Skin Wounds: A Major and Snowballing Threat to Public Health and the Economy. Wound Repair Regen. 2009; 17 (6): 763-771.

69. Stoll S, Johnson J, Elder J. Metalloproteinase-Mediated, Contest Dependent Function of Amphiregulin and HB-EGF in Human Keratinocytes and Skin. $J$ Invest Dermatol. 2010; 130 (1): 295-304.

70. Nagathihalli N, Beesetty Y, Lee W, Washington MK, Chen X, Lockhart AC, Merchant NB. Novel mechanistic insights into ectodomain shedding of EGFR Ligands Amphiregulin and TGF-a: Impact on gastrointestinal cancers driven by secondary bile acids. Cancer Res. 2014; 74 (7): 2062-72.

71. Jackson R. Tyndall J. The Early History of Diamagnetism. Annals of Science. $2014 ; 4$.

72. Fert A. Nobel Lecture: Origin, development, and future of Spintronics. Rev. Mod. Phys. 2008; 80 (4): 1517.

73. Giouroudi I. Keplinger F. Microfluidic Biosensing Systems Using Magnetic Nanoparticles. Int J Mol Sci. 2013; 14 (9): 18535-18556.

74. Indira T. Lakshmi P. Magnetic Nanoparticles- A Review. International Journal of Pharmaceutical Sciences and Nanotechnology. 2010; 3(3): 1035-1043.

75. Stohr J, Siegmann HC. Magnetism of Metals. Magnetism: From Fundamentals to Nanoscale Dynamics. 2006; 521-583.

76. Bastos J, Sadowski N. Magnetic Materials and 3D Finite Element Modeling. Baton Rouge Louisiana: CRC Press. 2013.

77. Gallo A, Hansen I, Sable H, Swift T. Coenzyme Interactions: Proton Magnetic Resonance Studies of Complexes of Thiamine Pyrophosphate with Divalent Cations. The Journal of Biological Chemistry. 1972; 247 (18): 5913-5920. 
78. Conroy S, Jerry Lee SH, Zhang M. Magnetic nanoparticles in MR imaging and drug delivery. Adv. Drug Deliv. Rev. 2008; 60: 1252-1265.

79. Cregg PJ, Murphy K, Mardinoglu A. Inclusion of magnetic dipole-dipole and hydrodynamic interactions in Implant-assisted magnet drug targeting. J. Magn. Magn. Mater. 2009; 321: 3893-3898.

80. Horiuchi N. Plasmonic Lorentz Force. Nature Photonics. 2014; 8: 880-881.

81. Billas I, Chatelain A, de Heer, W. Magnetism from the Atom to the Bulk in Iron, Cobalt, and Nickel Clusters. Science. 1994; 265 (5179): 1682-1684.

82. Camley RE, Barnas J. Theory of giant magnetoresistance effects in magnetic layered structures with antiferromagnetic coupling. Phys. Rev. Lett. 1989; 63: 664.

83. Mosca D, Petroff F, Fert A, Schroeder P, Pratt W, Laloee R. Oscillatory interlayer coupling and giant magnetoresistance in $\mathrm{Co} / \mathrm{Cu}$ multilayers. J. Magn. Magn. Mater. 1991; 94 (1): L1-L5.

84. Grandjean F, Long G. "Fundamental Concepts and Units in Magnetism." Supermagnets, Hard Magnetic Materials. 1991; 331: 27-48.

85. Muller G, Thomas H, Beck H, Bonner J. Quantum spin dynamics of the antiferromagnetic linear chain in zero and nonzero magnetic field. Phys Rev. B. 1981; 24: 1429.

86. Burgess J. Metal Ions in Solution. Chichester: Horwood. 1978.

87. Ohtaki H, Radnai T. Structure and dynamics of hydrated ions. Chem Rev. 1993; 93 (3): 1157-1204.

88. Sandstrom M, Persson I, Jalilehvand F, Lindquist-Reis P, Spangberg D, Hermansson K. Hydration of some large and highly charged metal ions. Journal of Synchotron Radiation. 2001; 8: 657-659.

89. Swift T, Connick R. NMR-Relaxation Mechanisms of $\mathrm{O}^{17}$ in Aqueous Solutions of Paramagnetic Cations and the Lifetime of Water Molecules in the First Coordination Sphere. J Chem. Phys. 1962; 37: 307.

90. Lu Y, Yeung N, Sieracki N, Marshall N. Design of functional metalloproteins. Nature. 2009; 460: 855-862.

91. McRee D. Living with metal ions. Nature Structural \& Molecular Biology. 1998; 5: 8-10. 
92. Kennedy M, Gibney B. Metalloprotein and redox protein design. Current Opinion in Structural Biology. 2001; 11 (4): 485-490.

93. Patel K, Kumar A, Durani S. Analysis of the structural consensus of the zinc coordination centers of metalloprotein structures. Biochimica et. Biophysica Acta (BBA) Proteins 2007; 1774 (10): 1247-1253.

94. Harding M. Geometry of metal-ligand interactions in proteins. Acta Cryst. 2001. 57: 401-411.

95. Dudev T, Carmay L. Metal Binding Affinity and Selectivity in Metalloproteins: Insights from Computational Studies. Annu. Rev. Biophys. 2008; 37: 97-116.

96. Sverjensky D, Shock E, Helgeson H. Prediction of the thermodynamic properties of aqueous metal complexes to $1000^{\circ} \mathrm{C}$ and $5 \mathrm{~kb}$. Geochimica et Cosmochimica 1997; 61 (7): 1359-1412. U.S.A., Elsevier Science Ltd.

97. Murugan N, Karbowski L, Lafrenie R, Persinger M. Temporally-patterned magnetic fields induce complete fragmentation in planaria. PLoS One 2013; 8 (4): 61714.

98. Tran N, Webster T. Magnetic nanoparticles: biomedical applications and challenges. J Mater. Chem (2010). 20: 8760-8767.

99. Tefferi A. et al. In Support of a Patient-Driven Initiative and Petition to Lower the High Price of Cancer Drugs. Mayo Clin Proc. 2015; 90 (8): 996-1000

100. Vinay DS, Kwon, BS. 4-1BB (CD137), an inducible costimulatory receptor, as a specific target for cancer therapy. BMB Reports. 2014; 47 (3): 122-129.

101. Coutts AS, LaThangue N. The P53 response during DNA damage: impact of transcriptional cofactors. Biochem. Soc. Symp. 2006; (73): 181-9.

102. Kim SJ, Zhang A, Hitomi E, Lee YC, Mukherjee AB. Endoplasmic Reticulum stress-induced caspase-4 activation mediates apoptosis and neurodegeneration in INCL. Hum Mol Genet. 2006; 15 (11): 1826-34.

103. Gudas, JM, Payton, M, Thukral S, Chen E, Bass Michael, Robinson MO, Coats S. Cyclin E2, a novel cyclin that binds CDK2 and is aberrantly expressed in human cancers. Molecular and Cellular Biology. 1999; 19 (1): 612-22.

104. Maxwell C, Keats J, Crainie M, Xuejun S, Yen T, Shibuya E, Hendzel M, Chan G, Pilarski L. RHAMM is a centrosomal protein that interacts with dynein and maintains spindle pole stability. Mol Biol Cell. 2003; 14 (6): 2262-2276. 
105. Suh KS, Malik M, Shukla A, Ryscavage A, Wright L, Jividen K, Crutchley JM, Dumont RA, Fernandez-Salas E, Webster JD, Simpson RM, Yuspa SH. CLIC4 is a tumor suppressor for cutaneous squamous cell cancer. Carcinogenesis 2012; 33 (5); 986-95.

106. Mungrue IN, Pagnon J, Kohannim O, Gargalovic PS, Lusis, AJ. CHAC1/MGC4504 is a Novel Proapoptotic Component of the Unfolded Protein Reponse, Downstream of the ATF4-ATF3-CHOP Cascade. J. Immunol. 2009; 182 (1): 466-476.

107. Schwartz H. Biological activities of reverse signal transduction through CD137 ligand. Journal of Leukocyte Biology. 2005; 77 (3): 281-286. 


\section{VITA}

Marcy Cain Purnell was born in Memphis, TN in 1964. She grew up in Memphis and graduated from Memphis Preparatory School in 1982. She received her Bachelor of Science in Nursing from the University of Tennessee Health Science Center in Memphis, Tennessee in June 1986. After raising four children, she returned to graduate school in 2007 and received her Master of Science in Nursing/ Family Nurse Practitioner Certificate in 2009 from the University of Memphis, Loewenberg College of Nursing. 